$$
\text { INEL-9610291-RéV.1 }
$$

February 1997

\title{
Integrated Thermal and Nonthermal Treatment Technology and Subsystem Cost Sensitivity Analysis
}

Engineering

Laboratory

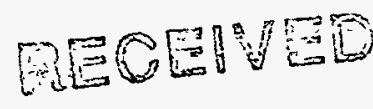

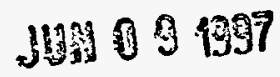

(6.5) 5 .

Lisa A. Harvego

James J. Schafer

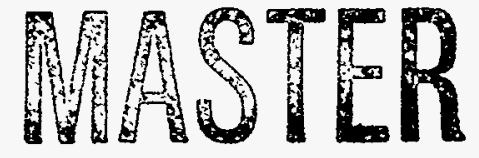

L OCKHEED MATTIN 

INEL-96/0291

Revision 1

\title{
Integrated Thermal and Nonthermal Treatment Technology and Subsystem Cost Sensitivity Analysis
}

\author{
Lisa A. Harvego \\ James J. Schafer
}

February 1997

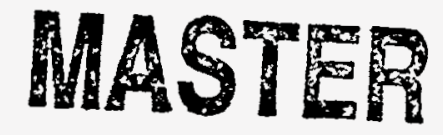

Idaho National Engineering Laboratory

Lockheed Martin Idaho Technologies Company

Idaho Falls, Idaho 83415

Prepared for the

U.S. Department of Energy

Assistant Secretary for Environmental Management

Under DOE Idaho Operations Office

Contract DE-AC07-94ID13223 


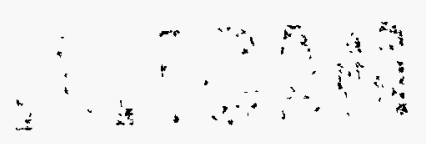

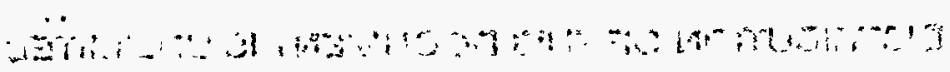




\section{DISCLAIMER}

Portions of this document may be illegible in electronic image products. Images are produced from the best available original document. 


\section{DISCLAIMER}

This report was prepared as an account of work sponsored by an agency of the United States Government. Neither the United States Government nor any agency thereof, nor any of their employees, make any warranty, express or implied, or assumes any legal liability or responsibility for the accuracy, completeness, or usefulness of any information, apparatus, product, or process disclosed, or represents that its use would not infringe privately owned rights. Reference herein to any specific commercial product, process, or service by trade name, trademark, manufacturer, or otherwise does not necessarily constitute or imply its endorsement, recommendation, or favoring by the United States Government or any agency thereof. The views and opinions of authors expressed herein do not necessarily state or reflect those of the United States Government or any agency thereof. 


\section{EXECUTIVE SUMMARY}

The U.S. Department of Energy's (DOE) Environmental Management Office of Science and Technology (EM-50) authorized studies on alternative systems for treating contact-handled DOE mixed low-level radioactive waste (MLLW). The on-going Integrated Thermal Treatment Systems ${ }^{1}$ (ITTS) and the Integrated Nonthermal Treatment Systems ${ }^{2}$ (INTS) studies satisfy this request. EM-50 further authorized supporting studies including this technology and subsystem cost sensitivity analysis.

This analysis identifies areas where technology development could have the greatest impact on total life cycle system costs. These areas are determined by evaluating the sensitivity of system life cycle costs relative to changes in life cycle component or phase costs, subsystem costs, contingency allowance, facility capacity, operating life, and disposal costs.

For all treatment systems, the most cost sensitive life cycle phase is the operations and maintenance phase and the most cost sensitive subsystem is the receiving and inspection/preparation subsystem. These conclusions were unchanged when the sensitivity analysis was repeated on a present value basis. Opportunity exists for technology development to reduce waste receiving and inspection/preparation costs by effectively minimizing labor costs, the major cost driver, within the maintenance and operations phase of the life cycle.

The capacity analysis demonstrates that life cycle costs are minimized with one large treatment facility for the entire MLLW inventory. In comparison to multiple smaller treatment facilities, the additional transportation costs associated with shipment of the MLLW to a single facility are more than off set by the economies of scale in building and operating a single facility. The analysis further demonstrates that additional life cycle cost savings can be attained by increasing annual facility availability. Although system unavailability is not attributed to a specific cause, it is clear that equipment reliability is a key determinant of availability. This provides incentive for future technology development and/or improvement toward increased equipment availability.

As a potential system discriminator, the sensitivity of life cycle costs to the contingency allowance is evaluated for the less developed technologies. Instead of using the same percent contingency allowance for all systems, as was done in the ITTS and INTS, the contingency allowance in this analysis was varied to account for the maturity of the technology. The results show that the less developed technologies are not as economically desirable when contingency costs are increased to reflect operational uncertainties.

The disposal cost analyses presented in the ITTS and INTS are extended to incorporate varying design capacities for future waste disposal facilities. The fixed and variable components of total disposal costs are calculated to determine the sensitivity of life cycle costs to the disposal volumes resulting from selected treatment systems. As expected, disposal costs decrease with the volume of waste requiring disposal. Maximum cost savings will be realized if the disposal site is designed and sized for the selected treatment technology. If a new RCRA-permitted engineered disposal facility is designed to accommodate a greater waste volume than the selected treatment technology produces, only the variable cost of disposal will be saved. The selection and/or development of treatment technologies, final waste form(s) and disposal site(s) should be coordinated to minimize total life cycle costs. The possibility of delisting certain final waste forms offers the opportunity for additional cost savings. 


\section{CONTENTS}

EXECUTIVE SUMMARY $\ldots \ldots \ldots \ldots \ldots \ldots \ldots \ldots \ldots \ldots \ldots \ldots \ldots \ldots \ldots \ldots \ldots \ldots \ldots \ldots$ iii

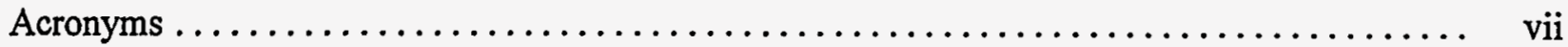

1. INTRODUCTION $\ldots \ldots \ldots \ldots \ldots \ldots \ldots \ldots \ldots \ldots \ldots \ldots \ldots \ldots \ldots \ldots \ldots \ldots \ldots \ldots$

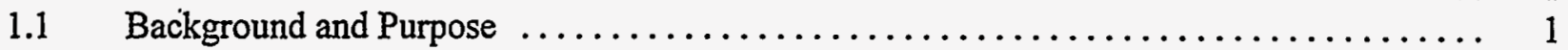

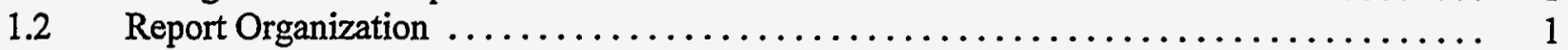

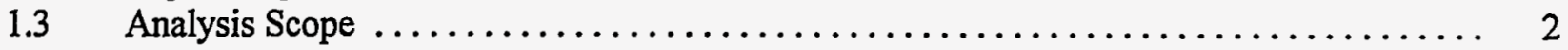

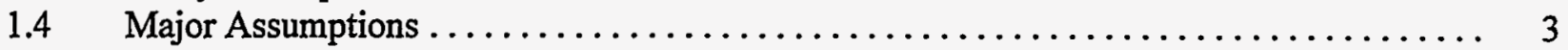

2. SENSITIVITY TO CHANGE IN COMPONENT AND SUBSYSTEM COSTS $\ldots \ldots \ldots .4$

2.1 Sensitivity to Change in Component Costs $\ldots \ldots \ldots \ldots \ldots \ldots \ldots \ldots \ldots \ldots \ldots \ldots \ldots$

2.2 Comparison of Component Present Value Costs $\ldots \ldots \ldots \ldots \ldots \ldots \ldots \ldots \ldots \ldots \ldots$

2.3 Sensitivity to Change in Subsystem Costs $\ldots \ldots \ldots \ldots \ldots \ldots \ldots \ldots \ldots \ldots \ldots \ldots$

3. SENSITIVITY TO SYSTEM CONFIGURATION $\ldots \ldots \ldots \ldots \ldots \ldots \ldots \ldots \ldots \ldots \ldots$

3.1 Sensitivity to Facility Capacity $\ldots \ldots \ldots \ldots \ldots \ldots \ldots \ldots \ldots \ldots \ldots \ldots \ldots \ldots \ldots$

3.1.1 Scaling Application Basis and Assumptions $\ldots \ldots \ldots \ldots \ldots \ldots \ldots \ldots \ldots \ldots \ldots \ldots$

3.1.2 Single Facility with Double Capacity $\ldots \ldots \ldots \ldots \ldots \ldots \ldots \ldots \ldots \ldots \ldots \ldots \ldots \ldots$

3.1.2.1 Net Present Value Cost Comparison $\ldots \ldots \ldots \ldots \ldots \ldots \ldots \ldots \ldots \ldots \ldots \ldots \ldots \ldots \ldots \ldots$

3.1.3 Multiple Facilities and Baseline Capacity $\ldots \ldots \ldots \ldots \ldots \ldots \ldots \ldots \ldots \ldots \ldots \ldots \ldots \ldots$

3.1.3.1 Central Treatment ......................................... 14

3.1.3.2 Regional Treatment $\ldots \ldots \ldots \ldots \ldots \ldots \ldots \ldots \ldots \ldots \ldots \ldots \ldots \ldots \ldots \ldots \ldots \ldots \ldots . \ldots \ldots$

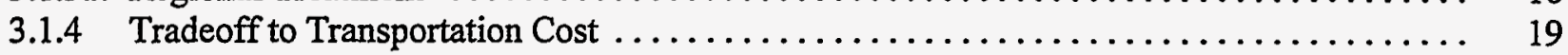

3.2 Sensitivity to Increased Availability of Treatment $\ldots \ldots \ldots \ldots \ldots \ldots \ldots \ldots \ldots \ldots \ldots \ldots$

4. ADDITIONAL TREATMENT COST SENSITIVITIES $\ldots \ldots \ldots \ldots \ldots \ldots \ldots \ldots \ldots$

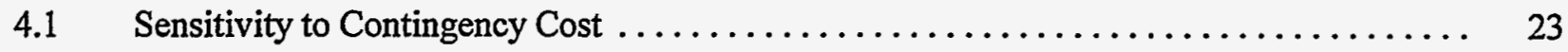

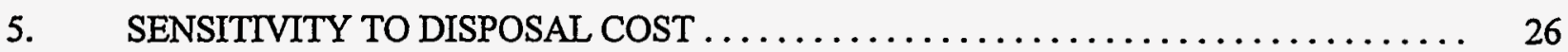

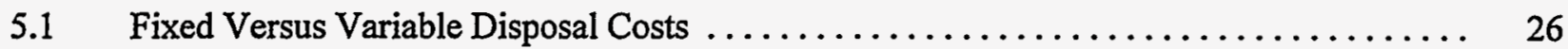

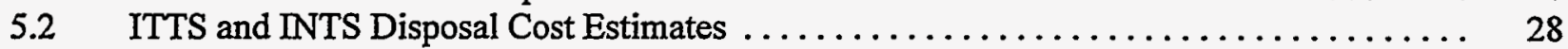

5.2.1 Disposal Cost Comparison for All Technologies $\ldots \ldots \ldots \ldots \ldots \ldots \ldots \ldots \ldots \ldots \ldots \ldots 28$

5.2.2 Disposal Cost Sensitivity as a Function of Facility Size $\ldots \ldots \ldots \ldots \ldots \ldots \ldots \ldots \ldots \ldots \ldots$

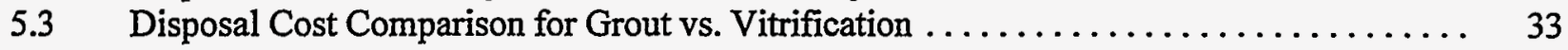

5.4 Economic Impact of Delisting Vitrified Waste Form $\ldots \ldots \ldots \ldots \ldots \ldots \ldots \ldots \ldots \ldots$

6. CONCLUSIONS AND RECOMMENDATIONS $\ldots \ldots \ldots \ldots \ldots \ldots \ldots \ldots \ldots \ldots$

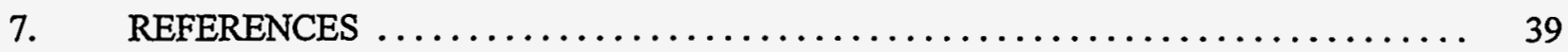

Appendix A-Life Cycle Component and Subsystem Cost Data . . . . . . . . . . . . A-1

Appendix B-Time Phased Life Cycle Costs and Transportation Data $\ldots \ldots \ldots \ldots \ldots \ldots \ldots \ldots$ B-1

Appendix C-Disposal Cost Data $\ldots \ldots \ldots \ldots \ldots \ldots \ldots \ldots \ldots \ldots \ldots \ldots \ldots \ldots \ldots \ldots \ldots \ldots \ldots \ldots \ldots \ldots$ 


\section{FIGURES}

2-1. Life cycle component cost sensitivity $\ldots \ldots \ldots \ldots \ldots \ldots \ldots \ldots \ldots \ldots \ldots \ldots \ldots \ldots$

2-2. Thermal treatment subsystem cost sensitivity $\ldots \ldots \ldots \ldots \ldots \ldots \ldots \ldots \ldots \ldots \ldots \ldots$

2-3. Nonthermal treatment subsystem cost sensitivity $\ldots \ldots \ldots \ldots \ldots \ldots \ldots \ldots \ldots \ldots \ldots . . \ldots$

3-1. Treatment cost sensitivity to scaling factors $\ldots \ldots \ldots \ldots \ldots \ldots \ldots \ldots \ldots \ldots \ldots \ldots \ldots$

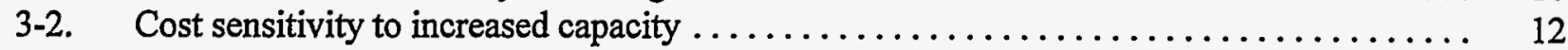

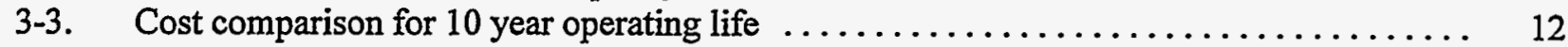

3-4. Cost comparison for 20 year operating life (baseline) $\ldots \ldots \ldots \ldots \ldots \ldots \ldots \ldots \ldots \ldots$

3-5. Life cycle cost sensitivity to scaling factor when the

3-6. Life cycle cost sensitivity to scaling factor when

waste quantity treated over 20 years is doubled $\ldots \ldots \ldots \ldots \ldots \ldots \ldots \ldots \ldots \ldots$

3-7. Life cycle cost sensitivity to scaling factor for centralized

treatment (60\% Eastern U.S. and $34 \%$ Western U.S.) $\ldots \ldots \ldots \ldots \ldots \ldots \ldots \ldots \ldots \ldots \ldots \ldots$

3-8. Life cycle cost sensitivity to scaling factor for regional

3-9. Volume $\%$ for regional treatment of MLLW (based on 1995 MWIR) $\ldots \ldots \ldots \ldots \ldots \ldots \ldots$

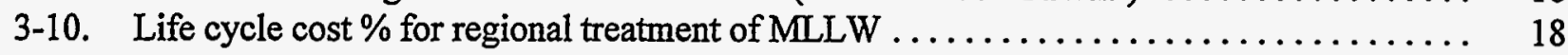

3-11. Total life cycle cost comparison $\$ 000$ (including transportation) $\ldots \ldots \ldots \ldots \ldots \ldots \ldots$

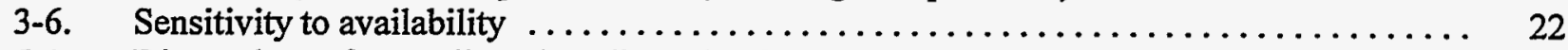

5-1. Disposal cost for small- and medium-size facilities at design capacity $\ldots \ldots \ldots \ldots \ldots \ldots 27$

5-2. Life cycle component cost sensitivity with increased disposal cost $\ldots \ldots \ldots \ldots \ldots \ldots . \ldots \ldots$

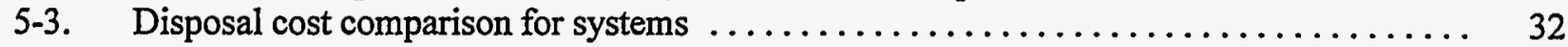

5-4. Disposal cost comparison for grout versus vitrified waste form (revised disposal costs) ... 34

5-5. Disposal cost comparison for grout versus vitrified waste form $\left(\$ 243\right.$ per $\left.\mathrm{ft}^{3}\right) \ldots \ldots \ldots$

\section{TABLES}

2-1. Present value life cycle cost comparison $\ldots \ldots \ldots \ldots \ldots \ldots \ldots \ldots \ldots \ldots \ldots \ldots \ldots$

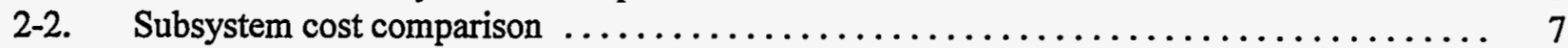

3-1. Life cycle costs for double capacity $(\$ 000) \ldots \ldots \ldots \ldots \ldots \ldots \ldots \ldots \ldots \ldots \ldots \ldots \ldots$

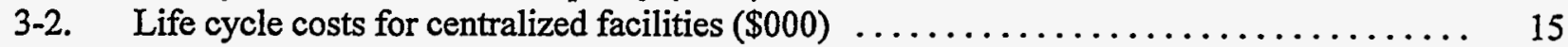

3-3. Life cycle costs for regional facilities $(\$ 000) \ldots \ldots \ldots \ldots \ldots \ldots \ldots \ldots \ldots \ldots \ldots \ldots \ldots \ldots$

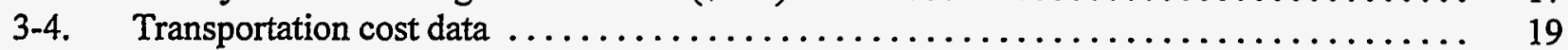

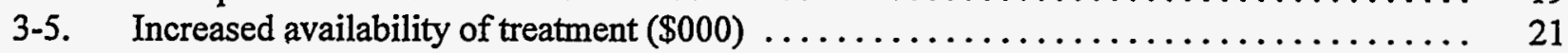

4-1. Total life cycle cost as a function of contingency allowance (\$million) $\ldots \ldots \ldots \ldots \ldots . . \ldots 24$

5-1. Disposal life cycle costs for small- and medium-size facilities $\ldots \ldots \ldots \ldots \ldots \ldots \ldots \ldots . \ldots \ldots$

5-2. Systems ranked by total life cycle cost including revised disposal costs . . . . . . . . 29

5-3. Disposal cost assuming demisting of vitrified waste form $\ldots \ldots \ldots \ldots \ldots \ldots \ldots \ldots \ldots$

A-1. Life cycle cost sensitivity to $100 \%$ increase in component cost $\ldots \ldots \ldots \ldots \ldots \ldots \ldots$ A-1

A-2. Time phased life cycle costs for baseline system $\ldots \ldots \ldots \ldots \ldots \ldots \ldots \ldots \ldots \ldots$ A-2

A-3. Present value life cycle cost comparison $(\$ 000) \ldots \ldots \ldots \ldots \ldots \ldots \ldots \ldots \ldots \ldots$ A-3

A-4. Thermal subsystem component cost sensitivity $(\$ 000) \ldots \ldots \ldots \ldots \ldots \ldots \ldots \ldots \ldots$ A-5

A-5. Nonthermal subsystem component cost sensitivity $(\$ 000) \ldots \ldots \ldots \ldots \ldots \ldots \ldots$ A-6

B-1. Time phased life cycle costs for baseline system $\ldots \ldots \ldots \ldots \ldots \ldots \ldots \ldots \ldots \ldots$ B-1 


\section{TABLES (cont'd)}

B-2. Time phased life cycle costs for 10 year operating life (scaling factor 0.5$) \ldots \ldots \ldots$ B-2

B-3. Net present value comparison for operating 20 versus 10 years $\ldots \ldots \ldots \ldots \ldots \ldots \ldots$ B-3

B-4. Transportation cost data for shipment to one facility $\ldots \ldots \ldots \ldots \ldots \ldots \ldots \ldots \ldots \ldots$ B-4

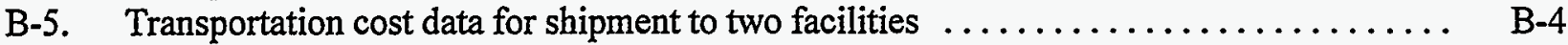

B-6. Transportation cost data for shipment to five facilities $\ldots \ldots \ldots \ldots \ldots \ldots \ldots \ldots \ldots$ B-5

C-1. Revised disposal cost estimates for small- and medium-size facilities $\ldots \ldots \ldots \ldots \ldots$ C-1

C-2. Vitrified and solid waste output and revised disposal cost $\ldots \ldots \ldots \ldots \ldots \ldots \ldots \ldots \ldots$ C-2 


\section{ACRONYMS}

DOE

EM

EPA

GOCO

INEL

INTS

ITTS

LCC

MK

MLLW

MWIR

NPV

ORNL

RCRA

RFP

SRS

WBS

U.S. Department of Energy

(U.S. Department of Energy) Environmental Management

U.S. Environmental Protection Agency

government-owned, contractor-operated

Idaho National Engineering Laboratory

Integrated Nonthermal Treatment Systems

Integrated Thermal Treatment Systems

life cycle cost

Morrison Knudsen

mixed low-level waste

Mixed Waste Inventory Report

net present value

Oak Ridge National Laboratory

Resource Conservation and Recovery Act

Rocky Flats Plant

Savannah River Site

work breakdown structure

vii

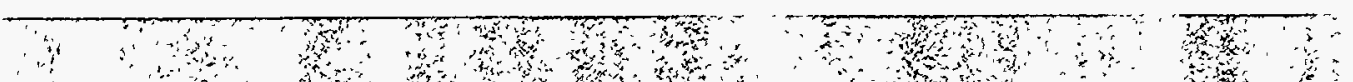




\subsection{INTRODUCTION}

\subsection{Background and Purpose}

The U.S. Department of Energy (DOE) Environmental Management Office of Science and Technology (EM-50) authorized studies on alternative thermal and nonthermal systems for treating contact-handled, alpha and non-alpha DOE mixed low-level radioactive waste (MLLW). The Integrated Thermal Treatment Systems ${ }^{1}$ (ITTS) and the Integrated Nonthermal Treatment Systems ${ }^{2}$ (INTS) studies satisfy this request. EM-50 further authorized various supporting activities including this technology and subsystem cost sensitivity analysis.

The purpose of this analysis is to identify areas where technology development and/or improvement could have the greatest impact on system life cycle costs. To identify these areas, the sensitivity of life cycle cost to changes in component or phase costs, subsystem costs, contingency allowance, operating life, and disposal cost is evaluated. Facility capacity is varied to determine the effect on treatment life cycle cost for construction and operation of multiple facilities versus a single facility. A present value analysis is included in anticipation of the requirement for all proposed EM projects, as explained in the Ten Year Plan guidance.

\subsection{Report Organization}

The ITTS and INTS Technology and Subsystem Cost Sensitivity Analysis report is organized into seven sections and three appendices.

Section 1.0 provides the background and purpose, report organization, scope, and major assumptions of the analysis along with a brief introduction to the treatment systems.

Section 2.0 presents the results of the treatment life cycle component and subsystem cost sensitivity analyses along with present value cost comparison for the components or phases of the life cycle. This section lists the life cycle components and the subsystems and identifies those that are most cost sensitive.

Section 3.0 estimates the effect on treatment life cycle costs for multiple versus a single treatment facility. In addition, cost savings is estimated by increasing annual facility availability (i.e., increasing annual operating hours). A present value comparison of the life cycle costs for a reduced operating life is included.

Section 4.0 considers an additional contingency allowance for technologies considered to have more operational uncertainty.

Section 5.0 estimates the cost for disposal as a function of the final waste volume produced by the treatment systems. This disposal cost comparison assumes that a mixed waste disposal facility would be constructed.

Section 6.0 summarizes the major conclusions and recommendations.

Section 7.0 lists the references used in this analysis. 


\subsection{Analysis Scope}

The technology and subsystem cost sensitivity analysis identifies areas where technology development and/or improvements could have the greatest impact on total system life cycle costs. These costs are the system life cycle costs for the twenty-five ITTS and INTS technologies. The cost estimates are based on construction and operation of government-owned contractor-operated (GOCO) facilities. The sensitivity of the system life cycle costs is evaluated relative to.changes in life cycle component or phase costs, subsystem costs, contingency allowance, facility capacity, operating life, and disposal costs.

A representative subset of the 20 ITTS and 5 INTS treatment systems is compared in the individual analyses contained in this study. These systems are:

Thermal Treatment Systems

A-1 rotary kiln with air for combustion and vitrification for stabilization,

A-2 rotary kiln with oxygen for combustion and vitrification for stabilization,

A-3 rotary kiln with air for combustion and wet air pollution control system,

A-4 rotary kiln with oxygen for combustion and $\mathrm{CO}_{2}$ retention,

A-5 rotary kiln with air for combustion and polymer stabilization,

A-6 rotary kiln with air for combustion and maximum recycling,

A-7 slagging rotary kiln with air for combustion,

A-8 rotary kiln with air for combustion and grouting for stabilization,

B-1 indirectly heated pyrolyzer with oxygen and dry/wet air pollution control,

C-1 plasma hearth furnace with air for combustion,

$\mathrm{C}-2$ plasma furnace with oxygen for combustion and $\mathrm{CO}_{2}$ retention,

C-3 plasma furnace with steam for combustion and dry/wet air pollution control,

D-1 fixed hearth with oxygen and $\mathrm{CO}_{2}$ retention,

E-1 debris desorption and grouting with rotary kiln for combustibles,

F-1 molten salt oxidation with air for combustion and dry/wet air pollution control,

G-1 molten metal waste destruction with oxygen for combustion,

H-1 steam gasification with steam for combustion and vitrification for stabilization,

$\mathrm{J}-1$ joule heated vitrification with oxygen for combustion and dry/wet air pollution control,

K-1 thermal desorption with starved air for combustion and mediated electrochemical oxidation for organic liquid destruction and dry air pollution control, and

L-1 thermal desorption with starved air for combustion and supercritical water oxidation for organic liquid destruction and dry air pollution control.

Nonthermal Treatment Systems

NT-1 grout debris,

NT-2 vacuum desorption,

NT-3 wash,

NT-4 acid digestion, and

NT-5 catalytic wet oxidation. 


\subsection{Major Assumptions}

The major assumptions in this analysis are summarized as follows:

- The ITTS and INTS facilities are designed and costed to operate three shifts per day, seven days per week, 40 weeks per year at $60 \%$ operating efficiency for a total of 4,032 hours per year.

- In the base case, bench scale testing and demonstration begins in year one with a duration of three years; permitting begins in year four with a duration of three years; construction begins in year seven with a duration of two years; one year of preoperations in year eight; operations begin in year nine with a duration of 20 years; disposal operations begin in year nine with a duration of 21 years; decontamination and decommissioning begins in year 29 with a duration of two years.

- The systems are designed for a 20 year operating life.

- The system feed rate calculations are based on a total of 2,927 pounds per hour. This feed rate was derived based on treating the majority of the DOE 1993 MLLW inventory.

- The base case treatment facility will process a portion of the DOE contact-handled, MLLW inventory equal to $236,033,280$ pounds (i.e., $2,927 \mathrm{lbs} / \mathrm{hr} \times 4,032 \mathrm{hrs} / \mathrm{yr} \times 20 \mathrm{yrs}$ ).

- The physical, chemical, and radiological characteristics of the MLLW inventory, as identified in the ITTS and INTS, are based on the DOE 1993 MLLW inventory.

- The treatment life cycle phases are: bench scale testing, demonstration, construction, preoperations, operations, disposal, and decontamination and decommissioning.

- The cost of transporting the waste to the treatment facility is independent of the treatment system used.

- The cost of transporting the treated waste to the disposal facility is not considered because the ITTS assumes that the residual waste will be disposed at the same location as the treatment facility and therefore, cost is negligible. 


\subsection{SENSITIVITY TO CHANGE IN COMPONENT AND SUBSYSTEM COSTS}

The following sections identify significant system component or phase and subsystem costs. Using parametric comparisons, the life cycle cost sensitivity is examined with respect to change in these cost areas. A present value cost comparison incorporates the time value of money to show the present cost for each life cycle component or phase.

\subsection{Sensitivity to Change in Component Costs}

Using a representative set of systems, this section identifies major cost components and shows how change to these costs affects treatment life cycle costs. The life cycle components or phases are: benchscale testing, demonstration, construction, preoperations, operations and maintenance, disposal, and decontamination and decommissioning activities. This analysis combines bench-scale testing and demonstration into one component called demonstration, and construction costs are divided into capital equipment and building cost components. This division maintains consistency with a similar comparison documented in the ITTS and INTS.

The cost sensitivity for each component is determined by doubling and halving the cost of the component or parameter and then measuring the resulting increase and decrease in the total life cycle cost. This cost variation was selected to maintain consistency with the comparison documented in the ITTS. Figure 2-1 illustrates this cost sensitivity. In this analysis, all dependent costs are changed with the parametric comparison; this is referred to as a secondary effect. For example, facility design, inspection, and project management costs are a percentage of construction costs; therefore, if construction costs increase or decrease, these costs also increase or decrease by the given percentage of the construction cost change.

For all systems, the most cost sensitive component is the operations and maintenance phase. When annual operating, utility, material, and maintenance costs are doubled, the total life cycle costs increase by an average of $68 \%$ for the technologies. The second and third most cost sensitive components are capital equipment and building expenditures resulting in a $12 \%$ and $13 \%$ increase, respectively, in total life cycle costs. Table A-1 in Appendix A provides a detailed break out for each of the eighteen systems showing the percentage increase in life cycle costs resulting from a $100 \%$ increase in the individual component costs.

As defined in the ITTS and INTS, the cost basis for the operations and maintenance is as follows: operating labor, utilities, consumable materials, maintenance parts and equipment, and maintenance labor. The first three costs are estimated by analyzing the requirements of each facility at the subsystem level. The remaining two costs are estimated as a percentage of the original equipment installed at the facility. That is, annual maintenance spare parts and replacement equipment are estimated to be about $7 \%$ of the original equipment purchase cost or $10 \%$ for subsystems amenable to corrosion. And lastly, maintenance labor is estimated to cost $250 \%$ of the cost of spare parts and replacement equipment on an annual basis. 


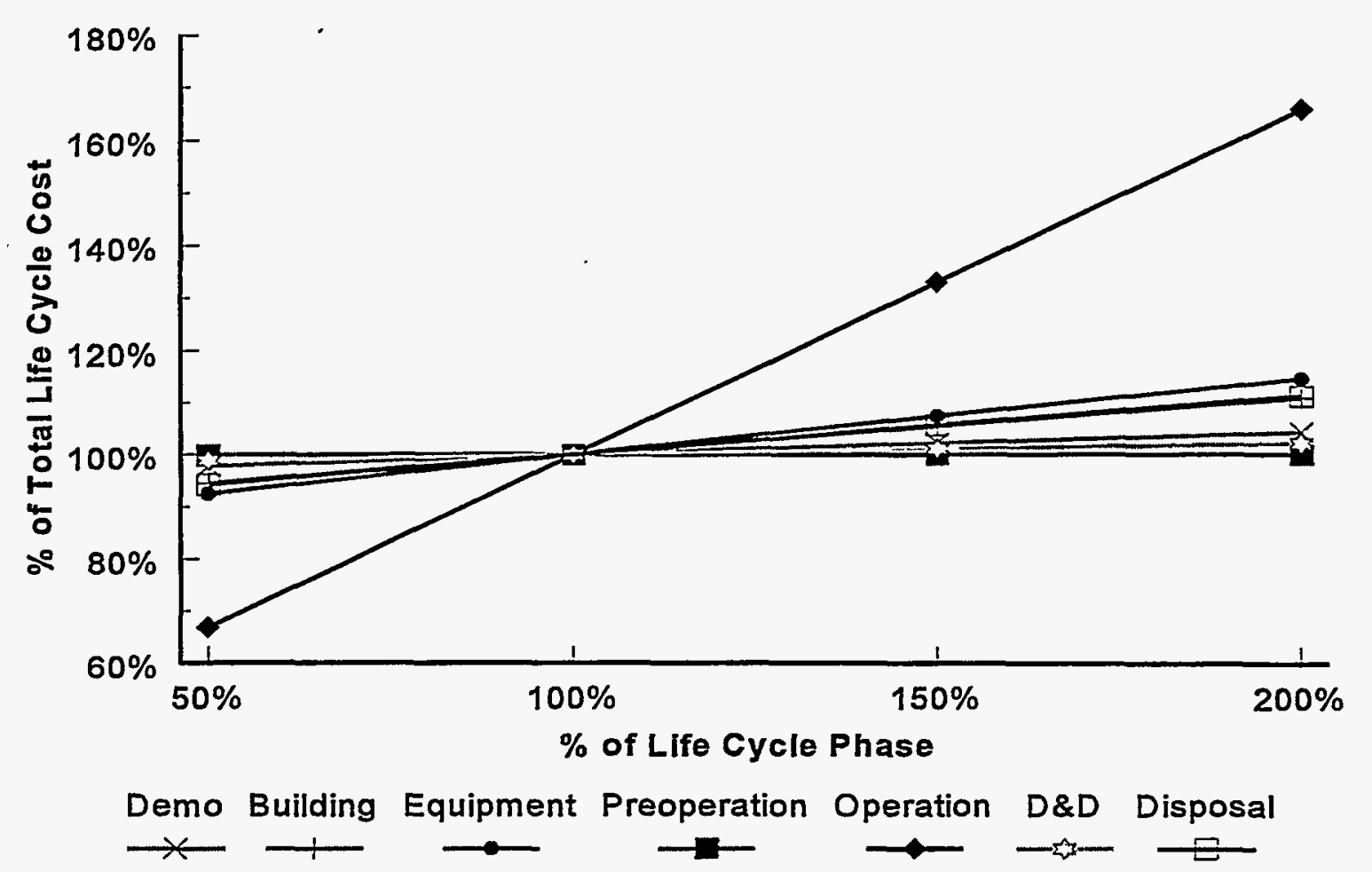

Figure 2-1. Life cycle component cost sensitivity.

Although this analysis focuses exploring cost reductions in the most expensive cost components, it is recognized that a high percentage cost reduction might be achieved in a less expensive cost component, thereby yielding an equivalent overall reduction in treatment life cycle cost.

\subsection{Comparison of Component Present Value Costs}

Up to this point, the analysis is based on a summation of the costs over the life cycle of the treatment facility. This section of the analysis is included to adhere to guidance from EM via the Ten Year Plans requiring that field offices and sites include present value analyses for all proposed projects whether line item projects or private sector ventures.

The analysis employs the fundamental concept of the time value of money by calculating the present value of costs in order to compensate for differing cash outlays or expenses during the life cycle of selected systems. That is, the value of a given sum of money depends on when the money is received or, as in this analysis, dispersed. The value, economic worth, or purchasing power of money changes over time with the preference being to receive the dollars today rather than at some time in the future or conversely to spend the dollars later rather than earlier. This preference is due to the opportunity cost of money or in other words, the cost of forgoing the opportunity to earn interest, or a return, on investment funds.

The present value of the costs of the life cycle components or phases are compared to the summation of these costs over time. The life cycle phases include building and equipment costs combined to form construction costs, bench scale testing and demonstration split, and disposal costs to form the seven components that are used in the remaining analyses (i.e., bench scale testing, demonstration, 
construction, preoperations, operations, disposal, and decontamination and decommissioning). This present value comparison is intended to illustrate the time value of money in the absence of inflation or deflation (i.e., constant dollars) using the current Federal Discount Rate of $6 \%$. The time phase for each of the life cycle components and the present value of the costs are included in Appendix A Table A-2 and A3.

As expected, the results of this analysis show that the present value of the cost for completing the earlier phases of the treatment life cycle is a greater percentage of the total life cycle costs, whereas the present value of the cost for completing the later phases of the treatment life cycle is a smaller percentage of the total life cycle costs. Table 2-1 compares the average total life cycle cost (\%) summed over time to the average present value cost (\%) for the major cost components.

Table 2-1. Present value life cycle cost comparison.

Thermal Treatment

Nonthermal Treatment

Life Cycle Phase

\% Life Cycle Cost

$\%$ Present Value

\% Life Cycle Cost

$\%$ Present Value Cost Cost

\begin{tabular}{l|ll|ll}
\hline Operations & $55 \%$ & $44 \%$ & $53 \%$ & $44 \%$ \\
Construction & $22 \%$ & $31 \%$ & $17 \%$ & $25 \%$ \\
Disposal & $13 \%$ & $10 \%$ & $20 \%$ & $16 \%$ \\
Other & $10 \%$ & $15 \%$ & $10 \%$ & $15 \%$
\end{tabular}

When taking into consideration the time value of money, the operating costs remain the most costly life cycle component followed by construction. However, when compared to adding up the life cycle costs over time, the present value comparison shows that the construction costs increase as a percentage of total life cycle costs; whereas, the operating costs decrease as a percentage of total life cycle costs. For the same fundamental concept that money has a time value, the present value of the bench scale testing and demonstration costs becomes a bigger cost component than the present value of the decontamination and decommissioning costs. The present value of the bench scale testing and demonstration costs increases on the average from $4 \%$ to $8 \%$ of the total life cycle costs; whereas, the present cost of the decontamination and decommissioning costs decreases from $2 \%$ to $1 \%$ of the total life cycle costs.

In conclusion, this cost comparison demonstrates that cash outlays in the later phases of the life cycle are more economically favorable than cash outlays in the earlier phases of the life cycle. This analysis does not change any previous conclusions and recommendations concerning areas for potential cost savings via technology development or improvement. Furthermore, the overall ranking of technologies and their individual cost components by the present value of the life cycle costs does not differ from the ranking of the technologies and components by summing the life cycle costs. The most costly systems when summing the life cycle costs remain the most costly from a present value perspective, and operations and maintenance costs are still the biggest cost driver for all systems. 


\subsection{Sensitivity to Change in Subsystem Costs}

Using a representative set of systems, this section identifies the most cost sensitive treatment subsystems and examines the treatment life cycle cost sensitivity with respect to changes in subsystem costs. For all systems examined, the most cost sensitive subsystem is the receiving and inspection/preparation subsystem. This cost data is included in Appendix A Tables A-4 and A-5.

As defined in the ITTS and INTS, the function of the receiving and inspection/preparation subsystem is to receive and inspect the incoming waste and prepare the waste for the appropriate treatment subsystems. The receiving and inspection subsystem has cranes and forklift trucks to unload waste containers from incoming vehicles. The physical state of the waste in containers is identified by a realtime radiography unit. A passive/active neutron assay unit determines the level of transuranic contamination of the waste and a gamma scanning unit is used to assay beta and gamma radioactivity. A computer software and bar code scanning unit records and tracks the waste. The wastes are classified either as those requiring sorting or not requiring sorting. Containers of wastes not requiring sorting are moved directly to the appropriate treatment subsystem. The ITTS and INTS assume approximately $50 \%$ and $75 \%$ of the waste will require sorting, respectively. If sorting is required, the container is decapped by a saw mounted on a gantry robot. After decapping, the container is emptied onto a sorting table equipped with master-slave and hydraulic manipulators used for segregating materials into treatment types. If required, the sorted waste material is size reduced by saw cutting and/or mechanical auger shredders. When ready, the sorted waste is placed in transfer bins and moved to the treatment subsystems.

Opportunity exists for technology development to reduce waste receiving and inspection/preparation costs by effectively minimizing labor costs, the major cost driver, within the maintenance and operations phase of the life cycle. For instance, as defined in the ITTS, the receiving and inspection subsystem requires three 28 person shifts per day or 84 persons per day to process approximately 15055 -gallon drums of waste. If the three shift requirement could be reduced to one 28 person shift per day, then treatment life cycle cost would be reduced by $\$ 235$ million or $11 \%$ of system A1 costs, rotary kiln with air for combustion. This modification would require that each person process a total of five drums per day at 1.6 hours per drum compared to 1.8 drums per day at 4.4 hours per drum. Time and motion studies on labor intensive subsystems such as the receiving and inspection subsystem are recommended to identify rate limiting steps or other reasons for maintaining three shift operations.

The subsystems that comprise the majority of the life cycle costs are listed in Table 2-2 and graphically presented in Figures 2-2 and 2-3.

Table 2-2. Subsystem cost comparison.

\begin{tabular}{lc|lc} 
Thermal Subsystem & \% Life Cycle Cost & Nonthermal Subsystem & \% Life Cycle Cost \\
\hline Receive and Inspect & $33 \%$ & Receive and Inspect & $31 \%$ \\
Primary Thermal Trtmt & $11 \%$ & Certify and Ship & $15 \%$ \\
Certify and Ship & $10 \%$ & Polymer Stabilization & $8 \%$ \\
Administration & $7 \%$ & Organic Destruction & $7 \%$ \\
Aqueous Waste Trtmt & $6 \%$ & Administration & $6 \%$ \\
Other (11 subsystems) & $33 \%$ & Other (14 subsystems) & $33 \%$
\end{tabular}




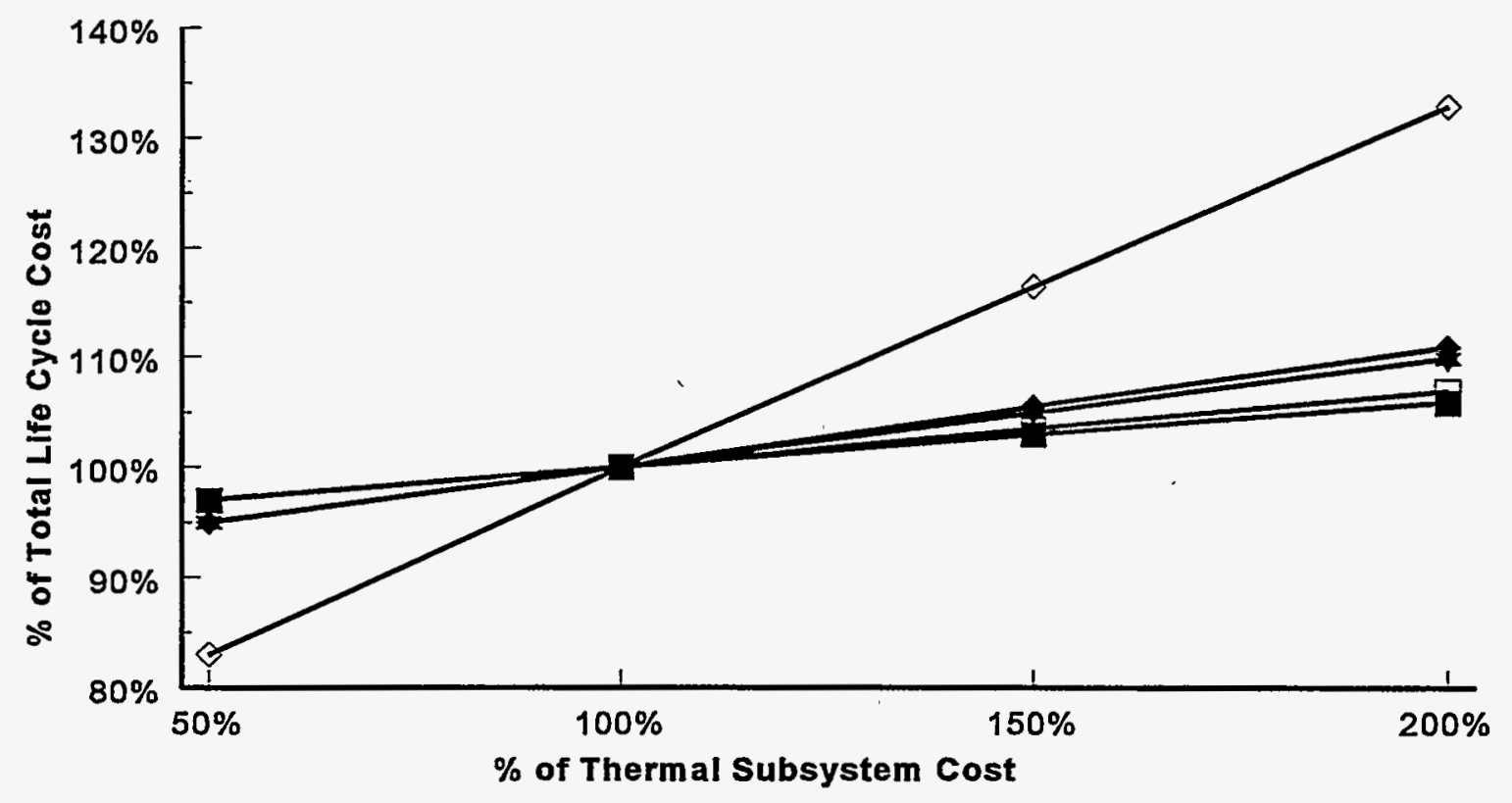

Receive \& Inspect Primary Trmt Certify \& Ship Admin Aqueous Trmt

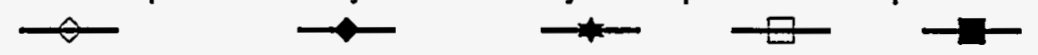

Figure 2-2. Thermal treatment subsystem cost sensitivity.

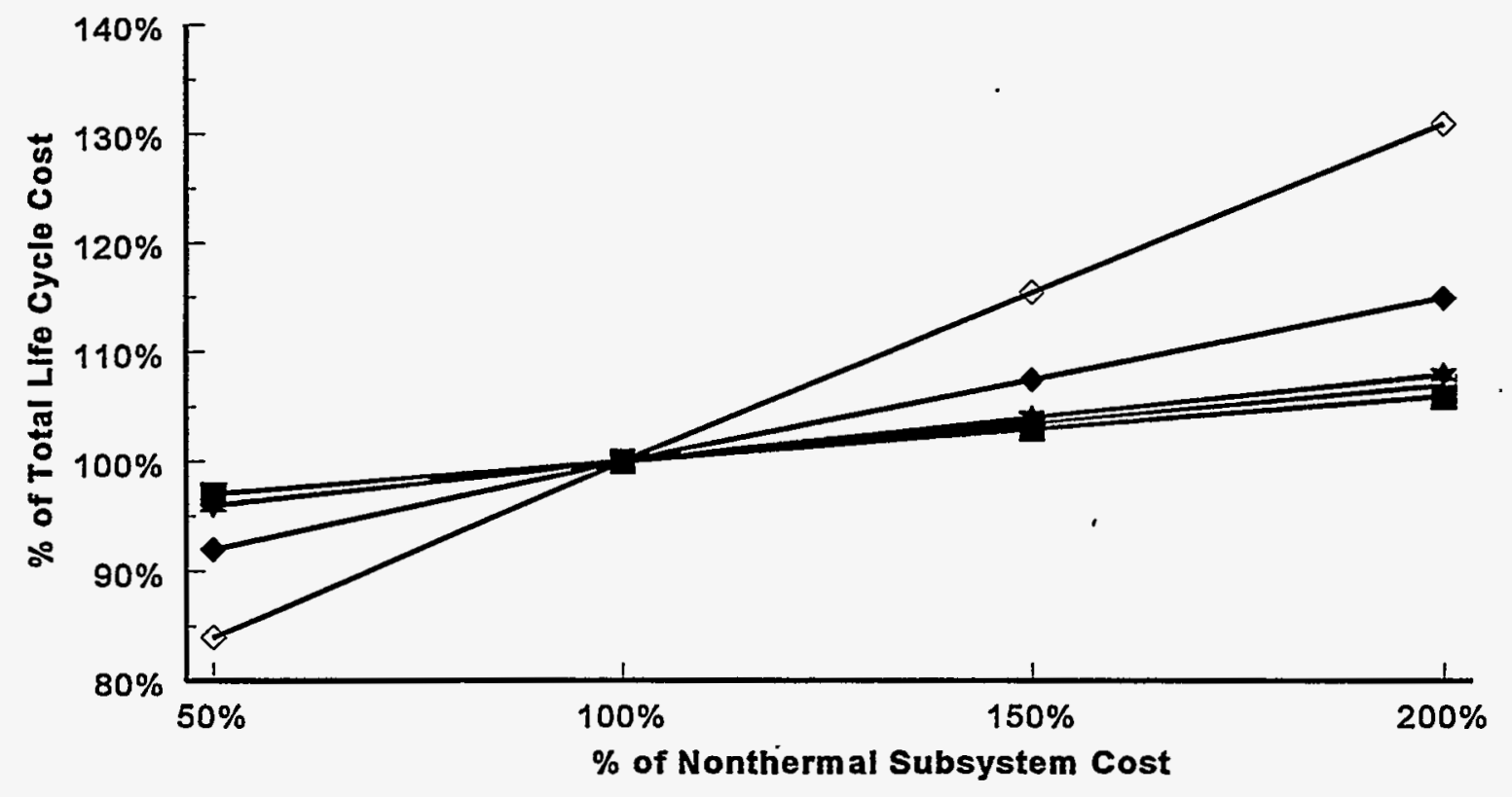

Receive \& Inspect Certify \& Ship Polymer Stabil Organic Dest Admin

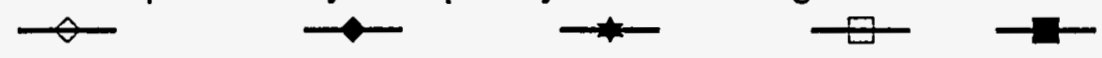

Figure 2-3. Nonthermal treatment subsystem cost sensitivity. 


\subsection{SENSITIVITY TO SYSTEM CONFIGURATION}

Variations in facility capacity are examined in this section to determine the effect of increased or decreased capacity on treatment life cycle costs. Transportation costs to the facility are included because these costs increase as the number of facilities decrease (i.e., tradeoff to transportation cost). The analysis further examines life cycle cost savings that can be attained by increasing annual facility availability.

\subsection{Sensitivity to Facility Capacity}

The economic scaling applications considered in this section are based on the costs for a baseline thermal treatment facility, system A-1, a system design developed for combustion of the wastes and vitrification of the ash residues. The impact to total treatment life cycle cost is estimated for operating a single facility with increased capacity and multiple facilities to treat the baseline capacity.

\subsubsection{Scaling Application Basis and Assumptions}

Life cycle costs are scaled up or down to show the cost sensitivity for construction and operation of one larger facility or two or more smaller facilities. Three independent scaling applications are analyzed to determine the change to life cycle cost (i.e., one, two, and five facilities).

The treatment systems described in the INTS and ITTS are sized to a capacity for treating 236 million pounds of MLLW over a 20 year operating life (i.e., 2,927 lbs/hr x 4,032 hrs/yr x $20 \mathrm{yrs}$ ). The cost estimates for each of the treatment systems are based on GOCO facility construction and operation. The economics of scaling indicate that treating additional quantities of waste would increase total savings, assuming that extensive design modifications are not required. This analysis uses the throughput rate and cost estimates for the baseline system, A-1, and then, as appropriate for each case, these quantities are scaled upward or downward.

The methodology used to analyze the impact to total life cycle cost for differing facility capacities is based on exponential scaling of the ITTS cost estimates (capacity-ratio exponents) ${ }^{3}$. For example, if the cost of a treatment facility component of capacity $q_{1}$ is $C_{1}$, then the cost of a similar treatment facility component of capacity $q_{2}$ is calculated from $C_{2}=C_{1}\left(q_{2} / q_{1}\right)^{n}$ where the value of the exponent $n$ is the scaling factor. The scaling factor, $n$, is varied from 0 to 1 , where scaling factors closer to 0 result in a cost, $\mathrm{C}_{2}$, that is independent of the size of the facility (i.e., resembles a fixed cost) and, conversely, scaling factors closer to 1 result in a cost, $C_{2}$, that is proportional to the change in facility size (i.e., resembles a variable cost). This approach for assessing cost sensitivity is derived from Perry's Chemical Engineers' Handbook $k^{3}$.

Costs are scaled uniformly in this analysis, using a factor of 0.5 . The scaled costs are capital equipment, building, operation and maintenance, and decontamination and decommissioning costs. Additional analyses may warrant varying the scaling factor for each individual cost component rather than applying a uniform scaling factor. For instance, although partially dependent on the size of the equipment, the operation and maintenance costs more than likely do not scale to the same magnitude as the equipment costs. The steel industry uses a scaling factor of 0.65 in estimating costs for a processing plant. For this analysis, this industry is compared to the waste processing industry. By comparison, MLLW processing is 
a much less developed industry than the steel industry and the costs will tend to be more fixed than variable. For example, special equipment used in metal decontamination, mercury amalgamation, special waste processing, etc., will not be easily sized to increase or decrease capacity, and new equipment will have to be designed and manufactured to vary capacity. A factor of 0.5 is used in this analysis to account for the higher percentage of fixed costs for construction and operation of a GOCO treatment facility. In addition, the life cycle cost sensitivity as a function of scaling factor is presented in each case of this analysis to bound any associated uncertainty with the selection of a specific factor. Figure 3-1 summarizes the treatment life cycle cost sensitivity to scaling factor for the applications presented in Sections 3.1.2 and 3.1.3.

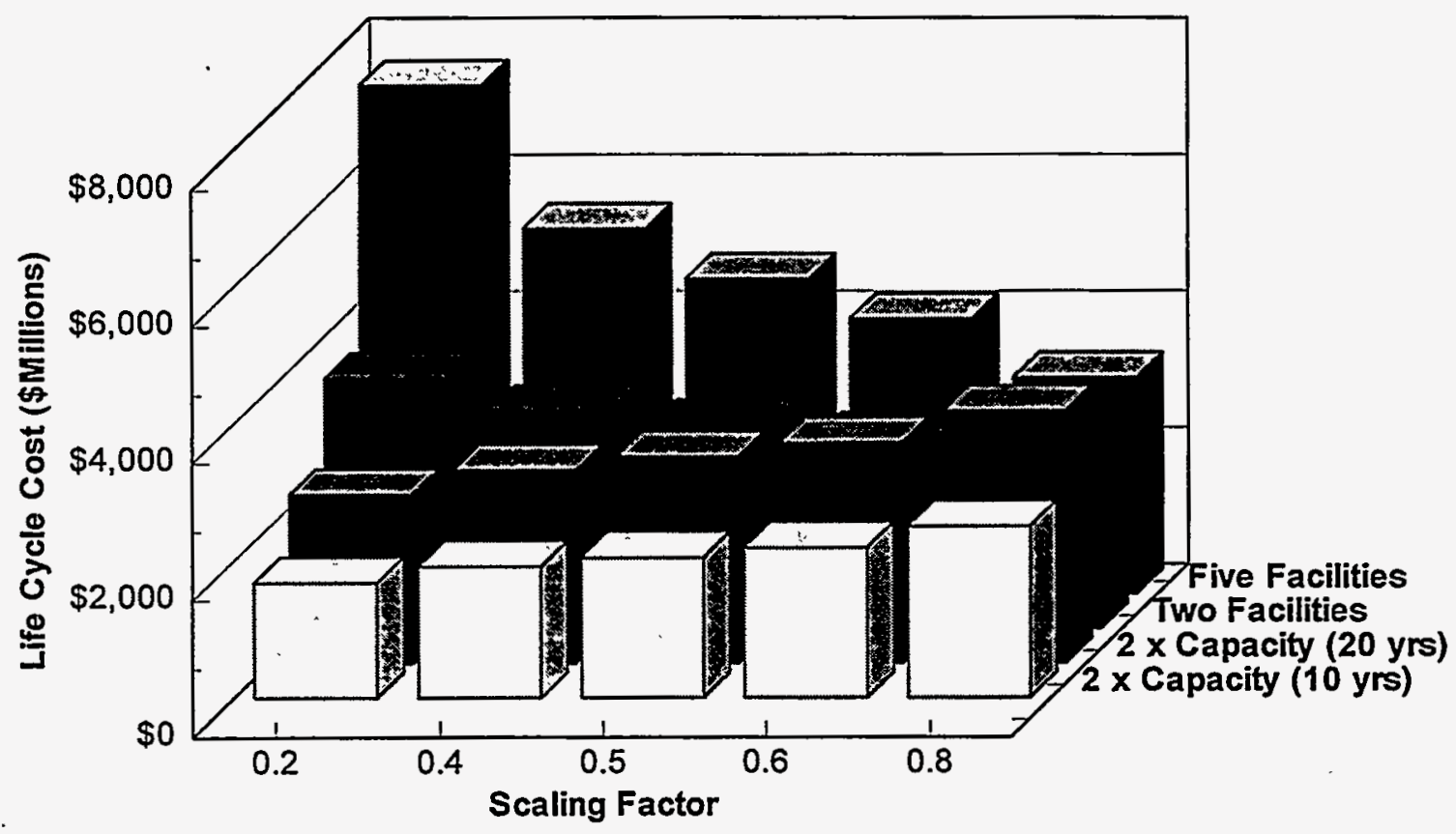

Figure 3-1. Treatment Cost Sensitivity to Scaling Factors.

\subsubsection{Single Facility with Double Capacity}

Consistent with the INTS and ITTS assumption that the MLLW inventory will be treated in one facility, the following examines the change to life cycle cost as a function of scaling factor, facility capacity, and operating life for a single facility. Section 3.2 examines the change to life cycle cost for a single facility as a function of facility availability without scaling the costs.

This case compares the life cycle cost of a facility sized for twice the capacity of the baseline system to the cost of the baseline system. Doubling the capacity implies doubling the throughput rate; therefore, the same quantity of waste can be treated in half the original time. The operating period is reduced from 20 to 10 years. Alternatively, doubling the capacity of the facility also implies that two times the input waste could be treated over a 20 year operating life, or 472 million pounds.

Doubling the facility capacity, scaling the costs, and reducing the operating period from 20 to 10 years offsets the increased costs for construction, preoperation, and decontamination and decommissioning by reducing operating costs. The total life cycle cost for operating 10 years is approximately the same as 
the baseline system operating 20 years when using a 0.58 scaling factor. This break-even point is important because it indicates that if costs are scaled using a factor less than 0.58 , then the total life cycle cost for operating 10 versus 20 years is less than the life cycle cost of the baseline system.

Alternatively, if the capacity is doubled, two times the input waste could be treated during a 20 year operating life yielding a lower unit cost o $\$ 6.75 / \mathrm{lb}$. These costs are shown in Table 3-1, life cycle costs for double capacity.

Table 3-1. Life cycle costs for double capacity $(\$ 000)$.

\begin{tabular}{|c|c|c|c|c|}
\hline & $\begin{array}{r}\text { Operating life } \\
\text { Waste treated (lbs) } \\
\end{array}$ & $\begin{array}{c}\text { Baseline system } \\
20 \text { years } \\
236 \mathrm{M} \\
\end{array}$ & $\begin{array}{c}2 \times \text { capacity } \\
10 \text { years } \\
236 \mathrm{M} \\
\end{array}$ & $\begin{array}{c}2 \text { x capacity } \\
20 \text { years } \\
472 \mathrm{M} \\
\end{array}$ \\
\hline WBS & Life cycle phase & & & \\
\hline 1.0 & Bench scale testing & $\$ 30,525$ & $\$ 30,525$ & $\$ 30,525$ \\
\hline 2.0 & Demonstration & $\$ 69,647$ & $\$ 69,647$ & $\$ 69,647$ \\
\hline 3.0 & Construction & $\$ 554,377$ & $\$ 784,008$ & $\$ 784,008$ \\
\hline 4.0 & Preoperation & $\$ 96,747$ & $\$ 134,087$ & $\$ 134,087$ \\
\hline 5.0 & Operations & $\$ 1,361,850$ & $\$ 962,973$ & $\$ 1,925,947$ \\
\hline 6.0 & $\mathrm{D} \& \mathrm{D}$ & $\$ 54,171$ & $\$ 76,609$ & $\$ 76,609$ \\
\hline \multirow{2}{*}{\multicolumn{2}{|c|}{$\begin{array}{l}\text { Total life cycle cost } \\
\text { Scaling factor }=0.5\end{array}$}} & $\$ 2,167,318$ & $\$ 2,057,850$ & $\$ 3,020,824$ \\
\hline & & $\$ 9.18 / \mathrm{lb}$ & $\$ 8.72 / \mathrm{b}$ & $\$ 6.40 / \mathrm{lb}$ \\
\hline
\end{tabular}

Figure 3-2 compares the change to life cycle cost and unit cost as a function of capacity and operating period. Figures 3-3 and 3-4 compare the cost components for operating 10 versus 20 years. 


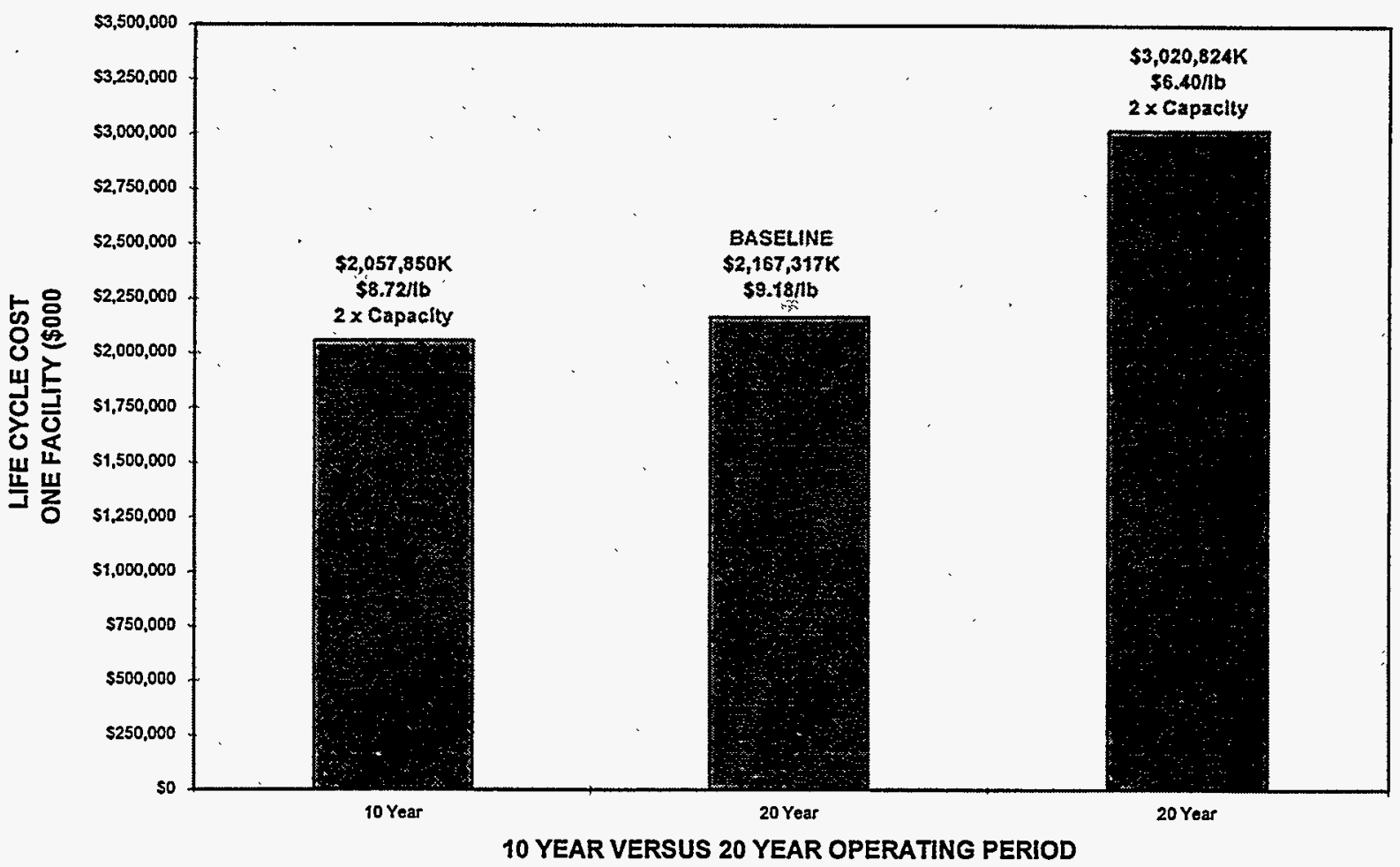

Figure 3-2. Cost sensitivity to increased capacity.

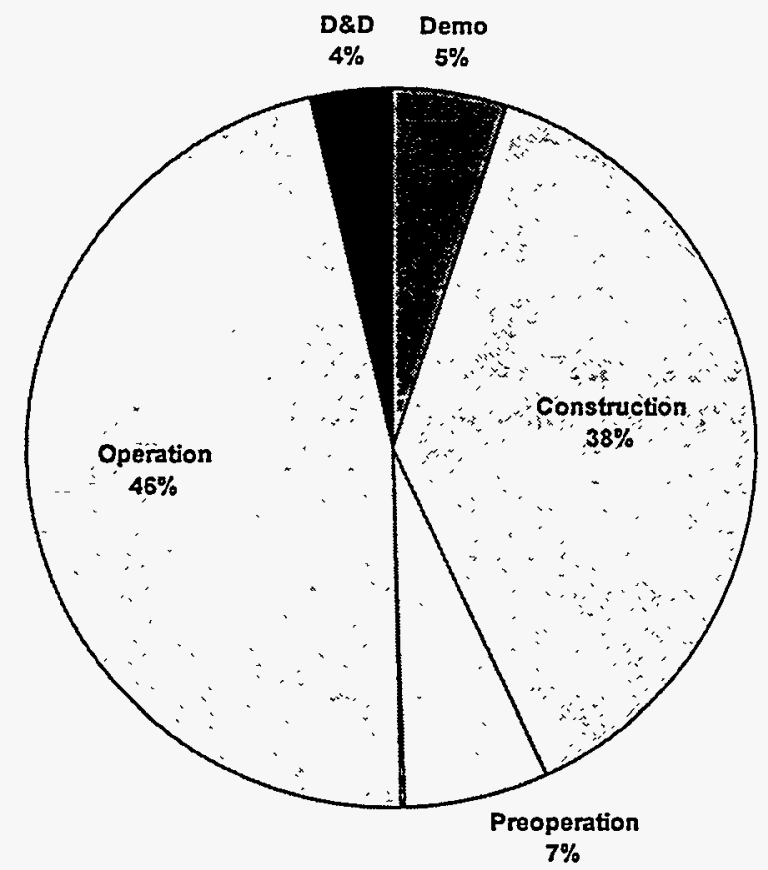

Figure 3-3. Cost comparison for 10 year operating life.

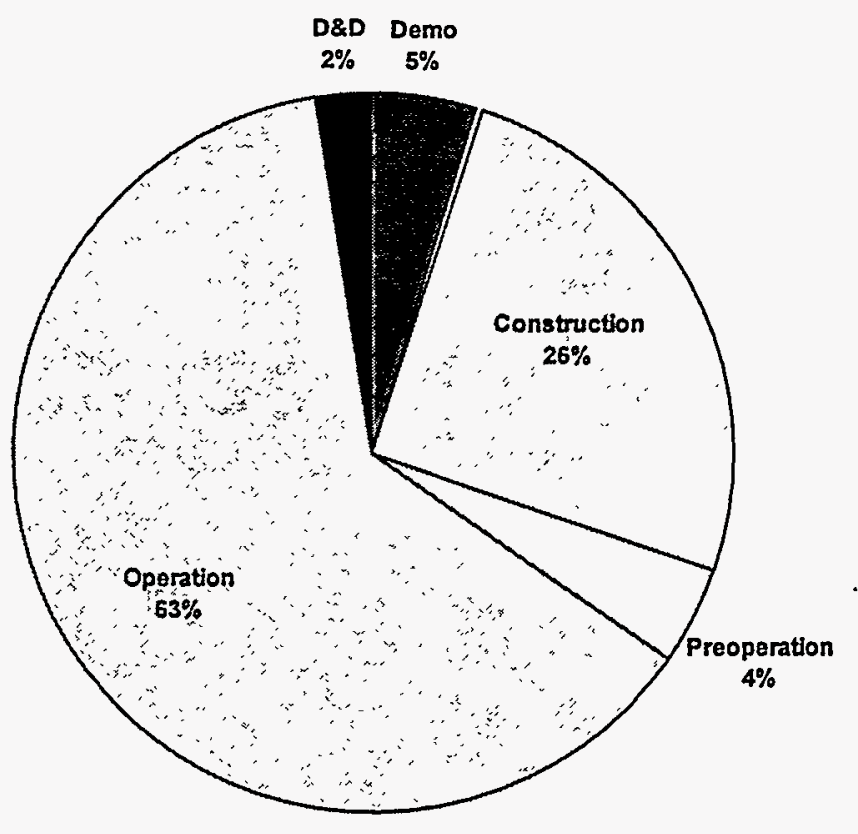

Figure 3-4. Cost comparison for 20 year operating life (baseline). 
In the previous example, capacity is doubled and a scaling factor of 0.5 is used to estimate the resulting increase to cost. Figure 3-5 shows the life cycle cost sensitivity when applying a range of scaling factors to the costs. In this case, the capacity is doubled, allowing treatment of the original quantity of waste in half the time, or a 10 year operating period. As shown, lower scaling factors result in a lower cost per pound. Figure 3-6 shows the life cycle cost sensitivity as a function of scaling factor for treating double the waste quantity over the original 20 year operating period.

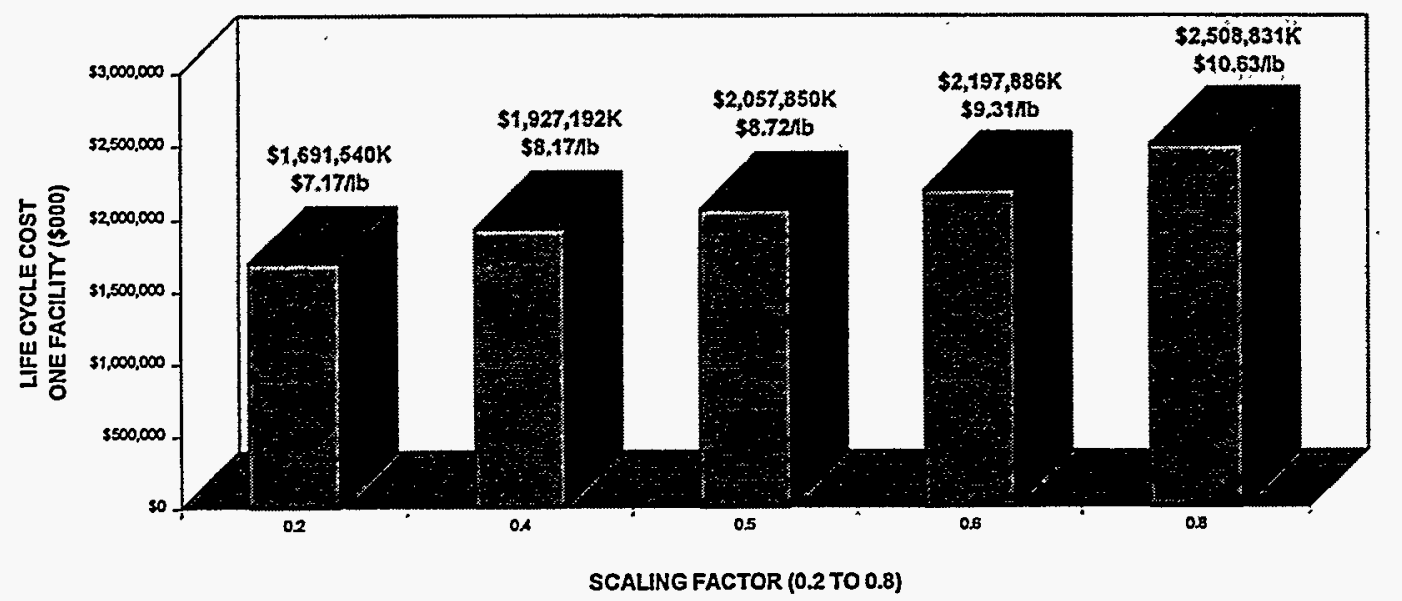

Figure 3-5. Life cycle cost sensitivity to scaling factor when the operating life is reduced from 20 to 10 years.

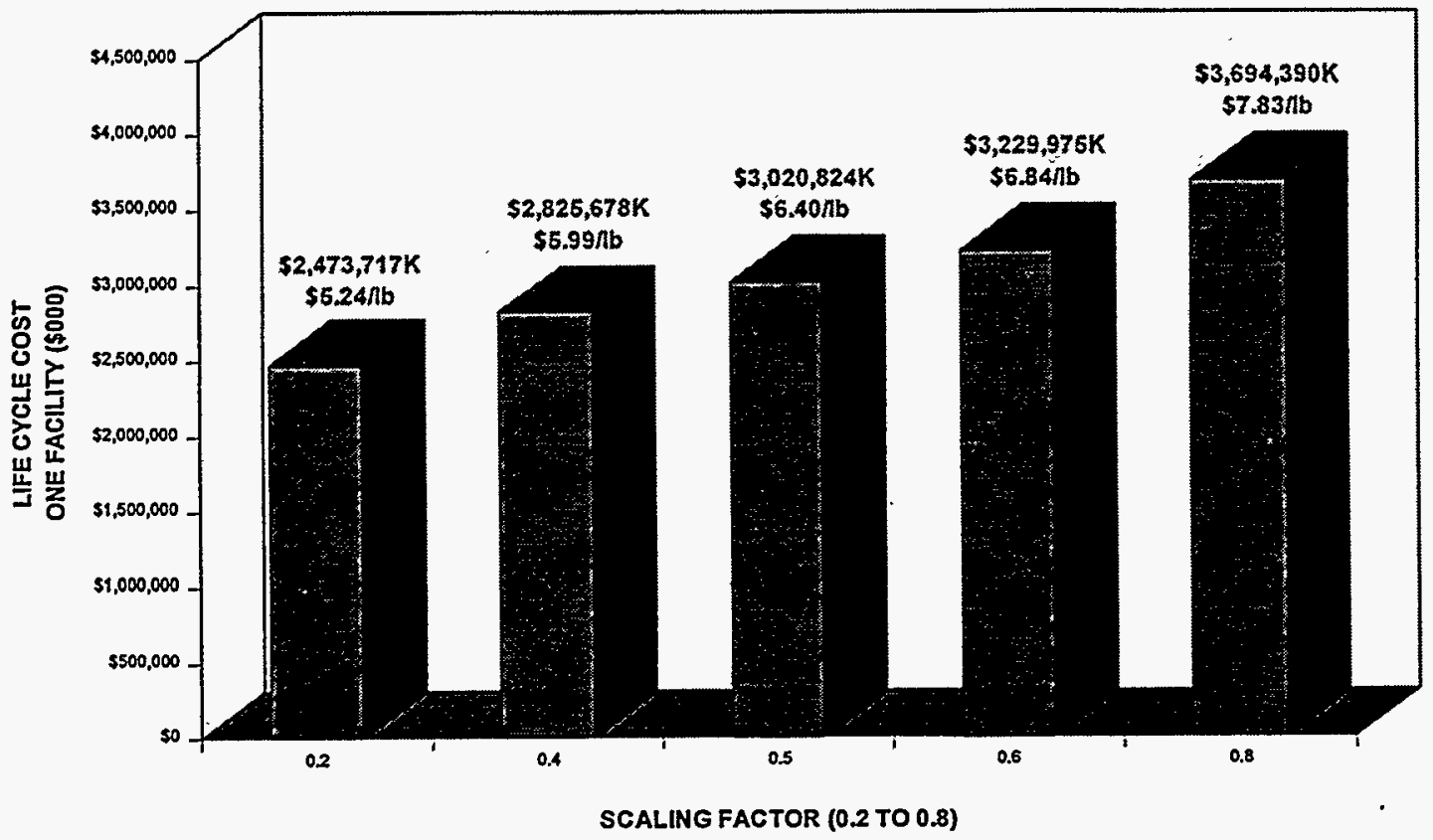

Figure 3-6. Life cycle cost sensitivity to scaling factor when waste quantity treated over 20 years is doubled. 


\subsubsection{Net Present Value Cost Comparison}

The time value of money is important in quantifying the cost benefit of early completion given an increased annual investment over the life of the project. As stated in Section 2.2, the value of money changes over time with the preference being to receive the dollars today rather than at some time in the future or conversely to spend the dollars later rather than earlier. The project of construction and operation of a GOCO treatment facility(s) deals with cash outlays without direct revenue to counterbalance the costs. Therefore, the preference, from a present value standpoint, is to postpone the expenditure as long as possible in order to maintain the earning power of the dollars.

As described in the previous section, doubling the facility capacity makes it feasible to treat the MLLW inventory in 10 years rather than 20 years. In this case, the fixed capital costs increase as the facility is scaled upward in size to treat the additional waste. Using a $6 \%$ discount rate (i.e., based on the current Federal Discount Rate) and assuming constant dollars (i.e., an inflation rate equal to zero), the present value of the life cycle costs is $\$ 1,012,821 \mathrm{~K}$ for a 20 year operating life and $\$ 1,155,801 \mathrm{~K}$ for a 10 year operating period. Since these are costs rather than revenue, the lower present value of the costs is favorable. As expected, without offsetting revenue flows, cash outlays made later in the project are favorable. Therefore, the 20 year operating life is the preferred alternative from a net present value (NPV) perspective. The difference between these NPVs represents the cost of completing operations sooner, keeping in mind that non-economic benefits may outweigh this cost. The NPV calculations and the timephased treatment life cycle schedules are included in Appendix B Tables B-1 through B-3.

\subsubsection{Multiple Facilities and Baseline Capacity}

Deviating from the INTS and ITTS by assuming that more than one facility will be constructed to treat the MLLW inventory, central treatment (two facilities) and regional treatment (five facilities) are compared to the baseline system in this section. Once again, these cases are based on treating 236 million pounds of MLLW over a 20 year operating period.

\subsubsection{Central Treatment}

This analysis assumes two facilities for the central case, one located in the Western U.S. and one located in the Eastern U.S. The target waste stream inventory for each facility is assumed to be representative of the entire inventory; therefore, the two facilities are assumed to be duplicated in design, demonstration, and testing. For this reason, these costs are not included in construction of the second facility.

The central case considers treatment facilities located at the Oak Ridge National Laboratory (ORNL) and the Idaho National Engineering Laboratory (INEL), the sites with the largest MLLW inventories, $33 \%$ and $19 \%$ of the current national inventory, respectively ${ }^{4}$. These facility locations are chosen for this study only to represent central locations with respect to the Western U.S. and the Eastern U.S. This selection does not in any way imply a Department of Energy (DOE) decision for siting such facilities at these locations. Based on the proportion of the waste currently stored at DOE sites located in the East and West, the 236 million pounds of input waste is split $66 \%$ to be treated at the eastern location and $34 \%$ to be treated at the western location. Table 3-2 breaks down the costs for each of the two facilities using a 0.5 scaling factor and shows the relative distribution of these costs compared to the baseline system. Figure 3-7 presents the life cycle cost and unit costs for two facilities as a percentage of 
the baseline system cost for a range of scaling factors.

- This analysis indicates that constructing and operating two treatment facilities will result in a $14 \%$ to $69 \%$ increase, based on a 0.8 to 0.2 range of scaling factors, in overall life cycle cost when compared to the baseline system. Because transportation costs will likely be less for shipping the waste to multiple facilities compared to transport to a single facility, transportation is considered as a discriminating factor in Section 3.6 Tradeoff to Transportation Cost, of this report.

Table 3-2. Life cycle costs for centralized facilities $(\$ 000)$.

\begin{tabular}{|c|c|c|c|c|c|}
\hline \multirow{2}{*}{\multicolumn{2}{|c|}{ Waste qty (lbs) }} & $\begin{array}{l}\text { Baseline } \\
\text { Facility }\end{array}$ & $\begin{array}{c}66 \% \text { Capacity } \\
\text { Facility }\end{array}$ & \multicolumn{2}{|l|}{ Facility } \\
\hline & & $236 \mathrm{M}$ & $156 \mathrm{M}$ & $80 \mathrm{M}$ & $236 \mathrm{M}$ \\
\hline WBS & Life cycle phase & & & & \\
\hline 1.0 & $\begin{array}{l}\text { Bench scale } \\
\text { testing }\end{array}$ & $\$ 30,525$ & $\$ 30,525$ & $\$ 0$ & $\$ 30,525$ \\
\hline 2.0 & Demonstration & $\$ 69,647$ & $\$ 69,647$ & $\$ 0$ & $\$ 69,647$ \\
\hline 3.0 & Construction & $\$ 554,377$ & $\$ 450,378$ & $\$ 323,255$ & $\$ 773,633$ \\
\hline 4.0 & Preoperation & $\$ 96,747$ & $\$ 79,836$ & $\$ 59,164$ & $\$ 139,000$ \\
\hline 5.0 & Operations & $\$ 1,361,850$ & $\$ 1,106,372$ & $\$ 794,088$ & $\$ 1,900,460$ \\
\hline 6.0 & $D \& D$ & $\$ 54,171$ & $\$ 44,009$ & $\$ 31,587$ & $\$ 75,596$ \\
\hline \multicolumn{2}{|c|}{ Total life cycle cost } & $\$ 2,167,318$ & $\$ 1,780,767$ & $\$ 1,208,094$ & $\$ 2,988,861$ \\
\hline \multicolumn{2}{|c|}{ *Scaling factor } & $\$ 9.18 / \mathrm{lb}$ & $\$ 11.42 / \mathrm{lb}$ & $\$ 15.10 / \mathrm{lb}$ & $\begin{array}{c}\$ 12.66 / \mathrm{lb} \\
\text { Weighted Avg. }\end{array}$ \\
\hline
\end{tabular}




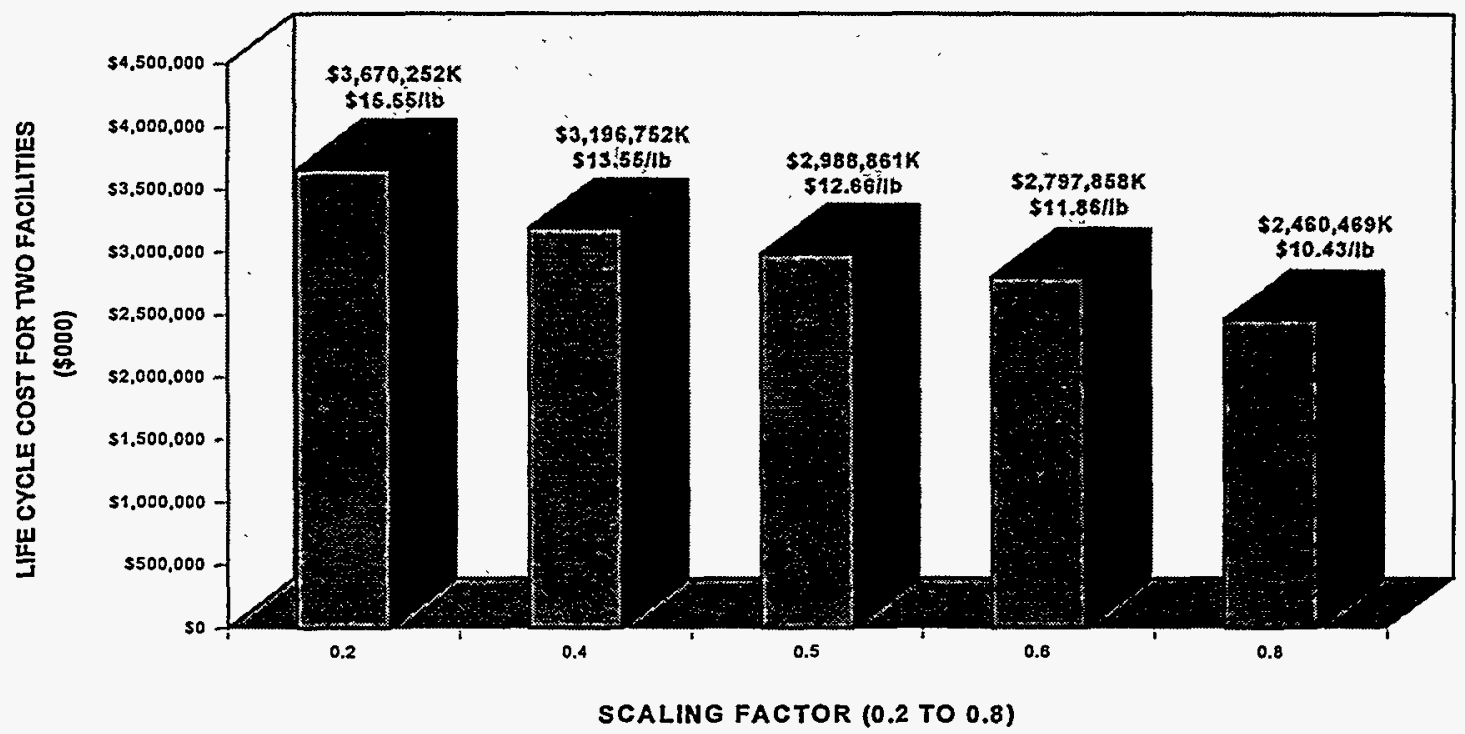

Figure 3-7. Life cycle cost sensitivity to scaling factor for centralized treatment (66\% Eastern U.S. and $34 \%$ Western U.S.).

\subsubsection{Regional Treatment}

The regional case considers five facilities located at the larger DOE sites where greater than 5,000 $\mathrm{m}^{3}$ of MLLW is in storage: Hanford, Idaho National Engineering Laboratory, Rocky Flats Plant, Savannah River Site, and Oak Ridge National Laboratory ${ }^{4}$. These sites are selected only for comparative purposes within this analysis. This selection does not in any way imply a DOE decision for siting such facilities at these locations. For the regional option, the potential waste stream inventory for treatment at each of the facilities will not be representative of the entire inventory; therefore, the design, demonstration, and testing phase will be required for all five facilities.

Once again, the proportion of the waste currently in storage at the DOE sites was used to apportion the 236 million pounds of input waste among the five treatment facilities. As shown in the following graphic, ORNL will treat $60 \%$ of the waste, INEL 20\%, Rocky Flats Plant (RFP) $10 \%$, Hanford 5\%, and Savannah River Site (SRS) 5\%.

Depending on the scaling factor applied, operating five treatment facilities results in a $46 \%$ to $244 \%$ increase in total life cycle cost when compared to the baseline system. This increase translates to a range of unit costs from $\$ 13.45$ per pound to $\$ 31.57$ per pound compared to $\$ 9.18$ per pound for the baseline system. Table 3-3 breaks down the costs for each of the five facilities using a 0.5 scaling factor and shows the relative distribution of these costs compared to the baseline system. Figure 3-8 shows the range of life cycle cost and unit costs as a function of scaling factor. 
Table 3-3. Life cycle costs for regional facilities $(\$ 000)$.

\begin{tabular}{|c|c|c|c|c|c|c|}
\hline & $\begin{array}{l}\text { Baseline } \\
\text { system }\end{array}$ & $\begin{array}{c}60 \% \\
\text { Capacity }\end{array}$ & $\begin{array}{c}20 \% \\
\text { Capacity }\end{array}$ & $\begin{array}{c}10 \% \\
\text { Capacity }\end{array}$ & $\begin{array}{l}2 @ 5 \% \\
\text { Capacity }\end{array}$ & $\begin{array}{c}\text { Total } \\
(\$ 000)\end{array}$ \\
\hline Waste treated (lbs) & $236 \mathrm{M}$ & $141 \mathrm{M}$ & $47 \mathrm{M}$ & $24 \mathrm{M}$ & $24 \mathrm{M}$ & $236 \mathrm{M}$ \\
\hline \multicolumn{7}{|l|}{ Life cycle phase } \\
\hline Bench scale testing & $\$ 30,525$ & $\$ 30,525$ & $\$ 30,525$ & $\$ 30,525$ & $\$ 61,050$ & $\$ 152,625$ \\
\hline Demonstration & $\$ 69,647$ & $\$ 69,647$ & $\$ 69,647$ & $\$ 69,647$ & $\$ 139,294$ & $\$ 348,235$ \\
\hline Construction & $\$ 554,377$ & $\$ 429,419$ & $\$ 247,925$ & $\$ 175,310$ & $\$ 247,926$ & $\$ 1,100,580$ \\
\hline Preoperation & $\$ 96,747$ & $\$ 76,428$ & $\$ 46,915$ & $\$ 35,107$ & $\$ 53,516$ & $\$ 211,966$ \\
\hline Operations & $\$ 1,361,850$ & $\$ 1,054,884$ & $\$ 609,038$ & $\$ 430,655$ & $\$ 609,038$ & $\$ 2,703,615$ \\
\hline $\mathrm{D} \& \mathrm{D}$ & $\$ 54,171$ & $\$ 41,961$ & $\$ 24,226$ & $\$ 17,130$ & $\$ 24,226$ & $\$ 107,543$ \\
\hline Total life cycle cost & $\$ 2,167,318$ & $\$ 1,702,864$ & $\$ 1,028,276$ & $\$ 758,374$ & $\$ 1,135,048$ & $\$ 4,624,562$ \\
\hline Scaling factor $=0.5$ & $\$ 9.18 / 1 b$ & $\$ 12.00 / \mathrm{lb}$ & $\$ 21.80 / \mathrm{lb}$ & $\$ 32.10 / \mathrm{lb}$ & $\$ 48.10 / \mathrm{lb}$ & $\begin{array}{r}\$ 19.60 / \mathrm{lb} \\
\text { Weighted } \\
\text { Avg. }\end{array}$ \\
\hline
\end{tabular}

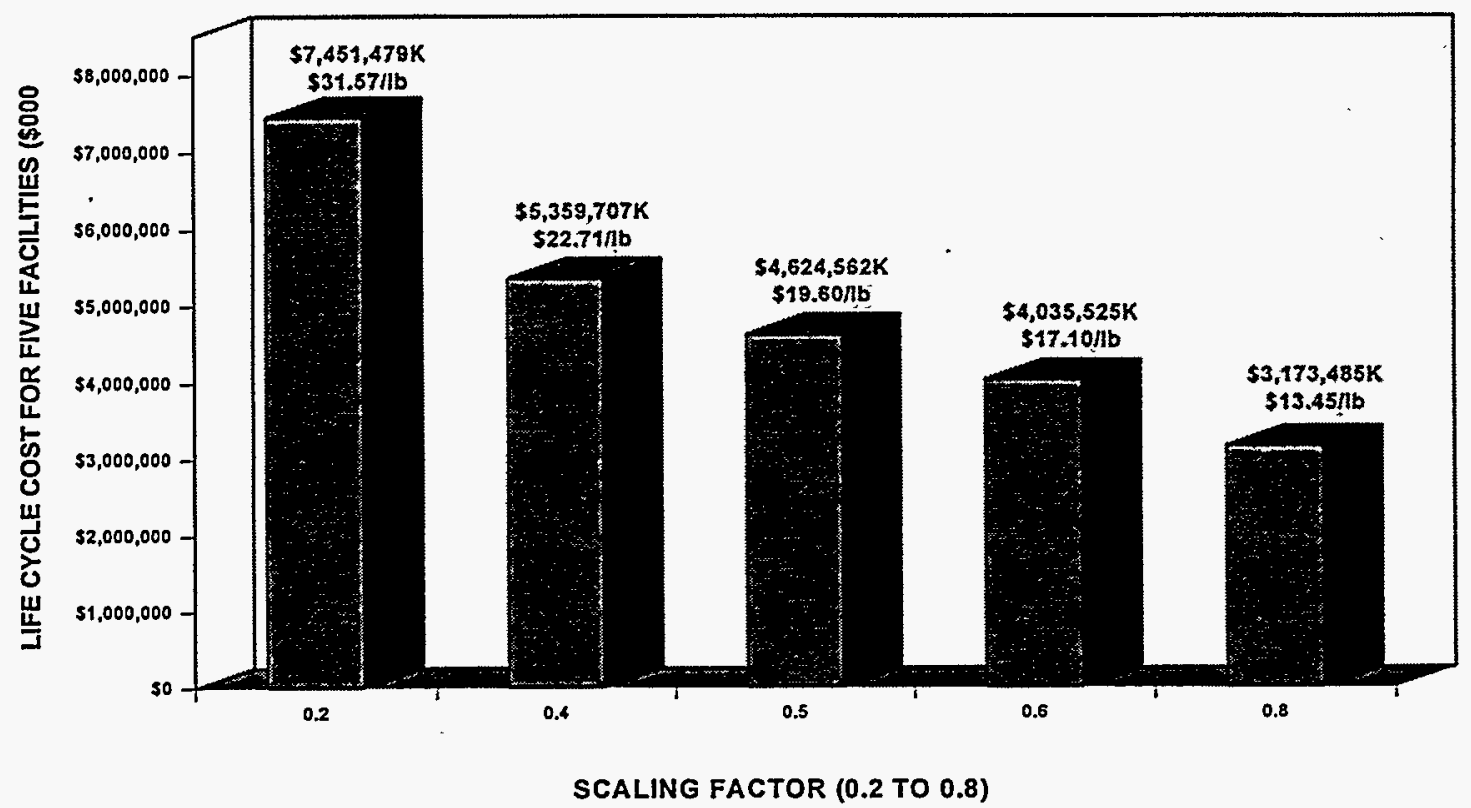

Figure 3-8. Life cycle cost sensitivity to scaling factor for regional treatment (five facilities). 
The results demonstrate that larger facilities can treat greater quantities of waste at a lower cost per pound than smaller facilities, as illustrated in Figures 3-9 and 3-10. For example, $60 \%$ of the waste can be treated at $\$ 12.00$ per pound compared to treating $20 \%$ of the waste at $\$ 21.80$ per pound.

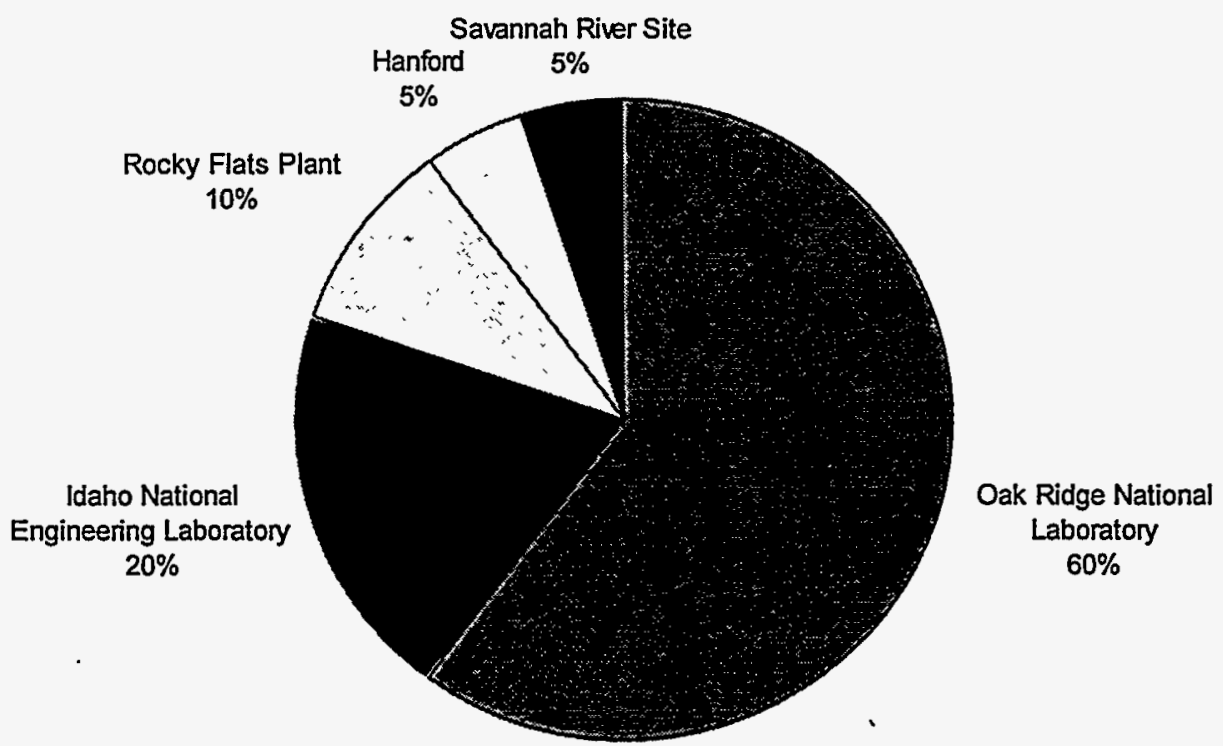

Figure 3-9. Volume \% for regional treatment of MLLW (based on 1995 MWIR).

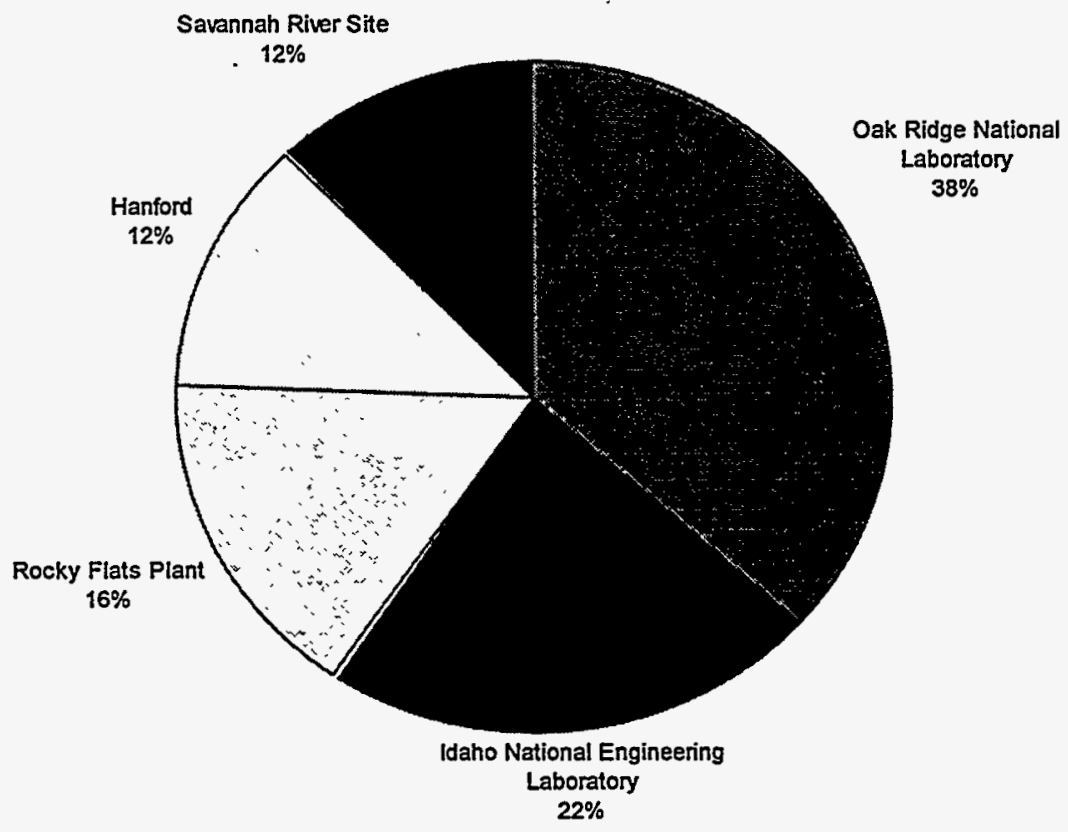

Figure 3-10. Life cycle cost \% for regional treatment of MLLW. 


\subsubsection{Tradeoff to Transportation Cost}

To be more complete, this section factors in transportation costs for shipping MLLW to a single large treatment facility and to multiple smaller treatment facilities. Transportation cost from the treatment facility to the disposal location is not included. The assumption made in the ITTS and INTS is that final waste output from the treatment process will be disposed at the same location as the treatment facility and therefore, the cost will be negligible.

The ORNL has approximately $33 \%$ of the national MLLW inventory in storage. The second largest inventory, approximately $19 \%$, is located at the INEL ${ }^{4}$. Based on this information, the location for treating all the waste in one facility is assumed to be at Oak Ridge, Tennessee. Transportation costs for shipping the waste inventories from all DOE sites to ORNL are calculated based on a methodology used for truck shipment ${ }^{5}$. To be conservative, truck shipment costs are used because they are slightly greater than rail shipment costs.

The amount of waste shipped from each site to ORNL is determined by applying the current percentage of the national inventory stored at each location ${ }^{4}$ to the input waste quantity, $236 \mathrm{M}$ pounds. The number of shipments is based on 44,000 pounds of waste per shipment. Variable transportation cost is $\$ 4.00$ per mile if transport is more than 200 miles and $\$ 4.98$ per mile for less than 200 miles. The variable carrier costs include tractor, fuel, labor, insurance, security escort, taxes, tools, permit fees, and related costs incurred while the waste is in transport. Fixed transportation cost is $\$ 880.00$ per shipment to account for demurrage costs of the carrier and the hardware used in the shipment. A breakdown of the transportation cost data is included in Appendix B, Table B-4 and Table B-6.

As expected, the results indicate that transportation cost to a single large treatment facility is the greatest but, still relatively small, at $<1 \%$ of the baseline system life cycle cost. This analysis demonstrates that transportation cost is relatively low and provides little incentive by itself for selecting one versus multiple facilities. However, non-economic drivers such as the ability to transport across state boundaries may favor multiple facility locations. Table 3-4 and Figure 3-11 present the life cycle cost comparison for a single facility, two facilities, and five facilities including the cost to transport the MLLW to the facilities.

Table 3-4. Transportation cost data.

\begin{tabular}{lccccc}
\hline & $\begin{array}{c}\text { Quantity } \\
(\mathrm{lbs})\end{array}$ & \# Shipments & Transport $\$$ & Life cycle $\$$ & Total \$ \\
\hline One Facility & $236 \mathrm{M}$ & 3,581 & $\$ 18,846,540$ & $\$ 2,167,318 \mathrm{~K}$ & $\$ 2,186,165 \mathrm{~K}$ \\
Two Facilities* & $236 \mathrm{M}$ & 2,578 & $\$ 7,104,960$ & $\$ 2,988,861 \mathrm{~K}^{*}$ & $\$ 2,995,966 \mathrm{~K}^{*}$ \\
Five Facilities* & $236 \mathrm{M}$ & 1,521 & $\$ 4,040,300$ & $\$ 4,624,562 \mathrm{~K}^{*}$ & $\$ 4,628,603 \mathrm{~K}^{*}$ \\
\multirow{2}{*}{ Scaling factor $=0.5$} & & & & \\
\hline
\end{tabular}




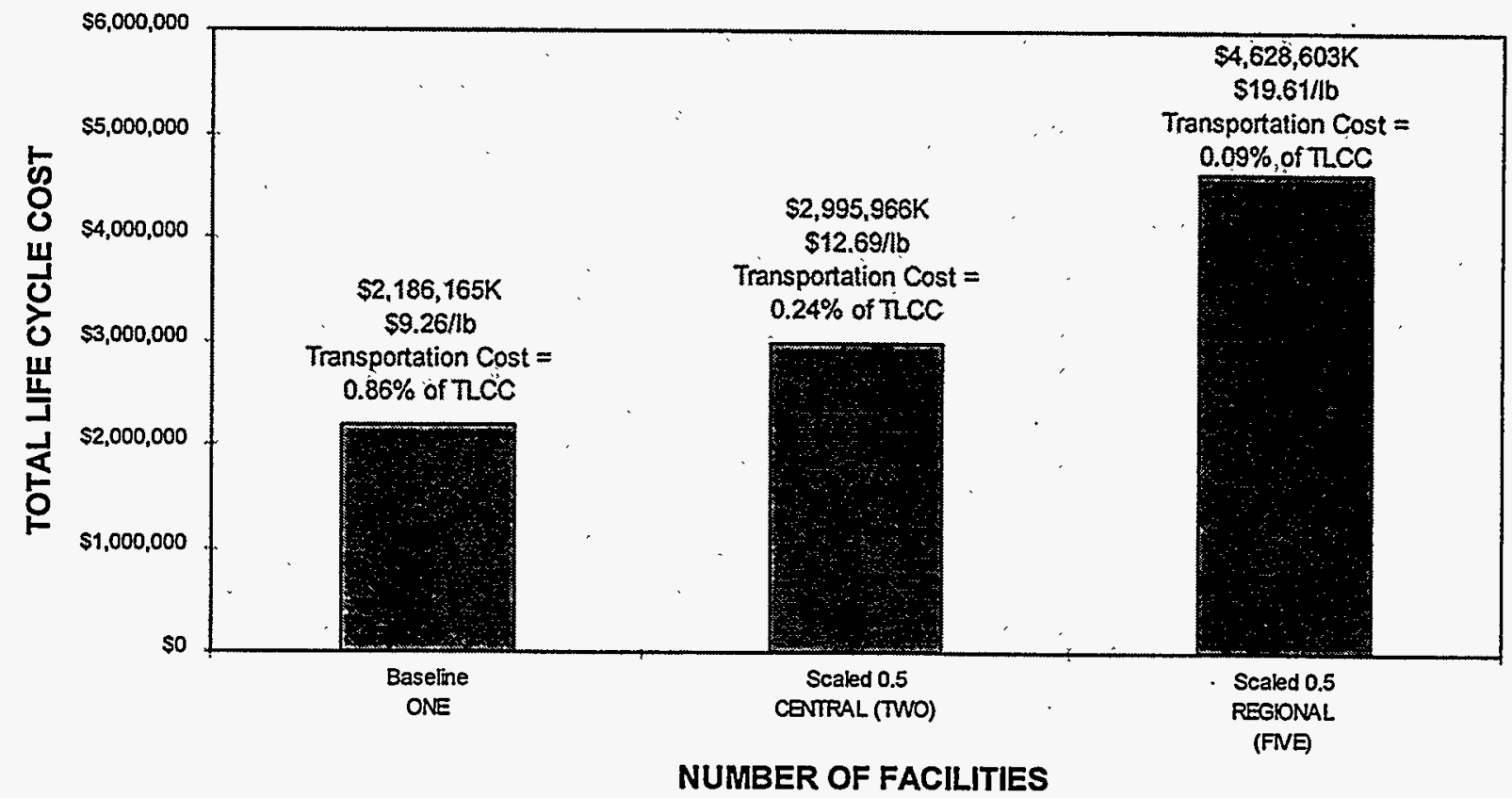

Figure 3-11. Total life cycle cost comparison $\$ 000$ (including transportation). 


\subsection{Sensitivity to Increased Availability of Treatment}

Another means for reducing the operating period or increasing the volume of waste treated is to increase the availability of treatment (i.e., increase the operating hours of the plant). The INTS and ITTS are based on operating 4,032 hours per year ( 280 days/year x 24 hours/day x .60 availability). In comparison, if treatment is fully functional 325 days per year at $75 \%$ availability, then total operating hours per year are 5,850 hours, a $45 \%$ increase. At this rate, the 236 million pounds of input waste (i.e., 2,927 pounds per hour) could be processed in 14 rather than 20 years resulting in a net decrease in operating and maintenance costs of $\$ 377 \mathrm{M}$, a reduction of $\$ 1.58$ per pound of input waste. This assumes that annual labor costs remain constant (i.e., as documented in the studies labor is based on 365 days/year; 4 shifts/week; 7 days/week; 24 hours/day) and material and utility costs increase to treat the additional volume of waste.

Alternatively, at the throughput rate of 2,927 pounds per hour, 343 million pounds of input waste can be processed over 20 years operating 5,850 hours per year. The cost per pound to treat the additional quantity of waste is $\$ 6.53$ per pound or $\$ 2.65$ less than the cost per pound for the baseline system.

The costs for increased availability of treatment, compared to the baseline system costs, are presented in Table 3-5.

Table 3-5. Increased availability of treatment $(\$ 000)$.

\begin{tabular}{|c|c|c|c|c|}
\hline & Baseline system & \multirow{2}{*}{$\begin{array}{c}5,850 \text { hours/year } \\
14 \text { years }\end{array}$} & \multirow{2}{*}{$\begin{array}{c}5,850 \text { hours/year } \\
20 \text { years }\end{array}$} \\
\hline & Operating life & 20 years & & \\
\hline & Waste treated (lbs) & $236 \mathrm{M}$ & $236 \mathrm{M}$ & $343 \mathrm{M}$ \\
\hline WBS & Life cycle phase & & & \\
\hline 1.0 & Bench scale testing & $\$ 30,525$ & $\$ 30,525$ & $\$ 30,525$ \\
\hline 2.0 & Demonstration & $\$ 69,647$ & $\$ 69,647$ & $\$ 69,647$ \\
\hline 3.0 & Construction & $\$ 554,377$ & $\$ 554,377$ & $\$ 554,377$ \\
\hline 4.0 & Preoperation & $\$ 96,747$ & $\$ 100,471$ & $\$ 100,471$ \\
\hline 5.0 & Operations & $\$ 1,361,850$ & $\$ 985,161$ & $\$ 1,429,564$ \\
\hline 6.0 & $D \& D$ & $\$ 54,171$ & $\$ 54,171$ & $\$ 54,171$ \\
\hline \multirow{2}{*}{\multicolumn{2}{|c|}{ Total life cycle cost }} & $\$ 2,167,318$ & $\$ 1,794,352$ & $\$ 2,238,755$ \\
\hline & & $\$ 9.18 / \mathrm{lb}$ & $\$ 7.60 / \mathrm{lb}$ & $\$ 6.53 / \mathrm{lb}$ \\
\hline
\end{tabular}


Figure 3-12 compares the baseline system to the baseline system operating 5,850 hours per year (i.e., $45 \%$ increase) as a function of operating period (i.e., 14 versus 20 years).

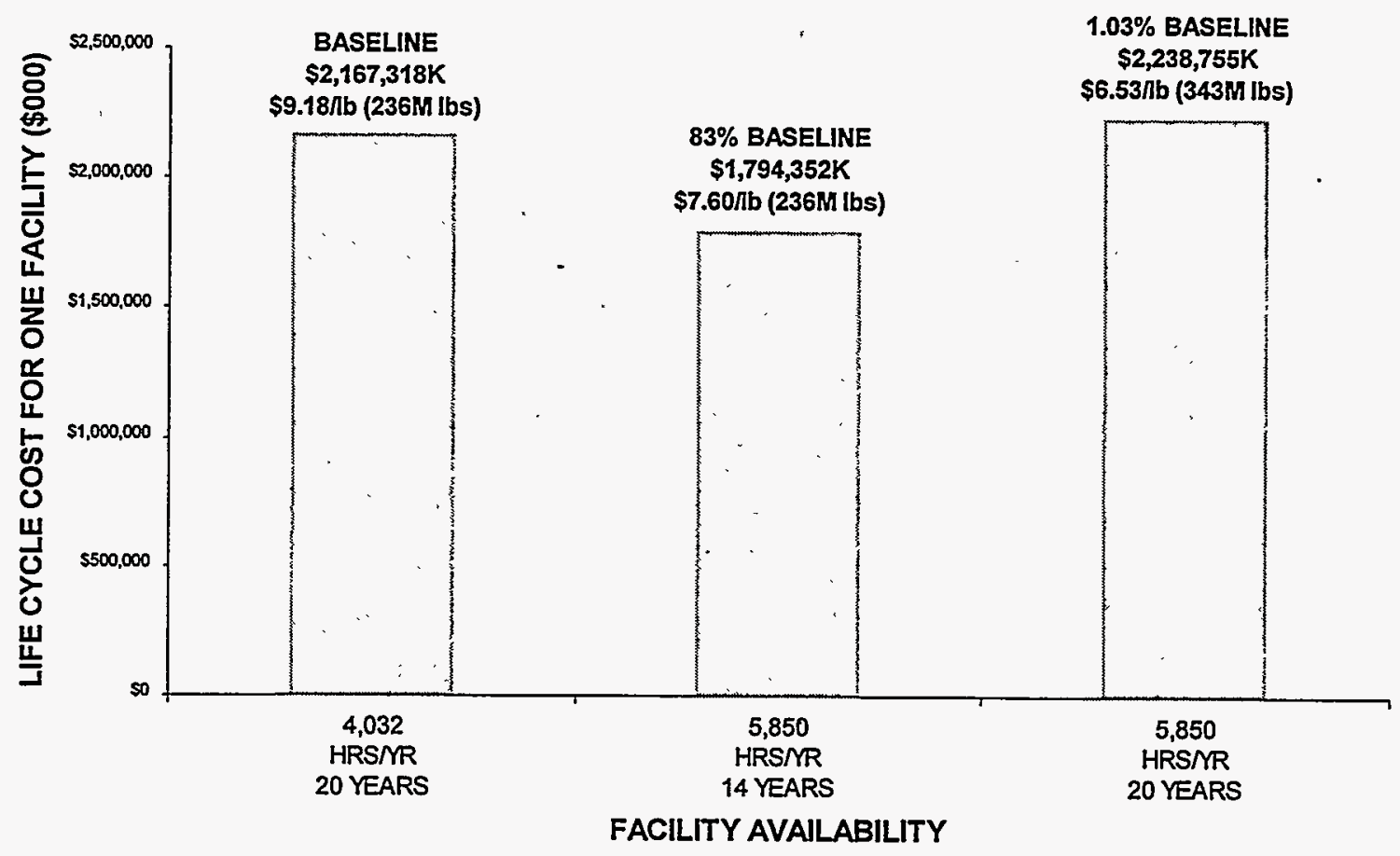

Figure 3-12. Sensitivity to availability. 


\subsection{ADDITIONAL TREATMENT COST SENSITIVITIES}

\subsection{Sensitivity to Contingency Cost}

When developing the ITTS and INTS life cycle costs, a standard contingency percentage of $25 \%$ was applied to cost components: studies and bench scale testing, demonstration, construction, and operating and maintenance. This contingency was defined as an allowance for scoping and costing inaccuracies. In reality, the systems are not equal in the degree of risk associated with the technology development state.

This section measures the sensitivity to contingency cost using a baseline of $25 \%$ for the more developed technologies and increasing this percentage for technologies that carry a greater degree of operational uncertainty. Based on the information provided in the ITTS and INTS studies, the systems considered more developed include: A-1 rotary kiln with air for combustion and vitrification for stabilization, A-2 rotary kiln with oxygen for combustion and vitrification for stabilization, A-7 slagging rotary kiln with air for combustion, and A-8 rotary kiln with air for combustion and grouting for stabilization. Systems considered less developed include: C-1 plasma hearth furnace with air for combustion, G-1 molten metal waste destruction with oxygen for combustion, $\mathrm{H}-1$ steam gasification with steam for combustion, NT-3 wash, NT-4 acid digestion, and NT-5 catalytic wet oxidation.

An increase in contingency percentage from $25 \%$ to $35 \%, 45 \%$, and $50 \%$ for the less-developed technologies results in a $7 \%, 15 \%$, and $18 \%$ increase in the total life cycle costs, respectively. This increase indicates that the operational uncertainty for the three thermal treatment systems, G-1, C-1, and H1 , lessens the economic desirability for these technologies. The nonthermal treatment systems maintain the same economic ranking with higher contingency costs. Table 4-1 shows the ranking of the technologies by treatment life cycle cost as a function of contingency cost percentage. 
Table 4-1. Total life cycle cost as a function of contingency allowance (\$million).

\begin{tabular}{|c|c|c|c|c|c|c|}
\hline $\begin{array}{l}\text { Total } \\
\text { treatment } \\
\text { cost }\end{array}$ & Rank & $\begin{array}{c}\text { Total } \\
\text { treatment } \\
\text { cost }\end{array}$ & Rank & $\begin{array}{l}\text { Total } \\
\text { treatment } \\
\text { cost }\end{array}$ & Rank & $\begin{array}{c}\text { Total } \\
\text { treatment } \\
\text { cost }\end{array}$ \\
\hline
\end{tabular}

\begin{tabular}{|c|c|c|c|c|c|c|c|c|}
\hline \multicolumn{2}{|c|}{ Contingency } & \multirow{2}{*}{$\frac{25 \%}{1}$} & & \multirow{2}{*}{$\frac{35 \%}{4}$} & \multirow{2}{*}{\multicolumn{2}{|c|}{$\begin{array}{lc} & 45 \% \\
\$ 2,171 & 12\end{array}$}} & & \multirow{2}{*}{$\frac{50 \%}{14}$} \\
\hline G-1 & $\$ 1,894$ & & $\$ 2,032$ & & & & $\$ 2,241$ & \\
\hline$A-7$ & $\$ 1,914$ & 2 & & 1 & & 1 & & 1 \\
\hline $\mathrm{J}-1$ & $\$ 1,922$ & 3 & & 2 & & 2 & & 2 \\
\hline C-3 & $\$ 1,929$ & 4 & & 3 & & 3 & & 3 \\
\hline$C-1$ & $\$ 1,981$ & 5 & $\$ 2,126$ & 8 & $\$ 2,272$ & 16 & $\$ 2,345$ & 19 \\
\hline A-5 & $\$ 2,083$ & 6 & & 5 & & 4 & & 4 \\
\hline$C-2$ & $\$ 2,096$ & 7 & & 6 & & 5 & & 5 \\
\hline L-1 & $\$ 2,098$ & 8 & & 7 & & 6 & & 6 \\
\hline $\mathrm{K}-1$ & $\$ 2,144$ & 9 & & 9 & & 7 & & 7 \\
\hline$A-3$ & $\$ 2,144$ & 10 & & 10 & & 8 & & 8 \\
\hline$A-8$ & $\$ 2,144$ & 11 & & 11 & & 9 & & 9 \\
\hline$A-2$ & $\$ 2,166$ & 12 & & 12 & & 10 & & 10 \\
\hline$A-1$ & $\$ 2,167$ & 13 & & 13 & & 11 & & 11 \\
\hline E-1 & $\$ 2,191$ & 14 & & 14 & & 13 & & 12 \\
\hline $\mathrm{H}-1$ & $\$ 2,193$ & 15 & $\$ 2,354$ & 20 & $\$ 2,515$ & 20 & $\$ 2,596$ & 20 \\
\hline$A-6$ & $\$ 2,236$ & 16 & & 15 & & 14 & & 13 \\
\hline B-1 & $\$ 2,242$ & 17 & & 16 & & 15 & & 15 \\
\hline F-1 & $\$ 2,275$ & 18 & & 17 & & 17 & & 16 \\
\hline$A-4$ & $\$ 2,282$ & 19 & & 18 & & 18 & & 17 \\
\hline D-1 & $\$ 2,338$ & 20 & & 19 & & 19 & & 18 \\
\hline
\end{tabular}


Table 4-1, Cont'd.

\begin{tabular}{|c|c|c|c|c|c|c|}
\hline $\begin{array}{l}\text { Total } \\
\text { treatment } \\
\text { cost }\end{array}$ & Rank & $\begin{array}{c}\text { Total } \\
\text { treatment } \\
\text { cost }\end{array}$ & Rank & $\begin{array}{c}\text { Total } \\
\text { treatment } \\
\text { cost }\end{array}$ & Rank & $\begin{array}{c}\text { Total } \\
\text { treatment } \\
\text { cost }\end{array}$ \\
\hline
\end{tabular}

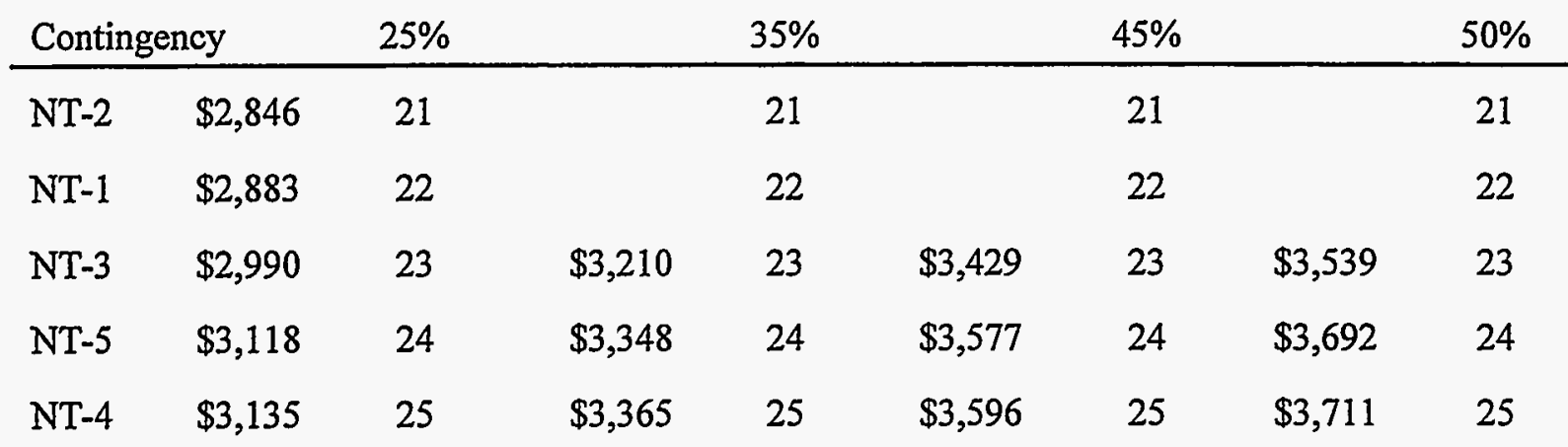

A methodology for assigning individual contingency cost has been developed by personnel at Morrison Knudsen (MK) Corporation. Using the MK methodology, contingencies are estimated for each phase of the life cycle based on a combination of engineering judgement, standard industrial contingency values, and facility scope certainties. The ITTS system A-1, rotary kiln with air for combustion was studied initially and the result lead to a $2 \%$ overall reduction in life cycle costs using the revised contingencies. Future work scope includes applying this methodology to additional systems so comparisons can be made across technologies. 


\subsection{SENSITIVITY TO DISPOSAL COST}

The ITTS and INTS studies assume a variable disposal cost of $\$ 243$ per $\mathrm{ft}^{3}$ based on a facility sized to accommodate disposal for all systems. Applying a single unit cost assumes that disposal cost is directly proportional to the volume of waste disposed. In contrast, the life cycle costs for constructing and operating a disposal facility include both fixed and variable components. To be more accurate and complete, this analysis takes into account the split between fixed and variable costs when calculating the cost for disposal.

This analysis compares disposal costs for all systems and assesses the overall impact to life cycle costs when incorporating the fixed and variable cost components for disposal. A separate comparison between systems using vitrification versus grouting for stabilization is examined to determine the effect final waste form has on disposal cost and total life cycle cost. In addition, the analysis looks at potential delisting of the vitrified waste form, making it possible to dispose of the stabilized waste in a low-level radioactive waste disposal facility.

The organization of the disposal section is as follows:

Section 5.1 identifies the fixed and variable cost components for constructing and operating two different sized disposal facilities (i.e., small- and medium-size facilities).

Section 5.2 compares the disposal cost for each of the systems as calculated using the applicable fixed and variable costs based on the final waste volume. This section also looks at disposal cost sensitivity as a function of the size of the facility.

Section 5.3 identifies potential disposal cost savings based on a reduced final waste volume by comparing disposal costs between a technology using vitrification and a technology using grout for stabilization.

Section 5.4 further expands on the potential cost savings for systems employing vitrification by reducing the disposal cost for the vitrified portion of the final waste volume assuming delisting of the waste form.

\subsection{Fixed Versus Variable Disposal Costs}

The cost estimates used in this analysis are based on construction and operation of a Government-Owned, Contractor-Operated (GOCO) Resource Conservation and Recovery Act (RCRA)permitted disposal facility ${ }^{6}$. These cost estimates are also the basis for the unit cost of $\$ 243$ used in ITTS and INTS.

The disposal cost estimates consist of two major cost modules: disposal administration and aboveground disposal. The above-ground disposal cost module is derived from costs for construction and operation of engineered disposal units that are based on the proposed Illinois low-level waste disposal facility design using an earth-mound concrete-cell concept with modifications to the leachate collection system for RCRA compliance. The disposal administration cost module provides the necessary disposal support functions such as truck loading and unloading areas, administrative offices, analytical laboratory facilities, and truck inspection and wash-down ${ }^{6}$. For each of the modules, the disposal life cycle costs are 
subdivided into phases of the life cycle: bench scale testing, demonstration, construction, preoperations, operations, and postoperations.

Certain costs are fixed with the size of the facility and certain costs vary with the volume of waste disposed; these costs are referred to as fixed and variable costs, respectively. The fixed costs are recovered on a per unit basis by allocating a percentage of the cost to an expected waste quantity. The unit cost is comprised of this fixed cost percentage and the variable cost per $\mathrm{ft}^{3}$. If the expected quantity of waste is not disposed, then the fixed costs incurred are not recovered unless the unit cost is increased to accomodate the smaller volume of waste disposed.

On examination, the total costs were logically divided between fixed and variable. Fixed costs include: capital construction costs, preoperating costs including permitting and contingency for any delays in start up operations, a percentage of the annual operating labor costs, annual maintenance costs, and postoperating costs. Variable costs include: a percentage of the annual operating labor costs, annual material costs, and annual utility costs. A comparison of the total life cycle costs for small- and mediumsize facilities is graphically illustrated in Figure 5-1 and Table 5-1 provides the life cycle cost breakdown for small- and medium-size disposal facilities.

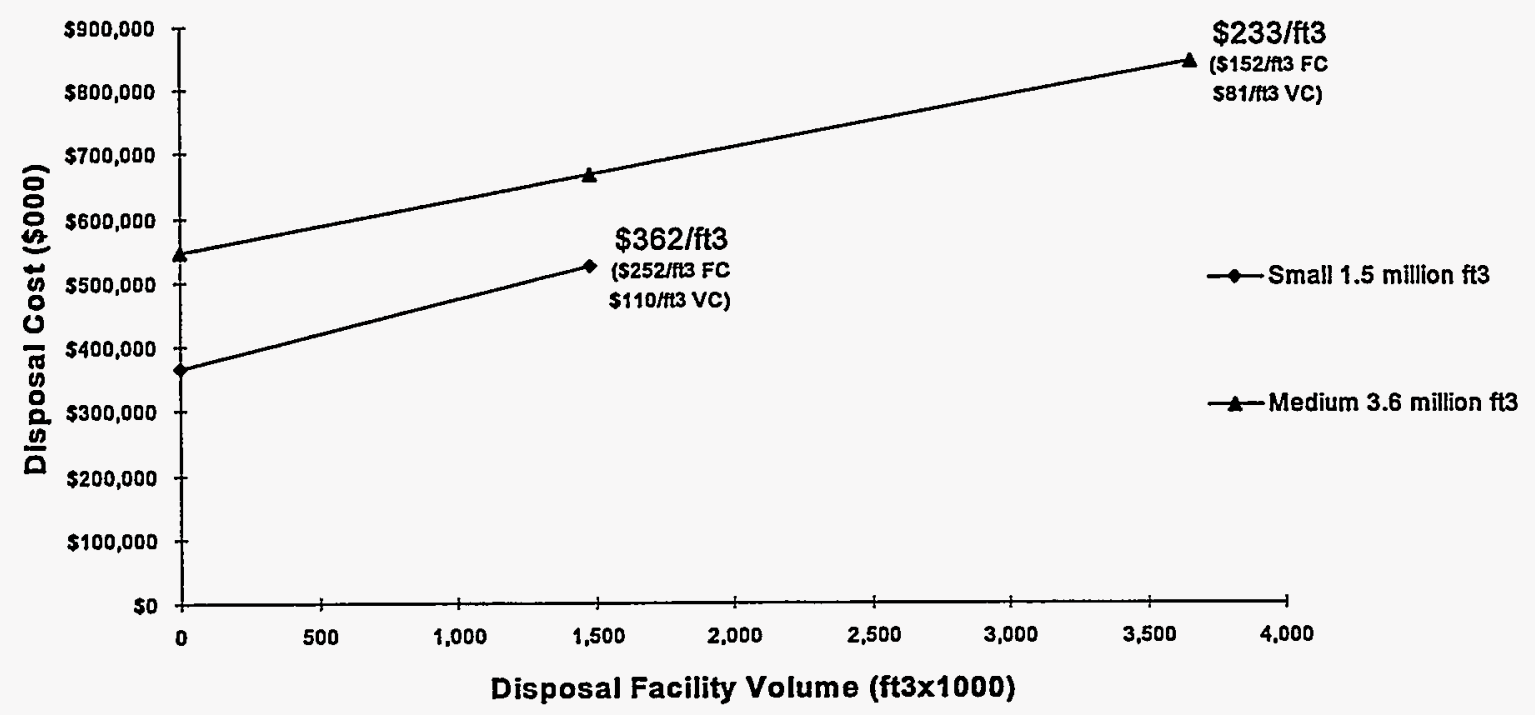

Figure 5-1. Disposal cost for small- and medium-size facilities at design capacity. 
Table 5-1. Disposal life cycle costs for small- and medium-size facilities.

\begin{tabular}{|c|c|c|c|c|c|c|c|c|}
\hline \multirow[b]{4}{*}{ Test \& demo } & \multicolumn{4}{|c|}{$\begin{array}{c}\text { Small-size facility }(1,451,488 \mathrm{ft3}) \\
\text { Total } \$ 525,184 \mathrm{~K} ; \$ 362 / \mathrm{ft3}\end{array}$} & \multicolumn{4}{|c|}{$\begin{array}{c}\text { Medium-size facility }(3,628,809 \mathrm{ft} 3) \\
\text { Total } \$ 845,276 \mathrm{~K} ; \$ 233 / \mathrm{ft3}\end{array}$} \\
\hline & \multicolumn{2}{|c|}{$\begin{array}{c}\text { Disposal } \\
\text { Administration }\end{array}$} & \multicolumn{2}{|c|}{$\begin{array}{l}\text { Above-ground } \\
\text { Disposal }\end{array}$} & \multicolumn{2}{|c|}{$\begin{array}{c}\text { Disposal } \\
\text { Administration }\end{array}$} & \multicolumn{2}{|c|}{$\begin{array}{l}\text { Above-ground } \\
\text { Disposal }\end{array}$} \\
\hline & $\begin{array}{l}\text { Fixed } \\
(\$ 000)\end{array}$ & $\begin{array}{l}\text { Variable } \\
(\$ 000)\end{array}$ & $\begin{array}{l}\text { Fixed } \\
(\$ 000)\end{array}$ & $\begin{array}{l}\text { Variable } \\
(\$ 000)\end{array}$ & $\begin{array}{l}\text { Fixed } \\
(\$ 000)\end{array}$ & $\begin{array}{l}\text { Variable } \\
(\$ 000)\end{array}$ & $\begin{array}{l}\text { Fixed } \\
(\$ 000)\end{array}$ & $\begin{array}{l}\text { Variable } \\
(\$ 000)\end{array}$ \\
\hline & $\$ 0$ & $\$ 0$ & $\$ 0$ & $\$ 0$ & $\$ 0$ & $\$ 0$ & $\$ 0$ & $\$ 0$ \\
\hline Construction & $\$ 11,565$ & $\$ 0$ & $\$ 99,561$ & \$o & $\$ 18,565$ & $\$ 0$ & $\$ 221,303$ & $\$ 0$ \\
\hline Preoperations & $\$ 7,095$ & $\$ 0$ & $\$ 13,495$ & $\$ 0$ & $\$ 10,327$ & $\$ 0$ & $\$ 22,568$ & $\$ 0$ \\
\hline Operations & $\$ 13,225$ & $\$ 110,000$ & $\$ 145,450$ & $\$ 50,125$ & $\$ 19,450$ & $\$ 159,025$ & $\$ 163,575$ & $\$ 136,100$ \\
\hline Postoperations & $\$ 4,163$ & $\$ 0$ & $\$ 70,505$ & $\$ 0$ & $\$ 7,763$ & $\$ 0$ & $\$ 86,600$ & $\$ 0$ \\
\hline $\begin{array}{l}\text { Total } \\
\text { fixed/variable }\end{array}$ & $\$ 36,048$ & $\$ 110,000$ & $\$ 329,011$ & $\$ 50,125$ & $\$ 56,105$ & $\$ 159,025$ & $\$ 494,046$ & $\$ 136,100$ \\
\hline$\%$ fixed/variable & $25 \%$ & $75 \%$ & $87 \%$ & $13 \%$ & $26 \%$ & $74 \%$ & $78 \%$ & $22 \%$ \\
\hline $\begin{array}{l}\text { Total by cost } \\
\text { module }\end{array}$ & \multicolumn{2}{|c|}{$\begin{array}{l}\text { Administration } \\
\$ 146,048\end{array}$} & \multicolumn{2}{|c|}{$\begin{array}{l}\text { Disposal } \\
\$ 379,136\end{array}$} & \multicolumn{2}{|c|}{$\begin{array}{l}\text { Administration } \\
\$ 215,130\end{array}$} & \multicolumn{2}{|c|}{$\begin{array}{l}\text { Disposal } \\
\$ 630,146\end{array}$} \\
\hline $\begin{array}{l}\text { Total disposal } \\
\text { life cycle costs }\end{array}$ & \multicolumn{4}{|c|}{$\begin{array}{c}70 \% \text { Fixed } \$ 365,059 \\
\text { 30\% Variable } \$ 160,125 \text { or } \$ 110 / \mathrm{ft}^{3} \\
\text { Total } \$ 525,184 \mathrm{~K} ; \$ 362 / \mathrm{ft3}\end{array}$} & \multicolumn{4}{|c|}{$\begin{array}{c}65 \% \text { Fixed } \$ 550,151 \\
35 \% \text { Variable } \$ 295,125 \text { or } \$ 81 / \mathrm{ft}^{3} \\
\text { Total } \$ 845,276 \mathrm{~K} ; \$ 233 / \mathrm{ft} 3\end{array}$} \\
\hline
\end{tabular}

\subsection{ITTS AND INTS DISPOSAL COST ESTIMATES}

Disposal costs, including both fixed and variable cost components, are presented in this section for each of the twenty thermal treatment systems and 5 nonthermal treatment systems. These revised disposal costs are used in the remainder of the analysis.

\subsubsection{Disposal Cost Comparison for All Technologies}

Depending on the final waste volume, disposal costs for a small- or medium-size facility as identified in the previous section, are calculated for each of the treatment systems. The greatest waste volume considered within the capacity of a small-size facility is $1,585 \mathrm{~K} \mathrm{ft}^{3}$ which is produced by system A4 , rotary kiln with oxygen. All final volumes greater than $1,585 \mathrm{~K} \mathrm{ft}^{3}$ are assumed to require a medium-size facility for disposal. This revised disposal cost is greater than the disposal cost estimated in the ITTS and INTS for all systems. In fact, the disposal cost has increased on the average by $35 \%$, and as a result, the system ranking by total life cycle cost has changed, as shown in Table 5-2. For example, system A-6, rotary kiln with maximum recycle, produces the least amount of final waste, $864 \mathrm{~K} \mathrm{ft}^{3}$, and ranks ninth in total life cycle cost when assuming that all costs are variable as estimated in the ITTS and INTS. However, after applying the revised disposal cost, system A-6 ranks eleventh in total life cycle cost. 
Table 5-2. Systems ranked by total life cycle cost including revised disposal costs.

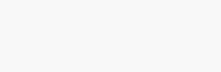

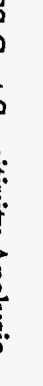

\begin{tabular}{|c|c|c|c|c|c|c|c|c|c|c|}
\hline & $\begin{array}{l}\text { Final waste } \\
\text { volume } \\
\left(\mathrm{ft}^{3} \times 1000\right)\end{array}$ & $\begin{array}{c}\text { Total } \\
\text { treatment } \\
\text { cost } \\
(\$ \text { million })\end{array}$ & $\begin{array}{c}\text { Revised* } \\
\text { disposal } \\
\text { cost } \\
\text { (\$million) }\end{array}$ & $\begin{array}{l}\text { Total LCC } \\
\text { (\$million) }\end{array}$ & Rank & $\%$ LCC & $\begin{array}{c}\text { Disposal } \\
\text { cost } \\
\$ 243 / \mathrm{ft}^{3} \\
\text { (\$million) }\end{array}$ & $\begin{array}{l}\text { Total LCC } \\
\text { (\$million) }\end{array}$ & Rank & $\%$ LCC \\
\hline G-1 & 929 & $\$ 1,894$ & $\$ 468$ & $\$ 2,361$ & 1 & $20 \%$ & $\$ 226$ & $\$ 2,119$ & 1 & $11 \%$ \\
\hline $\mathrm{J}-1$ & 1,095 & $\$ 1,922$ & $\$ 486$ & $\$ 2,408$ & 2 & $20 \%$ & $\$ 266$ & $\$ 2,188$ & 2 & $12 \%$ \\
\hline$A-7$ & 1,171 & $\$ 1,914$ & $\$ 494$ & $\$ 2,408$ & 3 & $21 \%$ & $\$ 284$ & $\$ 2,198$ & 4 & $13 \%$ \\
\hline$C-3$ & 1,067 & $\$ 1,929$ & $\$ 483$ & $\$ 2,412$ & 4 & $20 \%$ & $\$ 259$ & $\$ 2,189$ & 3 & $12 \%$ \\
\hline C-1 & 1,067 & $\$ 1,981$ & $\$ 483$ & $\$ 2,464$ & 5 & $20 \%$ & $\$ 259$ & $\$ 2,240$ & 5 & $12 \%$ \\
\hline$C-2$ & 1,220 & $\$ 2,096$ & $\$ 500$ & $\$ 2,595$ & 6 & $19 \%$ & $\$ 297$ & $\$ 2,392$ & 6 & $12 \%$ \\
\hline$A-2$ & 1,096 & $\$ 2,166$ & $\$ 486$ & $\$ 2,652$ & 7 & $18 \%$ & $\$ 266$ & $\$ 2,432$ & 7 & $11 \%$ \\
\hline$A-1$ & 1,096 & $\$ 2,167$ & $\$ 486$ & $\$ 2,653$ & 8 & $18 \%$ & $\$ 266$ & $\$ 2,434$ & 8 & $11 \%$ \\
\hline$A-3$ & 1,369 & $\$ 2,144$ & $\$ 516$ & $\$ 2,660$ & 9 & $19 \%$ & $\$ 333$ & $\$ 2,476$ & 11 & $13 \%$ \\
\hline $\mathrm{H}-1$ & 1,095 & $\$ 2,193$ & $\$ 486$ & $\$ 2,679$ & 10 & $18 \%$ & $\$ 266$ & $\$ 2,459$ & 10 & $11 \%$ \\
\hline$A-6$ & 864 & $\$ 2,236$ & $\$ 460$ & $\$ 2,697$ & 11 & $17 \%$ & $\$ 210$ & $\$ 2,446$ & 9 & $9 \%$ \\
\hline B-1 & 1,096 & $\$ 2,242$ & $\$ 486$ & $\$ 2,728$ & 12 & $18 \%$ & $\$ 266$ & $\$ 2,509$ & 12 & $11 \%$ \\
\hline F-1 & 1,176 & $\$ 2,275$ & $\$ 495$ & $\$ 2,770$ & 13 & $18 \%$ & $\$ 286$ & $\$ 2,561$ & 13 & $11 \%$ \\
\hline$A-5$ & 2,301 & $\$ 2,083$ & $\$ 737$ & $\$ 2,821$ & 14 & $26 \%$ & $\$ 559$ & $\$ 2,642$ & 15 & $21 \%$ \\
\hline$A-4$ & 1,585 & $\$ 2,282$ & $\$ 540$ & $\$ 2,822$ & 15 & $19 \%$ & $\$ 385$ & $\$ 2,667$ & 16 & $14 \%$ \\
\hline D-1 & 1,226 & $\$ 2,338$ & $\$ 500$ & $\$ 2,839$ & 16 & $18 \%$ & $\$ 298$ & $\$ 2,636$ & 14 & $11 \%$ \\
\hline A-8 & 2,508 & $\$ 2,144$ & $\$ 754$ & $\$ 2,898$ & 17 & $26 \%$ & $\$ 609$ & $\$ 2,754$ & 17 & $22 \%$ \\
\hline$L-1$ & 3,270 & $\$ 2,098$ & $\$ 816$ & $\$ 2,914$ & 18 & $28 \%$ & $\$ 795$ & $\$ 2,893$ & 19 & $27 \%$ \\
\hline
\end{tabular}


Table 5-2., Cont'd.

\begin{tabular}{|c|c|c|c|c|c|c|c|c|c|c|}
\hline & $\begin{array}{l}\text { Final waste } \\
\text { volume } \\
\left(\mathrm{ft}^{3} \mathrm{x} 1000\right)\end{array}$ & $\begin{array}{c}\text { Total } \\
\text { treatment } \\
\text { cost } \\
\text { (\$million) } \\
\end{array}$ & $\begin{array}{c}\text { Revised* } \\
\text { disposal } \\
\text { cost } \\
\text { (\$million) } \\
\end{array}$ & $\begin{array}{l}\text { Total LCC } \\
\text { (\$million) }\end{array}$ & Rank & \% LCC & $\begin{array}{c}\text { Disposal } \\
\text { cost } \\
\$ 243 / \mathrm{ft}^{3} \\
(\$ \text { million }) \\
\end{array}$ & $\begin{array}{l}\text { Total LCC } \\
\text { (\$million) }\end{array}$ & Rank & $\%$ LCC \\
\hline E-1 & 2,482 & $\$ 2,191$ & $\$ 752$ & $\$ 2,943$ & 19 & $26 \%$ & $\$ 603$ & $\$ 2,794$ & 18 & $22 \%$ \\
\hline $\mathrm{K}-1$ & 3,435 & $\$ 2,144$ & $\$ 830$ & $\$ 2,973$ & 20 & $28 \%$ & $\$ 835$ & $\$ 2,978$ & 20 & $28 \%$ \\
\hline NT-2 & 3,306 & $\$ 2,846$ & $\$ 820$ & $\$ 3,665$ & 21 & $22 \%$ & $\$ 803$ & $\$ 3,649$ & 21 & $22 \%$ \\
\hline NT-1 & 3,347 & $\$ 2,883$ & $\$ 822$ & $\$ 3,706$ & 22 & $22 \%$ & $\$ 813$ & $\$ 3,697$ & 22 & $22 \%$ \\
\hline NT-3 & 3,411 & $\$ 2,990$ & $\$ 828$ & $\$ 3,817$ & 23 & $22 \%$ & $\$ 829$ & $\$ 3,819$ & 25 & $22 \%$ \\
\hline NT-5 & 2,782 & $\$ 3,118$ & $\$ 776$ & $\$ 3,895$ & 24 & $20 \%$ & $\$ 676$ & $\$ 3,794$ & 24 & $18 \%$ \\
\hline NT-4 & 2,710 & $\$ 3,135$ & $\$ 771$ & $\$ 3,905$ & 25 & $20 \%$ & $\$ 658$ & $\$ 3,793$ & 23 & $17 \%$ \\
\hline
\end{tabular}

* Revised disposal cost includes fixed and variable cost components. 
On the average disposal costs increase from $16 \%$ to $21 \%$ of total life cycle costs. The higher cost for disposal indicates that total life cycle costs are slightly more sensitive to an increase or decrease in disposal costs. This sensitivity is illustrated in Figure 5-2 by showing the average percentage change in the total life cycle costs when cost components, including the higher disposal cost, are increased by $100 \%$ and decreased by $50 \%$.

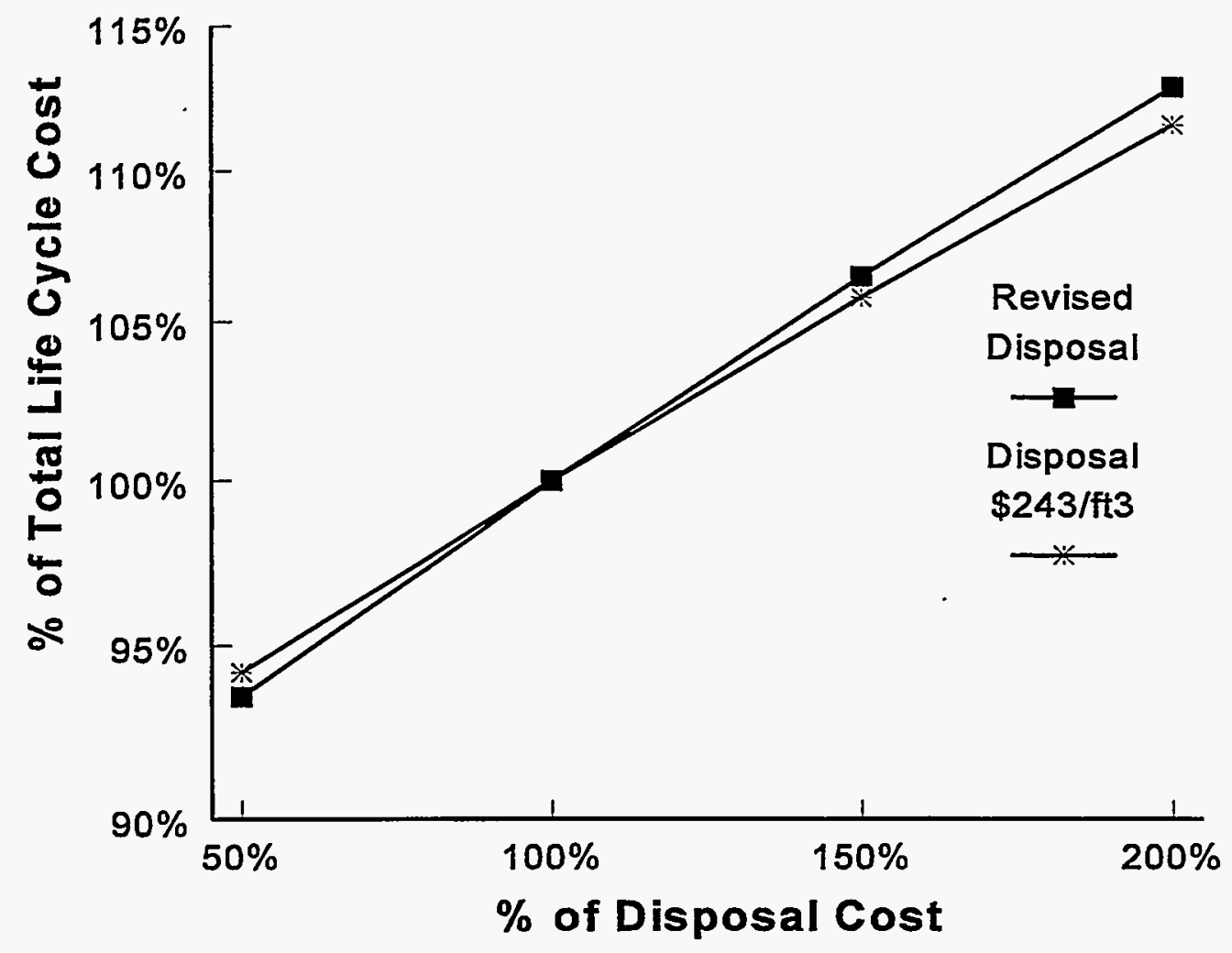

Figure 5-2. Life cycle component cost sensitivity with increased disposal cost. 


\subsubsection{Disposal Cost Sensitivity as a Function of Facility Size.}

To determine the disposal cost sensitivity as a function of the facility size, both the small- and medium-size facility cost estimates are applied to each system. The range of disposal costs across all the systems is illustrated in Figure 5-3. A breakdown of the cost estimates for small- and medium-size facilities is included in Appendix C Table C-1.

The data points for each system, as shown in Figure 5-3, represent the total cost for disposal in a small- and medium-size facility. Because costs are very close for several systems, distinguishing all 25 systems on the chart is difficult. The cost per $\mathrm{ft}^{3}$ is identified for various systems (i.e., $\$ 533$ on the smallsize facility cost curve and $\$ 718$ on the medium facility cost curve represents the cost per $\mathrm{ft}^{3}$ for disposal of the final waste volume, $864 \mathrm{~K} \mathrm{ft}^{3}$, for technology A-6, rotary kiln with air for combustion and maximum recycling). The results show that the total cost for disposal in a small-size facility is less than the cost for disposal in a medium-size facility as long as the waste quantity does not exceed the design capacity of the small-size facility (i.e., 1.5 million $\mathrm{ft}^{3}$ ).

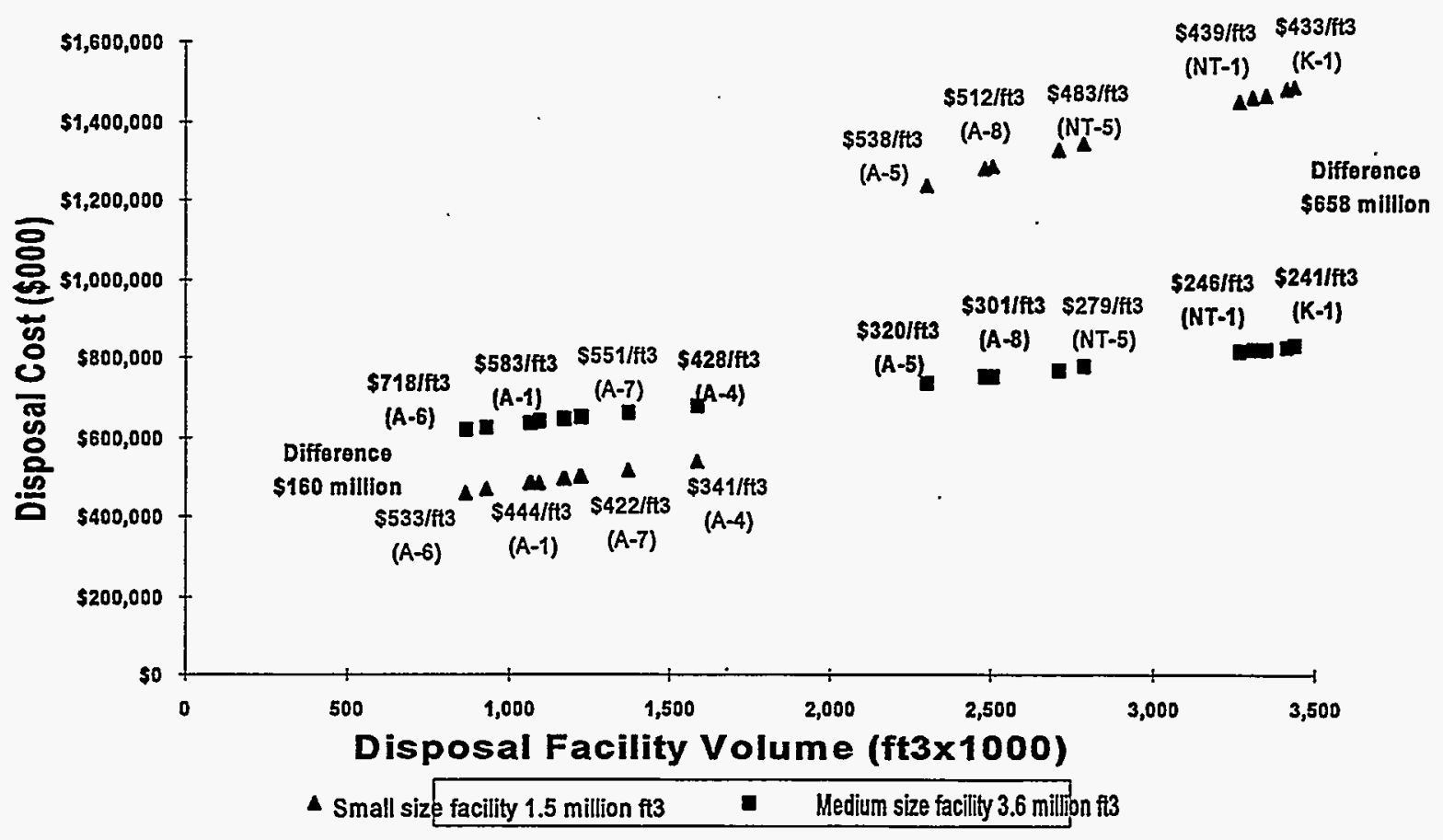

Figure 5-3. Disposal cost comparison for systems.

For example, suppose a small-size facility is constructed, and unexpectedly, waste quantity exceeds the design capacity. In this case, it is assumed that a second disposal facility would have to be built to accomodate the additional waste. Fixed costs for constructing and operating a second facility would be incurred as a result. To illustrate, if two small-size facilities are constructed to dispose of 2.3 million $\mathrm{ft}^{3}$, or the output volume for system A-5 rotary kiln utilizing air for combustion and polymer for stabilization, the total disposal cost increases by $\$ 500$ million (i.e., $\$ 320$ to $\$ 538$ per $\mathrm{ft}^{3}$ ).

As shown in Figure 5-3, the cost difference of $\$ 160$ million represents the cost risk for 
constructing a medium-size facility and disposing of the minimum waste volume. In comparison, the cost difference of $\$ 658$ million represents the cost risk for construction of two small-size facilities and disposing of the maximum waste volume. Based on these examples, it is advisable to construct a slightly larger facility at the risk of having excess disposal capacity.

These results demonstrate the importance of estimating the final waste volume with as much accuracy as possible before the disposal facility is designed and constructed. Selection of the waste treatment technology in advance is critical in determining disposal requirements because the output volume and final waste form are used to calculate capacity requirements.

\subsection{Disposal Cost Comparison for Grout vs. Vitrification}

When comparing treatment technology $\mathrm{A}-1$, a technology that uses vitrification for stabilization, to A-8, a technology that uses grout for stabilization, a cost savings of $\$ 268$ million could be realized if a smaller disposal facility is constructed compared to the cost of constructing a medium-size facility to dispose of the grout waste form (i.e., $\$ 754$ million less $\$ 486$ million). This is the maximum cost savings over the life of the facility assuming the disposal site is sized for and meets the expected waste quantity.

Realistically, the disposal facility can be sized for the estimated final waste volume only if the treatment technology and final waste forms are known prior to construction of the disposal facility. Once the disposal facility is constructed and the fixed costs are incurred, the cost for disposal will vary directly with the volume of waste disposed. Therefore, systems producing less immobilized waste volume are preferred over systems producing greater final waste volume. For example, to be conservative assume that a medium-size facility is constructed to accomodate output waste volume from all treatment systems. If ultimately the waste is vitrified, disposal of a smaller quantity of vitrified waste will still cost less because the variable cost per $\mathrm{ft}^{3}$ disposed will be saved. This is illustrated in Figure 5-4, $\$ 114$ million is saved by disposing of the lower quantity of vitrified waste form in a medium-size facility (i.e., $\$ 754$ million less $\$ 640$ million).

These results are illustrated in Figure 5-4. Throughout this section, caution should be taken when comparing the unit costs to avoid misinterpretation of the costs. That is, for a given facility, as waste volume increases so does total disposal cost even though unit cost decreases. 


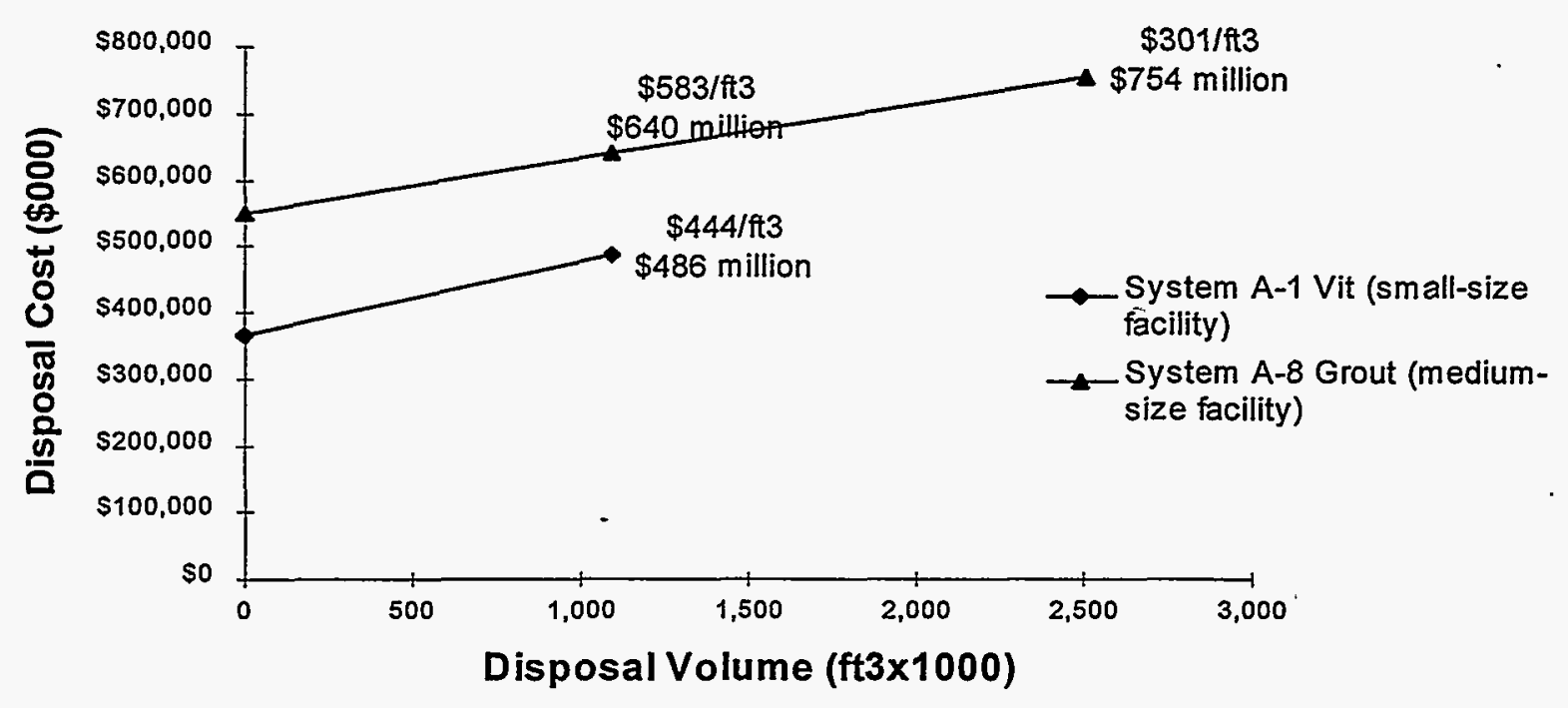

Figure 5-4. Disposal cost comparison for grout versus vitrified waste form (revised disposal costs).

For comparison, using the variable cost of $\$ 243$ per $\mathrm{ft}^{3}$ for disposal, the ITTS and INTS studies show a $\$ 343$ million cost savings for disposal of the smaller waste volume from system A-1 (i.e., $\$ 609$ million less $\$ 266$ million) as illustrated in Figure 5-5. However, as previously mentioned, applying a single unit cost assumes that disposal cost is directly proportional to the volume of waste disposed. In contrast, as defined in this analysis, the life cycle costs for constructing and operating a disposal facility include both fixed and variable components. It is the variable cost component only that is saved when disposing of a smaller waste volume. This accounts for the difference in projected cost savings for vitrification versus grout in this analysis and the ITTS and INTS studies (i.e., \$268 million versus $\$ 343$ million).

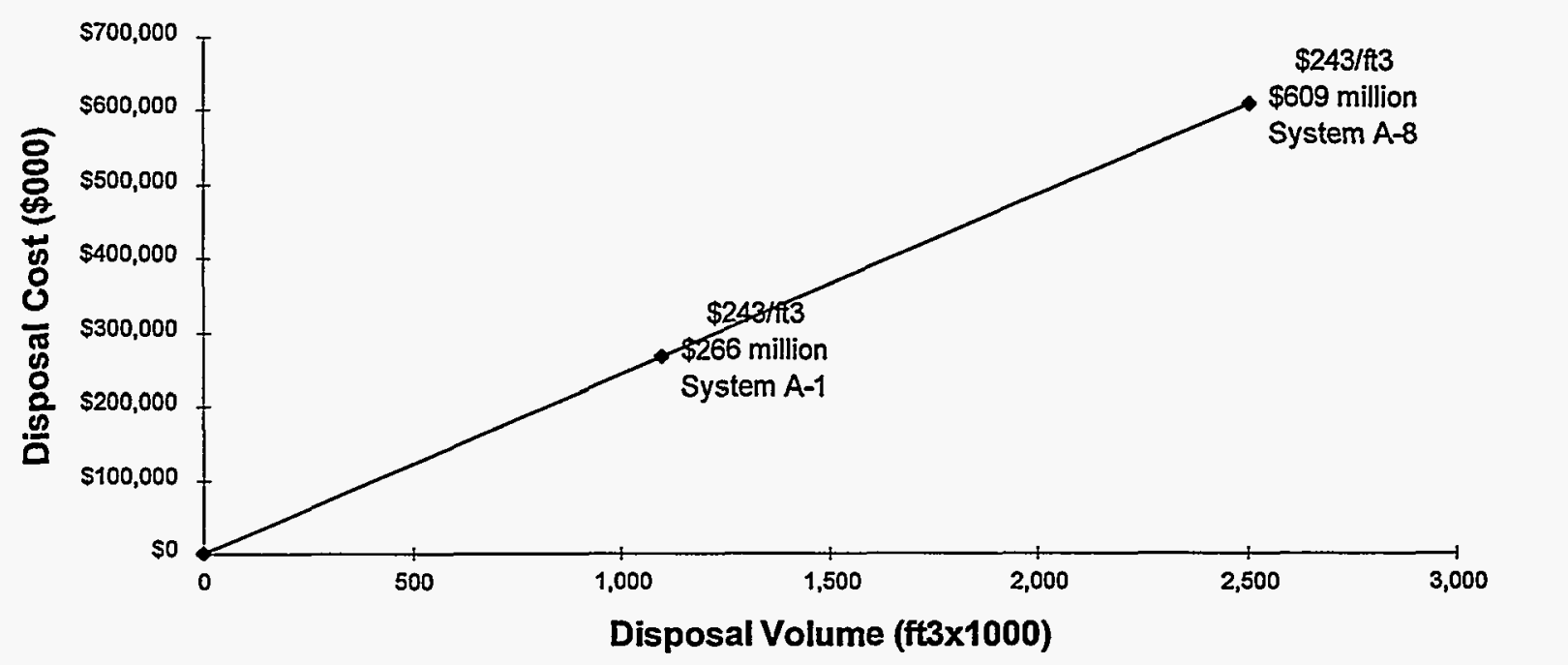

Figure 5-5. Disposal cost comparison for grout versus vitrified waste form ( $\$ 243$ per $\left.\mathrm{ft}^{3}\right)$. 


\subsection{Economic Impact of Delisting Vitrified Waste Form}

Currently, petitions to the U.S. Environmental Protection Agency (EPA) have been drafted within the DOE for exclusion of vitrified treatment residues from the lists of hazardous wastes ${ }^{7}$. Listed MLLW, as identified in the Resource Conservation and Recovery Act (RCRA) regulation 40 CFR Part 261.3, would be treated by a vitrification process and the resultant treatment residues would be regulated by 40 CFR 261.3(c)(2)(I) until delisted. When delisting for the RCRA hazardous constituents is complete, the stabilized waste form would be managed and disposed in a manner consistent with the requirements of the Atomic Energy Act of 1954 as implemented by the DOE Order 5820.2A Radioactive Waste Management. In order to delist the waste, the petitioner must demonstrate that the waste does not meet any of the criteria under which the waste was listed as a hazardous waste and that there are no factors other than those for which the waste was listed that could cause the waste to be a hazardous waste.

Delisting the vitrified waste form would be economically advantageous because the cost to dispose of low-level radioactive waste at existing shallow land disposal facilities is reported to be less than the cost for disposal in a RCRA-permitted engineered disposal facility, as estimated. For example, assume that a disposal facility such as the Richland shallow land disposal facility could accommodate the additional delisted vitrified waste volume without increasing their estimated cost of $\$ 40$ per $\mathrm{ft}^{3}$ for disposal ${ }^{8}$. This cost per $\mathrm{ft}^{3}$ is substantially less than the costs calculated in this analysis which range from $\$ 241$ to $\$ 718$ per $\mathrm{ft}^{3}$ for constructing and operating a medium-size RCRA-permitted facility, as shown in Appendix C, Table C-1.

This section estimates the potential cost savings that would result for each of the thermal treatment technologies using vitrification for primary stabilization if the vitrified waste form is delisted and disposed of at $\$ 40$ per $\mathrm{ft}^{3}$. The thermal treatment technologies using vitrification for primary stabilization include:

A-1 rotary kiln with air for combustion and dry/wet air pollution control,

A-2 rotary kiln with oxygen for combustion and dry/wet air pollution control,

A-3 rotary kiln with air for combustion and wet air pollution control,

A-4 rotary kiln with oxygen for combustion and $\mathrm{CO}_{2}$ retention,

A-6 rotary kiln with air for combustion and maximum recycling,

D-1 fixed hearth with oxygen and $\mathrm{CO}_{2}$ retention,

E-1 debris desorption and grouting with rotary kiln for combustion,

F-1 molten salt oxidation with air for combustion and dry/wet air pollution control, and

$\mathrm{H}-1$ steam gasification with steam for combustion.

Applying the shallow land disposal cost of $\$ 40$ per $\mathrm{ft}^{3}$ to the volume of slag output from the vitrification process ${ }^{9}$, and the applicable disposal cost for the remaining output volume of waste, the total estimated disposal cost for the systems employing vitrification for stabilization is reduced by as much as $\$ 45$ million, or $2 \%$ of the total life cycle costs. These disposal estimates are summarized in Table 5-3. However, even after reducing the disposal cost by assuming delisting of the slag output volume, the overall ranking of systems by total life cycle cost including disposal remains the same as presented in Table 5-2. A breakdown of the vitrified and solid output volume and disposal cost for each system is provided in Appendix C, Table C-2. 
Table 5-3. Disposal cost assuming delisting of vitrified waste form.

\begin{tabular}{rrrrrr}
$\begin{array}{l}\text { Final waste } \\
\text { volume } \\
\left(\mathrm{ft}^{3} \times 1000\right)\end{array}$ & $\begin{array}{l}\text { Total treatment } \\
\text { cost (\$million) }\end{array}$ & $\begin{array}{l}\text { Revised* } \\
\text { disposal cost } \\
\text { (\$million) }\end{array}$ & $\begin{array}{l}\text { Total LCC } \\
\text { (\$million) }\end{array}$ & $\begin{array}{l}\text { Disposal cost } \\
\text { assuming } \\
\text { delisting } \\
\text { (\$million) }\end{array}$ & $\begin{array}{l}\text { Total LCC } \\
\text { assuming } \\
\text { delisting } \\
\text { (\$million) }\end{array}$ \\
\hline 1,096 & $\$ 2,166$ & $\$ 486$ & $\$ 2,652$ & $\$ 440$ & $\$ 2,606$ \\
1,096 & $\$ 2,167$ & $\$ 486$ & $\$ 2,653$ & $\$ 440$ & $\$ 2,607$ \\
1,369 & $\$ 2,144$ & $\$ 516$ & $\$ 2,660$ & $\$ 482$ & $\$ 2,625$ \\
1,095 & $\$ 2,193$ & $\$ 486$ & $\$ 2,679$ & $\$ 440$ & $\$ 2,633$ \\
864 & $\$ 2,236$ & $\$ 460$ & $\$ 2,697$ & $\$ 414$ & $\$ 2,651$ \\
1,176 & $\$ 2,275$ & $\$ 495$ & $\$ 2,770$ & $\$ 449$ & $\$ 2,724$ \\
1,585 & $\$ 2,282$ & $\$ 540$ & $\$ 2,822$ & $\$ 494$ & $\$ 2,776$ \\
1,226 & $\$ 2,338$ & $\$ 500$ & $\$ 2,839$ & $\$ 454$ & $\$ 2,793$ \\
2,482 & $\$ 2,191$ & $\$ 752$ & $\$ 2,943$ & $\$ 749$ & $\$ 2,940$
\end{tabular}

*Revised disposal cost includes fixed and variable cost components. 


\subsection{CONCLUSIONS AND RECOMMENDATIONS}

For all systems, the most cost sensitive life cycle component is the operations and maintenance phase and the most cost sensitive subsystem component is the receiving and inspection/preparation subsystem. These conclusions were unchanged when the sensitivity analysis was repeated on a present value basis. Opportunity exists for technology development to reduce waste receiving and inspection/preparation costs by effectively minimizing labor costs, the major cost driver, within the maintenance and operations phase of the life cycle.

The capacity analysis demonstrates that treatment of the MLLW inventory in one facility is the most economically advantageous alternative. The economic scaling alternatives explored in this analysis show that even when factoring in the greater transportation costs associated with shipment of the MLLW to a single facility, the life cycle costs are still approximately $27 \%$ less for constructing and operating one facility versus two facilities, assuming a 0.5 scaling factor. If a single facility is sized to double the throughput capacity and treat the same quantity of waste in half the time, the life cycle cost will be less than the baseline system costs for any scaling factor less than 0.58 . However, from an NPV perspective, the higher cash outlays in the earlier years, due to the reduced operating period, are not preferred unless there is a non-economic driver to treat the waste sooner, such as the Federal Facility Compliance Act.

If feasible, the most economically favorable alternative would be one facility capable of operating more available hours. As shown in this analysis, if the facility is fully operational 5,850 hours per year, the operating period is reduced from 20 to 14 years and the total life cycle cost are $17 \%$ less than baseline system life cycle cost. Alternatively, rather than reducing the operating period, a $45 \%$ increase in the quantity of waste processed results in a cost of $\$ 6.75$ per pound versus $\$ 9.18$ per pound or net decrease of $\$ 2.65$ per pound over a 20 year operating life. Although system unavailability is not attributed to any specific cause, it is clear that reliable operating equipment is a key factor to increasing system availability. Therefore, a recommended area of focus is on improving equipment availability.

To further support treatment in a single facility, a recommended area for technology development and/or technology improvement is to ensure that the facility is capable of accepting and treating greater volumes of heterogenous waste streams. The increased technical risk associated with engineering a single large-scale process to accept heterogeneous waste streams with complex physical and chemical characteristics needs to be addressed. Treatment systems operate on tight controls in order to achieve organic destruction of the contaminants and produce a specific final waste form while insuring that no damage is done physically to the system itself. Therefore, there are normally restrictions on the chemical, physical, and radiological characteristics of the waste input to the treatment process. If input waste streams do not fit the input specifications of the treatment process, then only the portion of the mixed waste inventory that fits within the narrow specifications of the treatment system will undergo treatment in that given process. The challenge that remains is to treat waste streams that vary widely in physical, chemical, and radiological form (i.e., heterogeneous waste streams).

As a potential technology discriminator, the sensitivity of life cycle costs to contingency allowance was evaluated for the less-developed technologies. An increase in contingency percentage from $25 \%$ to $35 \%, 45 \%$, and $50 \%$ for the less developed technologies results in a $7 \%, 15 \%$, and $18 \%$ increase in the total life cycle costs, respectively. These results show that the less developed technologies are not as economically desirable when the contingency costs are increased to reflect operational uncertainties.

The disposal cost analyses presented in the ITTS and INTS were extended to incorporate varying 
design capacities for future waste disposal facilities. The fixed and variable components of total disposal costs were calculated to determine the sensitivity of life cycle costs to final waste volume. Disposal costs increased an average of $35 \%$ above the cost derived using $\$ 243$ per $\mathrm{ft}^{3}$, as documented in the ITTS and INTS.

If a new RCRA-permitted engineered disposal facility is designed to accomodate a greater waste volume than the selected treatment system produces, only the variable cost of disposal will be saved. As expected, disposal costs will decrease with the volume of waste requiring disposal due to the variable cost component savings. Maximum cost savings will be realized if the disposal site is designed and sized for the selected treatment system. The selection and/or development of treatment technologies, final waste form(s) and disposal site(s) should be coordinated to minimize total life cycle costs. The possibility of delisting certain final waste forms offers the opportunity for additional cost savings. 


\subsection{REFERENCES}

1. Fred Feizollahi, William J. Quapp, Integrated Thermal Treatment Systems Study, INEL-95/0129, August 1995.

2. Chuck Biagi, William J. Quapp, Daryoush Bahar, Blaine Brown, William Schwinkendorf, Ginger Swartz, Ben Teheranian, Julia Vetromile, Integrated Nonthermal Treatment System Study, Draft, March 1996.

3. Perry's Chemical Engineers' Handbook, Sixth Edition, McGraw-Hill Book Company, 1984.

4. 1995 Mixed Waste Inventory Report, Prepared for U.S. DOE Environmental Restoration and Waste Management (EM-30), Idaho National Engineering Laboratory, December 1995.

5. Fred Feizollahi, David Shropshire, David Burton, Waste Management Facilities Cost Information for Transportation of Radioactive and Hazardous Materials, INEL-95/0300, Idaho National Engineering Laboratory, June 1995.

6. David Shropshire, Michael Sherick, Chuck Biagi, Waste Management Facilities Cost Information for Mixed Low-Level Waste, INEL-95/0014, Idaho National Engineering Laboratory (June 1995).

7. J.B. Pickett, Draft for Comment Upfront Delisting Petition for Vitrified M-Area Plating Line Wastes, WSRC-TR-96-XX, Prepared for U.S. DOE, Savannah River Site.

8. Weapons Complex Monitor, Volume 7 No. 18, January 5, 1996.

9. Fred Feizollahi, William J. Quapp, Integrated Thermal Treatment Systems Study, Appendix B ITTS Study Mass Balance Modeling, INEL-95/0129, Revision 1, February 1996. 


\section{Appendix A}

\section{Life Cycle Component and Subsystem Cost Data}




\begin{tabular}{|c|c|c|c|c|c|c|c|c|}
\hline & & $\begin{array}{l}\text { Life Cycle Cost } \\
(\$ 000)\end{array}$ & $\begin{array}{l}\text { Studies, } \\
\text { Test, \& } \\
\text { Demo. }\end{array}$ & Building & Equipment & $\begin{array}{c}\text { Ops. } \\
\text { funded } \\
\text { activities }\end{array}$ & $\begin{array}{l}\text { Ops. \& } \\
\text { Maint. }\end{array}$ & D\&D \\
\hline Rotary kiln, air/vit. & $A-1$ & $\$ 2,167,318$ & $5 \%$ & $11 \%$ & $15 \%$ & $0.3 \%$ & $66 \%$ & $3 \%$ \\
\hline Rotary kiln, oxygen & $A-2$ & $\$ 2,165,709$ & $5 \%$ & $11 \%$ & $14 \%$ & $0.3 \%$ & $66 \%$ & $3 \%$ \\
\hline Slagging rotary kiln & A-7 & $\$ 1,913,812$ & $5 \%$ & $11 \%$ & $14 \%$ & $0.3 \%$ & $66 \%$ & $3 \%$ \\
\hline $\begin{array}{l}\text { Rotary kiln, } \\
\text { air/grouut }\end{array}$ & A-8 & $\$ 2,144,205$ & $4 \%$ & $12 \%$ & $13 \%$ & $0.3 \%$ & $68 \%$ & $3 \%$ \\
\hline Plasma furnace & $C-1$ & $\$ 1,980,756$ & $5 \%$ & $11 \%$ & $13 \%$ & $0.3 \%$ & $68 \%$ & $3 \%$ \\
\hline Plasma furnace, $\mathrm{CO} 2$ ret. & $C-2$ & $\$ 2,095,782$ & $5 \%$ & $11 \%$ & $14 \%$ & $0.3 \%$ & $67 \%$ & $2 \%$ \\
\hline Plasma gasification & $\mathrm{C}-3$ & $\$ 1,929,110$ & $4 \%$ & $11 \%$ & $15 \%$ & $0.3 \%$ & $66 \%$ & $3 \%$ \\
\hline Molten salt oxidation & $\mathrm{F}-1$ & $\$ 2,275,209$ & $3 \%$ & $11 \%$ & $15 \%$ & $0.3 \%$ & $68 \%$ & $2 \%$ \\
\hline Molten metal waste destruction & G-1 & $\$ 1,893,481$ & $5 \%$ & $13 \%$ & $10 \%$ & $0.3 \%$ & $68 \%$ & $3 \%$ \\
\hline Steam gasification & $\mathrm{H}-1$ & $\$ 2,193,160$ & $3 \%$ & $11 \%$ & $16 \%$ & $0.3 \%$ & $67 \%$ & $1 \%$ \\
\hline Joule heated vitrification & $\mathrm{J}-1$ & $\$ 1,921,590$ & $4 \%$ & $12 \%$ & $14 \%$ & $0.3 \%$ & $68 \%$ & $3 \%$ \\
\hline Thermal desorption and MEO & $\mathrm{K}-1$ & $\$ 2,143,501$ & $3 \%$ & $10 \%$ & $14 \%$ & $0.3 \%$ & $70 \%$ & $3 \%$ \\
\hline Thermal desorption and SCWO & L-1 & $\$ 2,098,135$ & $3 \%$ & $11 \%$ & $13 \%$ & $0.3 \%$ & $70 \%$ & $3 \%$ \\
\hline Grout debris & NT-1 & $\$ 2,883,364$ & $5 \%$ & $13 \%$ & $9 \%$ & $0.3 \%$ & $71 \%$ & $3 \%$ \\
\hline Desorption & NT-2 & $\$ 2,845,686$ & $5 \%$ & $13 \%$ & $9 \%$ & $0.3 \%$ & $71 \%$ & $3 \%$ \\
\hline Wash & NT-3 & $\$ 2,989,775$ & $5 \%$ & $13 \%$ & $9 \%$ & $0.3 \%$ & $71 \%$ & $3 \%$ \\
\hline Acid digestion & NT-4 & $\$ 3,134,475$ & $7 \%$ & $13 \%$ & $9 \%$ & $0.3 \%$ & $68 \%$ & $3 \%$ \\
\hline Catalyzed wet oxidation & NT-5 & $\$ 3,118,337$ & $6 \%$ & $13 \%$ & $9 \%$ & $0.3 \%$ & $69 \%$ & $3 \%$ \\
\hline
\end{tabular}


Table A-2. Time phased life cycle costs for baseline system A-1 rotary kiln with air combustion $(\$ 000)$.

\begin{tabular}{|c|c|c|c|c|c|c|c|c|c|c|}
\hline $\begin{array}{l}\text { Cost Category } \\
\text { Bench scale testing }\end{array}$ & $\begin{array}{l}\text { Year 1 } \\
\$ 30,525\end{array}$ & Year 2 & Year 3 & Year 4 & Year 5 & Year 6 & Year 7 & Year 8 & Year 9 & Year 10 \\
\hline Capital demonstration & & $\$ 20,000$ & & & & & & & & \\
\hline Annual demonstration & & $\$ 24,824$ & $\$ 24,824$ & & & & & & & \\
\hline Permilting & & & & $\$ 2,000$ & $\$ 2,000$ & $\$ 2,000$ & & & & \\
\hline Capilal construction & & & & & & & $\$ 205,745$ & & & \\
\hline Annual construction & & & & & & & $\$ 174,316$ & $\$ 174,316$ & & \\
\hline Other preoperations & & & & & & & & $\$ 90,747$ & & \\
\hline Annual operations \& maintenance & & & & & & & & & $\$ 68,093$ & $\$ 68,093$ \\
\hline Decontamination \& decommissioning & & & & & & & & & & \\
\hline Disposal & & & & & & & & & $\$ 6,656$ & $\$ 13,312$ \\
\hline TOTAL COST & $(\$ 30,525)$ & $(\$ 44,824)$ & $(\$ 24,824)$ & $(\$ 2,000)$ & $(\$ 2,000)$ & $(\$ 2,000)$ & $(\$ 380,061)$ & $(\$ 265,063)$ & $(\$ 68,093)$ & $(\$ 68,093)$ \\
\hline
\end{tabular}

Cost Category

Year 11 Year 12

Year 13

Yoar 14

Yoar 15

Year 16

Year 17

Year 18

Year $19 \quad$ Year 20

Capital der

Annual demonstration

N Permitting

Annual construction

Olher preoperations

Annual operations \& maintenance

Decontamination \& decommissioning

Disposal

$\$ 68,093$

$\$ 68,093$

$\$ 68,093$

$\$ 68,093$

$\$ 68,093$

$\$ 68,093$

$\$ 68,093$

$\$ 68,093$

TOTALCOST

$\$ 13,312 \$ 13,312$

$\$ 13,312 \quad \$ 13,312 \quad \$ 13,312 \quad \$ 13,312$

$\$ 13,312$

$\$ 13,312 \$ \$ 13,312$

$\$ 13,312$

Cost Category

Yoar 21 Yoar 22

Bench scale testing

Capital demonstration

Annual demonstration

Permitting

Capital construction

Annual construction

Other preoperations

Annual operations \& maintenance

Decontamination \& decommissioning

Disposal

Year 22 Year 23

Yaar 24

$(\$ 68,093) \quad(\$ 68,093) \quad(\$ 68,093)$

TOTAL COST

$\$ 68,093$

$\$ 68,093$

$\$ 68,093$

$\$ 68,093$

$\$ 13,312 \quad \$ 13,312 \quad \$ 13,312$

$\$ 13,312$

13,312

$\$ 13,312$

$(\$ 68,093)$

$\begin{array}{lll}(\$ 68,093) & (\$ 68,093) & (\$ 68,093)\end{array}$

Year 29 Year 30 TOTAL $\$$ 
Table A-3. Present value life cycle cost (LCC) comparison (\$000).

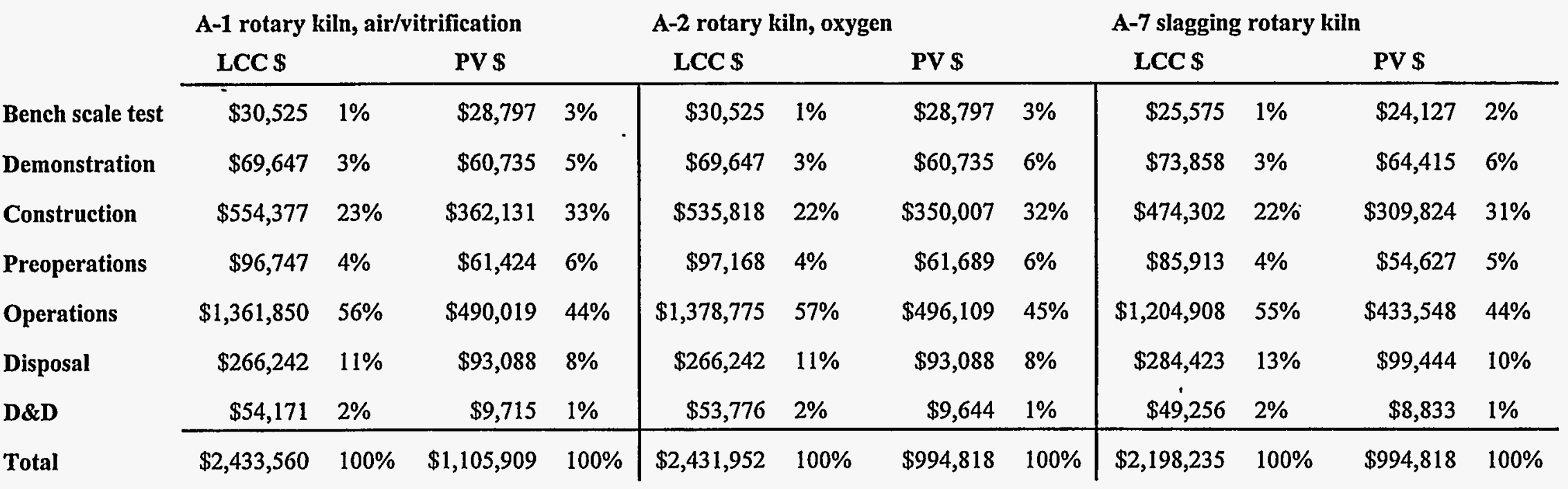

\begin{tabular}{|c|c|c|c|c|c|c|c|c|c|c|c|c|}
\hline \multirow[b]{3}{*}{ Bench scale test } & \multicolumn{3}{|c|}{ A-8 rotary kiln, air/grout } & \multicolumn{4}{|c|}{ C-1 plasma arc furnace } & \multicolumn{4}{|c|}{ G-1 molten metal melter } & \\
\hline & $\mathrm{LCC} \$$ & & PV \$ & & LCC $\$$ & & PV \$ & & LCC \$ & & PV \$ & \\
\hline & $\$ 25,575$ & $1 \%$ & $\$ 24,127$ & $2 \%$ & $\$ 29,288$ & $1 \%$ & $\$ 27,630$ & $3 \%$ & $\$ 25,369$ & $1 \%$ & $\$ 23,933$ & $3 \%$ \\
\hline Demonstration & $\$ 69,647$ & $3 \%$ & $\$ 60,735$ & $5 \%$ & $\$ 69,647$ & $3 \%$ & $\$ 60,735$ & $6 \%$ & $\$ 62,248$ & $3 \%$ & $\$ 54,303$ & $6 \%$ \\
\hline Construction & $\$ 513,656$ & $19 \%$ & $\$ 335,530$ & $28 \%$ & $\$ 458,639$ & $20 \%$ & $\$ 299,592$ & $30 \%$ & $\$ 449,457$ & $21 \%$ & $\$ 293,595$ & $31 \%$ \\
\hline Preoperations & $\$ 96,785$ & $4 \%$ & $\$ 61,448$ & $5 \%$ & $\$ 89,796$ & $4 \%$ & $\$ 57,063$ & $6 \%$ & $\$ 86,064$ & $4 \%$ & $\$ 54,722$ & $6 \%$ \\
\hline Operations & $\$ 1,382,900$ & $49 \%$ & $\$ 497,593$ & $41 \%$ & $\$ 1,283,333$ & $57 \%$ & $\$ 461,767$ & $46 \%$ & $\$ 1,220,078$ & $58 \%$ & $\$ 439,006$ & $46 \%$ \\
\hline Disposal & $\$ 609,421$ & $22 \%$ & $\$ 213,075$ & $18 \%$ & $\$ 259,168$ & $12 \%$ & $\$ 90,614$ & $9 \%$ & $\$ 225,780$ & $11 \%$ & $\$ 78,940$ & $8 \%$ \\
\hline D\&D & $\$ 55,642$ & $2 \%$ & $\$ 9,978$ & $1 \%$ & $\$ 50,053$ & $2 \%$ & $\$ 8,976$ & $1 \%$ & $\$ 50,266$ & $2 \%$ & $\$ 9,014$ & $1 \%$ \\
\hline Total & $\$ 2,753,626$ & $100 \%$ & $\$ 1,202,488$ & $100 \%$ & $\$ 2,239,924$ & $100 \%$ & $1,006,378$ & $100 \%$ & $\$ 2,119,261$ & $100 \%$ & $\$ 953,514$ & $100 \%$ \\
\hline
\end{tabular}


Table A-3. Present value life cycle cost (LCC) comparison ( $\$ 000)$ (continued).

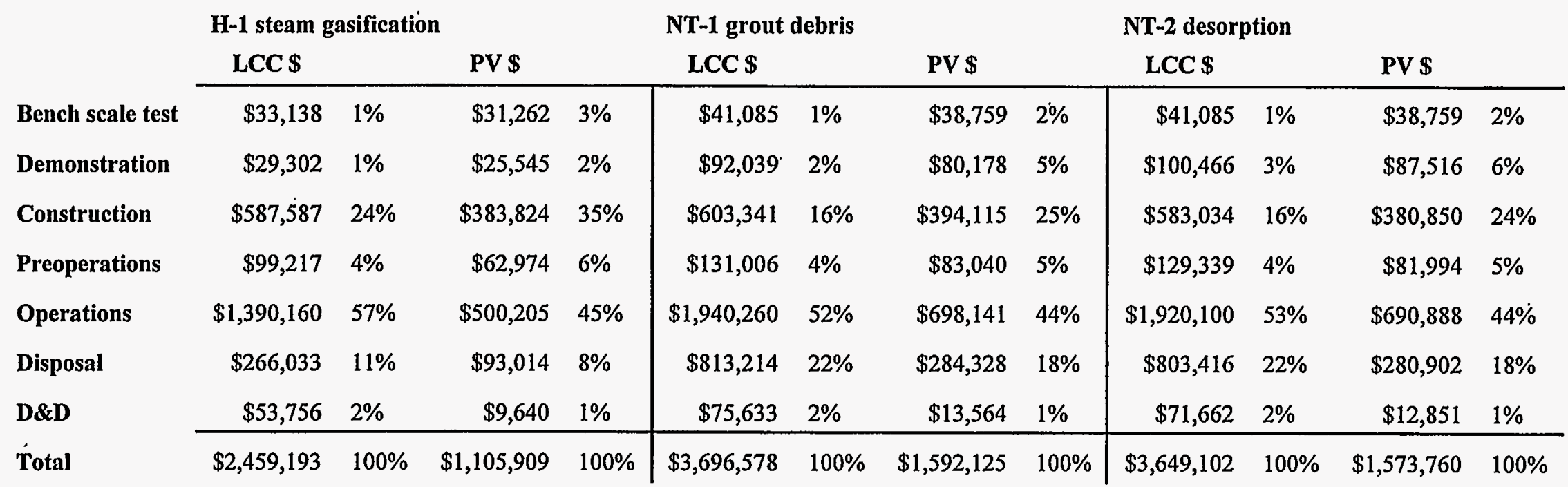

孛

\begin{tabular}{|c|c|c|c|c|c|c|c|c|c|c|c|c|}
\hline \multirow{3}{*}{ Bench scale test } & \multirow{2}{*}{\multicolumn{2}{|c|}{$\begin{array}{c}\text { NT-3 wash } \\
\text { LCC \$ }\end{array}$}} & \multicolumn{5}{|c|}{ NT-4 acid digestion } & \multicolumn{5}{|c|}{ NT-5 catalyzed wet oxidation } \\
\hline & & & PV \$ & & LCC \$ & & PV \$ & & LCC $\$$ & & PV $\$$ & \\
\hline & $\$ 41,635$ & $1 \%$ & $\$ 39,278$ & $2 \%$ & $\$ 58,341$ & $2 \%$ & $\$ 55,039$ & $3 \%$ & $\$ 47,685$ & $1 \%$ & $\$ 44,986$ & $3 \%$ \\
\hline Demonstration & $\$ 100,090$ & $3 \%$ & $\$ 87,196$ & $5 \%$ & $\$ 157,389$ & $4 \%$ & $\$ 137,111$ & $8 \%$ & $\$ 127,055$ & $3 \%$ & $\$ 110,682$ & $7 \%$ \\
\hline Construction & $\$ 638,231$ & $17 \%$ & $\$ 416,905$ & $25 \%$ & $\$ 670,985$ & $18 \%$ & $\$ 438,301$ & $26 \%$ & $\$ 677,764$ & $18 \%$ & $\$ 442,729$ & $26 \%$ \\
\hline Preoperations & $\$ 135,101$ & $4 \%$ & $\$ 85,609$ & $5 \%$ & $\$ 137,781$ & $4 \%$ & $\$ 87,290$ & $5 \%$ & $\$ 138,954$ & $4 \%$ & $\$ 88,026$ & $5 \%$ \\
\hline Operations & $\$ 1,997,280$ & $52 \%$ & $\$ 718,658$ & $44 \%$ & $\$ 2,029,600$ & $54 \%$ & $\$ 730,288$ & $43 \%$ & $\$ 2,047,560$ & $54 \%$ & $\$ 736,750$ & $44 \%$ \\
\hline Disposal & $\$ 828,891$ & $22 \%$ & $\$ 289,809$ & $18 \%$ & $\$ 658,409$ & $17 \%$ & $\$ 230,203$ & $14 \%$ & $\$ 676,045$ & $18 \%$ & $\$ 236,369$ & $14 \%$ \\
\hline D\&D & $\$ 77,438$ & $2 \%$ & $\$ 13,887$ & $1 \%$ & $\$ 80,379$ & $2 \%$ & $\$ 14,415$ & $1 \%$ & $\$ 79,319$ & $2 \%$ & $\$ 14,225$ & $1 \%$ \\
\hline Total & $\$ 3,818,666$ & $100 \%$ & $\$ 1,651,343$ & $100 \%$ & $\$ 3,792,884$ & $100 \%$ & $\$ 1,692,647$ & $100 \%$ & $\$ 3,794,382$ & $100 \%$ & $1,673,767$ & $100 \%$ \\
\hline
\end{tabular}


Table A-4. Thermal subsystem component cost sensitivity ( $\$ 000)$.

Thermal Subsystems

System Abbreviation

Primary Thermal

Treatment

Certifiy \& Ship

Administration

Aqueous Waste

Treatment

is

Support

Air Pollution Control

Lead Recovery

Secondary Stabil.

Mercury Amalgam.

Metal Decon

Metal Melting

Special Waste

Grout Stabilization

Total Life Cycle $\$$
Receive \& Inspect

Primary Stabilization
Rotary kiln, Rotary kiln, Slagging air, vit. oxygen, vit. rotary kiln

A-2

$$
\text { A-7 }
$$

$\$ 193,049 \quad \$ 193$

$\$ 139,037$

$\$ 149,186$

$\$ 139,037$

$\$ 149,186$

$\$ 243,688$

$\$ 101,200$

$\$ 115,219$

$\$ 81,130$

$\$ 80,942$

$\$ 52,244$

$\$ 243,688$

$\$ 101,200$

$\$ 76,224$

$\$ 81,129$

$\$ 81,148$

$\$ 61,878 \quad \$ 61,878$

$\$ 92,110 \quad \$ 92,110$

$\$ 29,350$

$\$ 29,351$

$\$ 0$

$\$ 0$

$\$ 2,167,318 \$ 2,165,709$

$\$ 666$

$\$ 51,625$

Rotary kiln, grout hearth, air

A-8

C-1

Molten metal Steam
gasification

Average \% G-1 H-1 
Table A-5. Nonthermal subsystem component cost sensitivity ( $\$ 000)$.

\begin{tabular}{|c|c|c|c|c|c|c|}
\hline $\begin{array}{l}\text { Nonthermal } \\
\text { Subsystems }\end{array}$ & $\begin{array}{l}\text { Grout } \\
\text { debris }\end{array}$ & $\begin{array}{l}\text { Vacuum } \\
\text { desorption }\end{array}$ & Wash & $\begin{array}{c}\text { Acid } \\
\text { digestion }\end{array}$ & $\begin{array}{l}\text { Catalytic } \\
\text { wet oxid. }\end{array}$ & $\begin{array}{l}\text { Average } \\
\% \text { Life } \\
\text { Cycle } \$\end{array}$ \\
\hline System Abbrev. & NT-1 & NT-2 & NT-3 & NT-4 & NT-5 & \\
\hline Receive \& Inspect & $\$ 940,494$ & $\$ 940,494$ & $\$ 940,494$ & $\$ 940,494$ & $\$ 940,494$ & $31 \%$ \\
\hline Certify \& Ship & $\$ 480,507$ & $\$ 472,550$ & $\$ 495,277$ & $\$ 401,899$ & $\$ 405,490$ & $15 \%$ \\
\hline $\begin{array}{l}\text { Polymer } \\
\text { Stabilization }\end{array}$ & $\$ 289,200$ & $\$ 289,200$ & $\$ 291,101$ & $\$ 95,995$ & $\$ 289,200$ & $8 \%$ \\
\hline Organic Destruction & $\$ 245,695$ & $\$ 195,695$ & $\$ 245,695$ & $\$ 181,074$ & $\$ 176,979$ & $7 \%$ \\
\hline Administration & $\$ 169,917$ & $\$ 169,917$ & $\$ 169,917$ & $\$ 169,917$ & $\$ 169,917$ & $6 \%$ \\
\hline $\begin{array}{l}\text { Aqueous Waste } \\
\text { Treatment }\end{array}$ & $\$ 149,655$ & $\$ 149,655$ & $\$ 149,655$ & $\$ 146,285$ & $\$ 146,285$ & $5 \%$ \\
\hline $\begin{array}{l}\text { Process Residue \& } \\
\text { Sludge }\end{array}$ & $\$ 134,292$ & $\$ 156,658$ & $\$ 84,882$ & $\$ 126,717$ & $\$ 126,717$ & $4 \%$ \\
\hline Grout Stabilization & $\$ 119,186$ & $\$ 120,011$ & $\$ 119,073$ & $\$ 75,907$ & $\$ 120,011$ & $4 \%$ \\
\hline $\begin{array}{l}\text { Soft Debris } \\
\text { Treatment }\end{array}$ & $\$ 0$ & $\$ 0$ & $\$ 0$ & $\$ 209,380$ & $\$ 219,317$ & $3 \%$ \\
\hline Support & $\$ 84,388$ & $\$ 77,086$ & $\$ 81,203$ & $\$ 82,982$ & $\$ 80,649$ & $3 \%$ \\
\hline $\begin{array}{l}\text { Air Pollution } \\
\text { Control }\end{array}$ & $\$ 70,896$ & $\$ 70,896$ & $\$ 90,694$ & $\$ 70,896$ & $\$ 70,896$ & $3 \%$ \\
\hline Metal Decon & $\$ 69,323$ & $\$ 69,323$ & $\$ 69,323$ & $\$ 69,003$ & $\$ 69,003$ & $2 \%$ \\
\hline $\begin{array}{l}\text { Phosphate } \\
\text { Stabilization }\end{array}$ & $\$ 0$ & $\$ 0$ & $\$ 0$ & $\$ 273,259$ & $\$ 0$ & $2 \%$ \\
\hline Special Waste & $\$ 53,990$ & $\$ 58,388$ & $\$ 53,990$ & $\$ 51,474$ & $\$ 51,474$ & $2 \%$ \\
\hline Lead Recovery & $\$ 41,123$ & $\$ 41,123$ & $\$ 54,954$ & $\$ 41,123$ & $\$ 54,954$ & $2 \%$ \\
\hline Open Debris & $\$ 0$ & $\$ 0$ & $\$ 0$ & $\$ 97,896$ & $\$ 97,896$ & $1 \%$ \\
\hline $\begin{array}{l}\text { Mercury } \\
\text { Amalgamation }\end{array}$ & $\$ 34,707$ & $\$ 34,707$ & $\$ 34,707$ & $\$ 34,707$ & $\$ 34,707$ & $1 \%$ \\
\hline Bulk Soil Treatment & $\$ 0$ & $\$ 0$ & $\$ 0$ & $\$ 64,365$ & $\$ 64,365$ & $1 \%$ \\
\hline Complex Debris & $\$ 0$ & $\$ 0$ & $\$ 108,840$ & $\$ 0$ & $\$ 0$ & $1 \%$ \\
\hline Total Life Cycle \$ & $\$ 2,883,373$ & $\$ 2,845,703$ & $\$ 2,989,805$ & $\$ 3,133,373$ & $\$ 3,118,354$ & \\
\hline
\end{tabular}




\section{Appendix B}

\section{Time Phased Life Cycle Costs and Transportation Data}




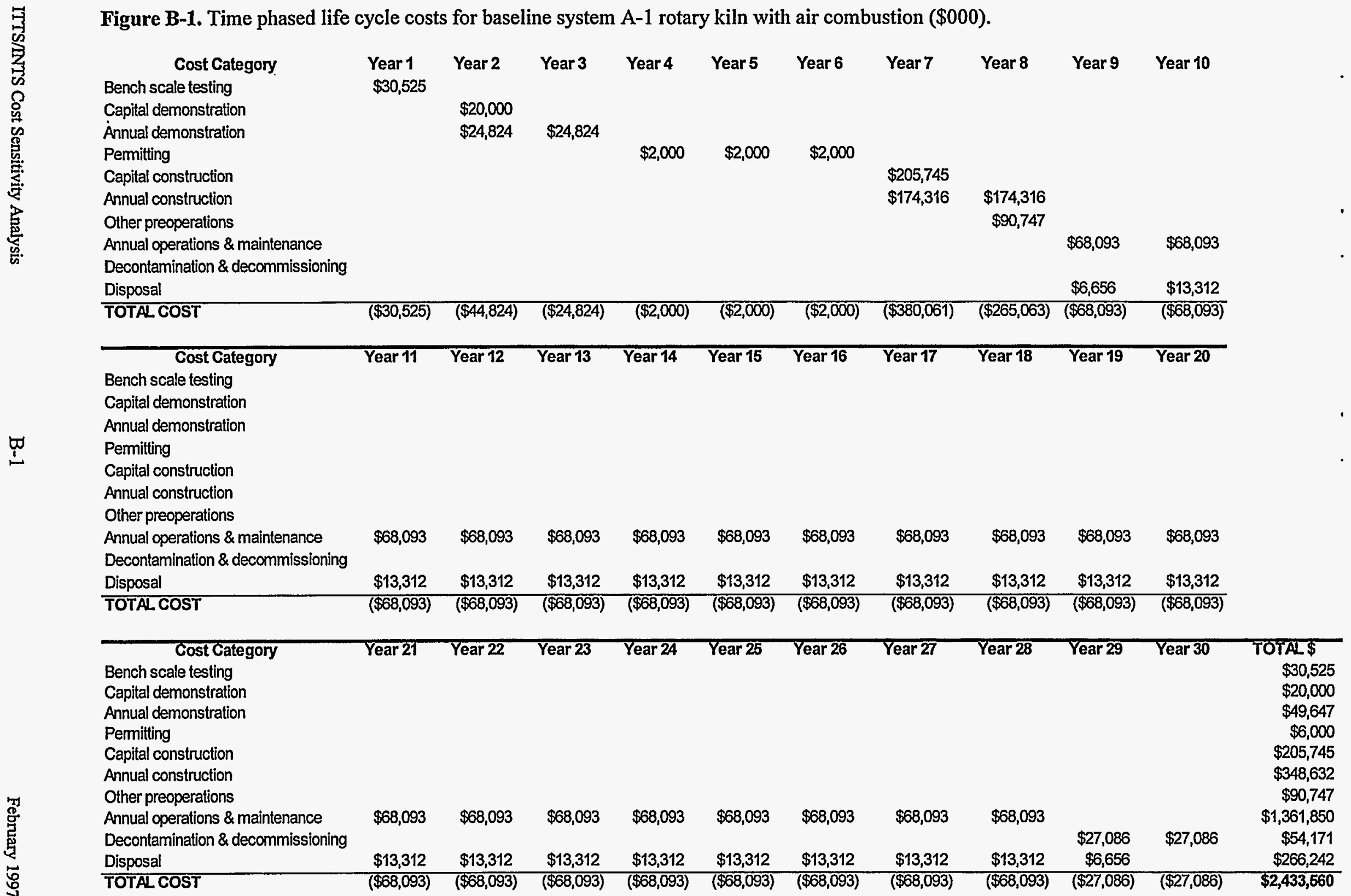


Table B-2. Time phased life cycle costs $(\$ 000)$ for 10 year operating life (scaling factor 0.5 ).

\begin{tabular}{|c|c|c|c|c|c|c|c|c|c|c|c|}
\hline $\begin{array}{l}\text { Cost Category } \\
\text { Bench scale testing }\end{array}$ & $\begin{array}{l}\text { Year 1 } \\
\$ 30,525\end{array}$ & Year 2 & Year 3 & Year 4 & Year 5 & Year 6 & Year 7 & Year 8 & Year 9 & Year 10 & \\
\hline $\begin{array}{l}\text { Capital demonstration } \\
\text { Annual demonstration }\end{array}$ & & $\$ 20,000$ & $\$ 24.824$ & & & & & & & & \\
\hline Permitting & & $\$ 24,824$ & $\$<4,8<4$ & $\$ 2,000$ & $\$ 2,000$ & $\$ 2,000$ & & & & & \\
\hline Capital construction & & & & & & & $\$ 290,967$ & & & & \\
\hline Annual construction & & & & & & & $\$ 246,521$ & $\$ 246,521$ & & & \\
\hline Other preoperations & & & & & & & & $\$ 128,087$ & & & \\
\hline Annual operations \& maintenance & & & & & & & & & $\$ 96,297$ & $\$ 96,297$ & \\
\hline Decontamination \& decommissioning & & & & & & & & & & & \\
\hline TOTALCOST & $(\$ 30,525)$ & $(\$ 44,824)$ & $(\$ 24,824)$ & $(\$ 2,000)$ & $(\$ 2,000)$ & $(\$ 2,000)$ & $(\$ 537,488)$ & $(\$ 374,608)$ & $(\$ 96,297)$ & $7 \$ 96,297)$ & \\
\hline Cost Category & Year 11 & Year 12 & Year 13 & Year 14 & Year 16 & Year 16 & Year 17 & Year 18 & Year 19 & Year 20 & TOTAL $\$$ \\
\hline Bench scale testing & & & & & & & & & & & $\$ 30,525$ \\
\hline Capital demonstration & & & & & & & & & & & $\$ 20,000$ \\
\hline Annual demonstration & & & & & & & & & & & $\$ 49,647$ \\
\hline Permitting & & & & & & & & & & & $\$ 6,000$ \\
\hline Capital construction & & & & & & & & & & & $\$ 290,967$ \\
\hline Annual construction & & & & & & & & & & & $\$ 493,041$ \\
\hline Other preoperations & & & & & & & & & & & $\$ 128,087$ \\
\hline Annual operations \& maintenance & $\$ 96,297$ & $\$ 96,297$ & $\$ 96,297$ & $\$ 96,297$ & $\$ 96,297$ & $\$ 96,297$ & $\$ 96,297$ & $\$ 96,297$ & & & $\$ 962,973$ \\
\hline Decontamination \& decommissioning & & & & & & & & & $\$ 38,305$ & $\$ 38,305$ & $\$ 76,609$ \\
\hline TOTAL COST & $(\$ 96,297)$ & $(\$ 96,297)$ & $(\$ 96,297)$ & $(\$ 96,297)$ & $(\$ 96,297)$ & $(\$ 96,297)$ & $(\$ 96,297)$ & $(\$ 96,297)$ & $(\$ 38,305)$ & $(\$ 38,305)$ & $(\$ 2,057,850)$ \\
\hline
\end{tabular}


Table B-3. Net present value comparison for operating 20 versus 10 years $(\$ 000$; discount rate $=0.06$, constant $\$$ ).

Net Present Value (NPV)

\begin{tabular}{|c|c|c|c|c|c|c|c|c|c|c|c|}
\hline & Total LCC $(\$ 000)$ & Year 1 & Year 2 & Year 3 & Year 4 & Year 5 & Year 6 & Year 7 & Year 8 & Year 9 & Year 10 \\
\hline Baseline A1 Rotary Kiln & $(\$ 1,012,821)$ & $(\$ 30,525)$ & $(\$ 44,824)$ & $(\$ 24,824)$ & $(\$ 2,000)$ & $(\$ 2,000)$ & $(\$ 2,000)$ & $(\$ 380,061)$ & $(\$ 265,063)$ & $(\$ 68,093)$ & $(\$ 68,093)$ \\
\hline
\end{tabular}

$2 \times$ Capacity Scaled 0.5

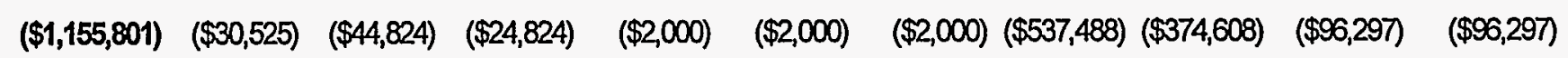

10 Year Operating Life

\begin{tabular}{|c|c|c|c|c|c|c|c|c|c|c|c|}
\hline & Year 11 & Year 12 & Year 13 & Year 14 & Year 15 & Year 16 & Year 17 & Year 18 & Year 19 & Year 20 & Year 21 \\
\hline Baseline A.1 Rotary Kin & $(\$ 68,093)$ & $(\$ 68,093)$ & $(\$ 68,093)$ & $(\$ 68,093)$ & $(\$ 68,093)$ & $(\$ 68,093)$ & $(\$ 68,093)$ & $(\$ 68,093)$ & $(\$ 68,093)$ & $(\$ 68,093)$ & $(\$ 68,093)$ \\
\hline
\end{tabular}

20 Year Operating Life

2xCapacity Scaled 0.5

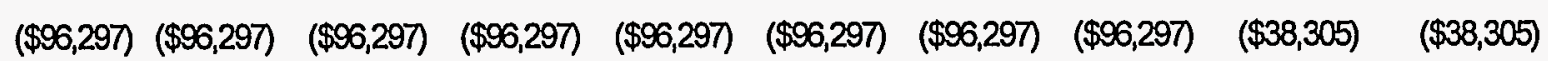

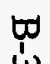

10 Year Operating Life

\section{Baseline A1 RotaryKiln
20 Year Operating Life}

$\begin{array}{lllllllll}\text { Year 22 } & \text { Year 23 } & \text { Year 24 } & \text { Year 25 } & \text { Year 26 } & \text { Year 27 } & \text { Year 28 } & \text { Year 29 } & \text { Year 30 TOTALLCC }(\$ 000)\end{array}$

2xCapacity Scaled 0.5

10 Year Operating Life.

$\$ 0$

$\$ 0 \$ 0$

$\$ 0$

$\$ 0$

$\$ 0$

$\$ 0$

$\$ 0$

$\$ 0 \quad(\$ 2,057,850) 10$ Year 
Table B-4. Transportation cost data for shipment to one facility.

\begin{tabular}{lrrrrrr} 
& MILES & \multicolumn{1}{c}{ LBS } & \#SHIPMENTS & VARIABLE $\$$ & FIXED $\$$ & \multicolumn{1}{c}{ TOTAL $\$$} \\
Califomia & 2,400 & 922,536 & 21 & $\$ 201,600$ & $\$ 18,480$ & $\$ 220,080$ \\
Colorado & 1,300 & $23,150,520$ & 526 & $\$ 2,735,200$ & $\$ 462,880$ & $\$ 3,198,080$ \\
ldaho & 1,850 & $44,129,665$ & 1,003 & $\$ 7,422,200$ & $\$ 882,640$ & $\$ 8,304,840$ \\
Illinois & 455 & 58,086 & 1 & $\$ 1,820$ & $\$ 880$ & $\$ 2,700$ \\
Kentucky & 260 & $1,763,068$ & 40 & $\$ 41,600$ & $\$ 35,200$ & $\$ 76,800$ \\
Maine & 845 & 1,708 & 1 & $\$ 3,380$ & $\$ 880$ & $\$ 4,260$ \\
Missouri & 450 & $3,456,092$ & 79 & $\$ 142,200$ & $\$ 69,520$ & $\$ 211,720$ \\
Nevada & 2,010 & 509,103 & 12 & $\$ 96,480$ & $\$ 10,560$ & $\$ 107,040$ \\
New Jersey & 520 & $41,821,617$ & 950 & $\$ 1,976,000$ & $\$ 836,000$ & $\$ 2,812,000$ \\
New Mexico & 1,300 & $1,160,003$ & 26 & $\$ 135,200$ & $\$ 22,880$ & $\$ 158,080$ \\
New York & 620 & 239,176 & 5 & $\$ 12,400$ & $\$ 4,400$ & $\$ 16,800$ \\
Ohio & 260 & $16,721,813$ & 380 & $\$ 395,200$ & $\$ 334,400$ & $\$ 729,600$ \\
Pennsyivania & 455 & 64,919 & 1 & $\$ 1,820$ & $\$ 880$ & $\$ 2,700$ \\
South Carolina & 230 & $12,303,892$ & 280 & $\$ 257,600$ & $\$ 246,400$ & $\$ 504,000$ \\
Tennessee & 0 & $78,475,326$ & 0 & $\$ 0$ & $\$ 0$ & $\$ 0$ \\
Texas & 1,050 & 218,675 & 5 & $\$ 21,000$ & $\$ 4,400$ & $\$ 25,400$ \\
Virginia & 390 & 8,542 & 1 & $\$ 1,560$ & $\$ 880$ & $\$ 2,440$ \\
Washington & 2,250 & $10,995,258$ & 250 & $\$ 2,250,000$ & $\$ 220,000$ & $\$ 2,470,000$ \\
& 16,645 & $236,000,000$ & 3,581 & $\$ 15,695,260$ & $\$ 3,151,280$ & $\$ 18,846,540$
\end{tabular}

Table B-5. Transportation cost data for shipment to two facilities.

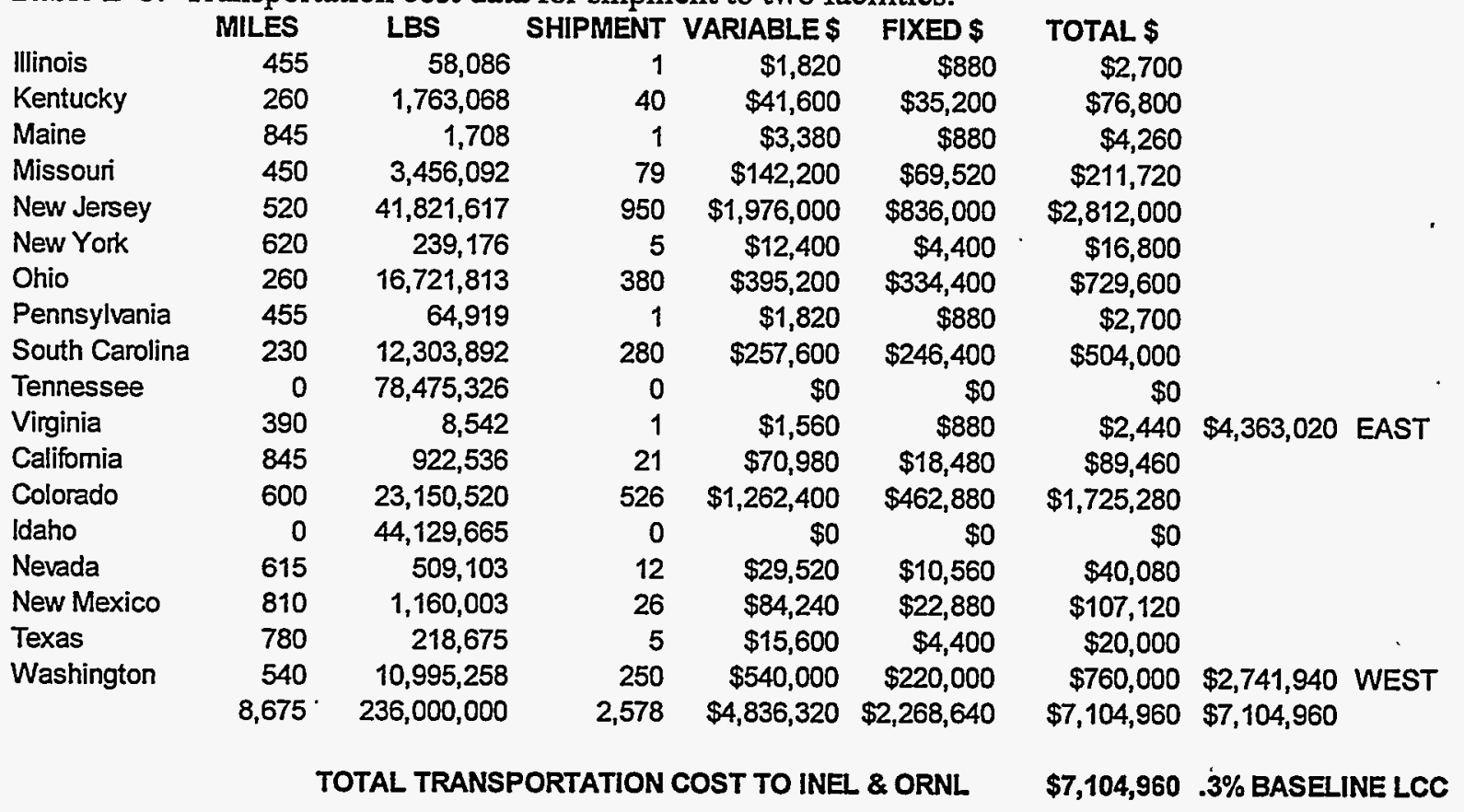


Table B-6. Transportation cost data for shipment to five facilities.

\begin{tabular}{|c|c|c|c|c|c|c|c|c|}
\hline Califomia & $\begin{array}{l}\text { MILES } \\
\sigma 20\end{array}$ & $\begin{array}{l}\text { LBS - } \\
\text { 922.536 }\end{array}$ & $\begin{array}{r}\text { \#SHPMENTS } \\
21\end{array}$ & $\begin{array}{l}\text { VARIABLE \$ } \\
\$ 52,080\end{array}$ & $\begin{array}{l}\text { FIXED \$ } \\
\$ 18,480\end{array}$ & $\begin{array}{l}\text { TOTAL \$ } \\
\$ 70,560\end{array}$ & & \\
\hline Nevada & 715 & 509,103 & 12 & $\$ 34,320$ & $\$ 10,560$ & $\$ 44,880$ & & \\
\hline Washington & 0 & $10,995,258$ & 0 & $\$ 0$ & $\$ 0$ & \$o & $\$ 115,440$ & Hanford \\
\hline Idaho & 0 & $44,129,665$ & 0 & $\$ 0$ & $\$ 0$ & $\$ 0$ & $\$ 0$ & INEL \\
\hline Illinois & 455 & 58,086 & 1 & $\$ 1,820$ & $\$ 880$ & $\$ 2,700$ & & \\
\hline Kentucky & 260 & $1,763,068$ & 40 & $\$ 41,600$ & $\$ 35,200$ & $\$ 76,800$ & & \\
\hline Maine & 845 & 1,708 & 1 & $\$ 3,380$ & $\$ 880$ & $\$ 4,260$ & & \\
\hline Missouri & 450 & $3,456,092$ & 79 & $\$ 142,200$ & $\$ 69,520$ & $\$ 211,720$ & & \\
\hline New Jersey & 520 & $41,821,617$ & 950 & $\$ 1,976,000$ & $\$ 836,000$ & $\$ 2,812,000$ & & \\
\hline New Yotk & 620 & 239,176 & 5 & $\$ 12,400$ & $\$ 4,400$ & $\$ 16,800$ & & \\
\hline Ohio & 260 & $16,721,813$ & 380 & $\$ 395,200$ & $\$ 334,400$ & $\$ 729,600$ & & \\
\hline Pennsylvania & 455 & 64,919 & 1 & $\$ 1,820$ & $\$ 880$ & $\$ 2,700$ & & \\
\hline Tennessee & 0 & $78,475,326$ & 0 & $\$ 0$ & $\$ 0$ & $\$ 0$ & & \\
\hline Virginia & 390 & 8,542 & 0 & $\$ 0$ & $\$ 0$ & \$o & $\$ 3,856,580$ & ORNL \\
\hline Colorado & 0 & $23,150,520$ & 0 & $\$ 0$ & $\$ 0$ & $\$ 0$ & & \\
\hline New Mexico & 325 & $1,160,003$ & 26 & $\$ 33,800$ & $\$ 22,880$ & $\$ 56,680$ & & \\
\hline Texas & 360 & 218,675 & 5 & $\$ 7,200$ & $\$ 4,400$ & $\$ 11,600$ & $\$ 68,280$ & RFP \\
\hline \multirow[t]{2}{*}{ South Carolina } & 0 & $12,303,892$ & 0 & $\$ 0$ & $\$ 0$ & $\$ 0$ & $\$ 0$ & SRS \\
\hline & 6,275 & $236,000,000$ & 1,521 & $\$ 2,701,820$ & $\$ 1,338,480$ & $\$ 4,040,300$ & $\$ 4,040,300$ & \\
\hline
\end{tabular}




\section{Appendix C}

\section{Disposal Cost Data}


Table C-1. Revised disposal cost estimates for small- and medium-size facilities.

\begin{tabular}{|c|c|c|c|c|c|}
\hline Treatment System & $\begin{array}{l}\text { Final Waste } \\
\text { Volume }\left(\mathrm{ft}^{3}\right)\end{array}$ & $\begin{array}{c}\text { Small } \\
\left(1.5 \text { million } \mathrm{ft}^{3}\right) \\
(\$ 000)\end{array}$ & $\$ / \mathrm{ft}^{3}$ & $\begin{array}{l}\text { Medium }(3.6 \\
\left.\text { million } \mathrm{ft}^{3}\right) \\
(\$ 000)\end{array}$ & $\$ / \mathrm{ft}^{3}$ \\
\hline A-1 Rotary kiln, air & $1,095,648$ & $\$ 485,920$ & $\$ 444$ & $\$ 639,260$ & $\$ 583$ \\
\hline A-2 Rotary kiln, oxygen & $1,095,648$ & $\$ 485,920$ & $\$ 444$ & $\$ 639,260$ & $\$ 583$ \\
\hline A-3 Rotary kiln, air, wet APC & $1,369,325$ & $\$ 516,109$ & $\$ 377$ & $\$ 661,518$ & $\$ 483$ \\
\hline A-4 Rotary kiln, oxygen, $\mathrm{CO}_{2}$ retention & $1,585,118$ & $\$ 539,913$ & $\$ 341$ & $\$ 679,069$ & $\$ 428$ \\
\hline A-5 Rotary kiln, air, polymer stabil. & $2,300,532$ & $\$ 1,237,661$ & $\$ 538$ & $\$ 737,253$ & $\$ 320$ \\
\hline A-6 Rotary kiln, air, maximum recycling & 864,018 & $\$ 460,369$ & $\$ 533$ & $\$ 620,422$ & $\$ 718$ \\
\hline A-7 Slagging rotary kiln & $1,170,466$ & $\$ 494,173$ & $\$ 422$ & $\$ 645,345$ & $\$ 551$ \\
\hline A-8 Rotary kiln, grout stabilization & $2,507,904$ & $\$ 1,283,412$ & $\$ 512$ & $\$ 754,119$ & $\$ 301$ \\
\hline B-1 Indirectly heated pyrolyzer & $1,095,648$ & $\$ 485,920$ & $\$ 444$ & $\$ 639,260$ & $\$ 583$ \\
\hline C-1 Plasma furnace & $1,066,540$ & $\$ 482,709$ & $\$ 453$ & $\$ 636,893$ & $\$ 597$ \\
\hline C-2 Plasma furnace, $\mathrm{CO}_{2}$ retention & $1,220,080$ & $\$ 499,646$ & $\$ 410$ & $\$ 649,380$ & $\$ 532$ \\
\hline C-3 Plasma gasification & $1,067,403$ & $\$ 482,804$ & $\$ 452$ & $\$ 636,963$ & $\$ 597$ \\
\hline D-1 Fixed hearth pyrolyzer, $\mathrm{CO}_{2}$ retent. & $1,226,221$ & $\$ 500,323$ & $\$ 408$ & $\$ 649,880$ & $\$ 530$ \\
\hline E-1 Rotary kiln, air, thermal desorption & $2,482,376$ & $\$ 1,277,780$ & $\$ 515$ & $\$ 752,043$ & $\$ 303$ \\
\hline F-1 Molten salt oxidation & $1,176,428$ & $\$ 494,831$ & $\$ 421$ & $\$ 645,830$ & $\$ 549$ \\
\hline G-1 Molten metal waste destruction & 929,131 & $\$ 467,551$ & $\$ 503$ & $\$ 625,717$ & $\$ 673$ \\
\hline H-1 Steam gasification & $1,094,786$ & $\$ 485,825$ & $\$ 444$ & $\$ 639,190$ & $\$ 584$ \\
\hline J-1 Joule-heated vitrification & $1,095,217$ & $\$ 485,872$ & $\$ 444$ & $\$ 639,225$ & $\$ 584$ \\
\hline K-1 Thermal desorption and MEO & $3,435,031$ & $\$ 1,487,955$ & $\$ 433$ & $\$ 829,522$ & $\$ 241$ \\
\hline L-1 Thermal desorption and SCWO & $3,269,719$ & $\$ 1,451,483$ & $\$ 444$ & $\$ 816,077$ & $\$ 250$ \\
\hline NT-1 Grout debris & $3,346,560$ & $\$ 1,468,436$ & $\$ 439$ & $\$ 822,327$ & $\$ 246$ \\
\hline NT-2 Desorption & $3,306,240$ & $\$ 1,459,541$ & $\$ 441$ & $\$ 819,047$ & $\$ 248$ \\
\hline NT-3 Wash & $3,411,072$ & $\$ 1,482,669$ & $\$ 435$ & $\$ 827,573$ & $\$ 243$ \\
\hline NT-4 Acid digestion & $2,709,504$ & $\$ 1,327,889$ & $\$ 490$ & $\$ 770,515$ & $\$ 284$ \\
\hline NT-5 Catalyzed wet oxidation & $2,782,080$ & $\$ 1,343,900$ & $\$ 483$ & $\$ 776,418$ & $\$ 279$ \\
\hline
\end{tabular}


Table C-2. Vitrified and solid waste output and revised disposal cost.

\begin{tabular}{|c|c|c|c|c|c|c|c|}
\hline Treatment System & $\begin{array}{l}\text { Final } \\
\text { waste } \\
\text { volume } \\
\left(\mathrm{ft}^{3} \times 1000\right)\end{array}$ & $\begin{array}{l}\text { Vitrified } \\
\text { waste } \\
\text { output } \\
\left(\mathrm{ft}^{3} \times 1000\right)\end{array}$ & $\begin{array}{l}\text { Other } \\
\text { waste to } \\
\text { disposal } \\
\left(\mathrm{ft}^{3} \times 1000\right)\end{array}$ & $\begin{array}{l}\text { Disposal cost } \\
\text { for delisted } \\
\text { vitrified waste } \\
\text { (\$million) }\end{array}$ & $\begin{array}{l}\text { Other } \\
\text { disposal } \\
\text { cost } \\
\text { (\$million) }\end{array}$ & $\begin{array}{l}\text { Total } \\
\text { disposal cost } \\
\text { assuming } \\
\text { delisting }\end{array}$ & $\begin{array}{l}\text { Total } \\
\text { disposal cost } \\
\text { without } \\
\text { delisting }\end{array}$ \\
\hline A-1 Rotary kiln, air & 1,096 & 653 & 442 & $\$ 26,127$ & $\$ 413,867$ & $\$ 439,995$ & $\$ 485,920$ \\
\hline A-2 Rotary kiln, oxygen & 1,096 & 653 & 442 & $\$ 26,127$ & $\$ 413,867$ & $\$ 439,995$ & $\$ 485,920$ \\
\hline A-3 Rotary kiln, air, wet APC & 1,369 & 492 & 877 & $\$ 19,676$ & $\$ 461,847$ & $\$ 481,523$ & $\$ 516,109$ \\
\hline A-4 Rotary kiln & 1,585 & 653 & 932 & $\$ 26,127$ & $\$ 467,861$ & $\$ 493,988$ & $\$ 539,913$ \\
\hline A-5 Rotary kiln, air, polymer stabil. & 2,301 & 0 & 2,301 & $\$ 0$ & $\$ 737,253$ & $\$ 737,253$ & $\$ 737,253$ \\
\hline A-6 Rotary kiln, air, maximum recycling & 864 & 653 & 211 & $\$ 26,127$ & $\$ 388,316$ & $\$ 414,443$ & $\$ 460,369$ \\
\hline A-7 Slagging rotary kiln & 1,170 & 0 & 1,170 & $\$ 0$ & $\$ 494,173$ & $\$ 494,173$ & $\$ 494,173$ \\
\hline A-8 Rotary kiln, grout stabilization & 2,508 & 0 & 2,508 & $\$ 0$ & $\$ 754,119$ & $\$ 754,119$ & $\$ 754,119$ \\
\hline B-1 Indirectly heated pyrolyzer & 1,096 & 0 & 1,096 & $\$ 0$ & $\$ 485,920$ & $\$ 485,920$ & $\$ 485,920$ \\
\hline C-1 Plasma furnace & 1,067 & 0 & 1,067 & $\$ 0$ & $\$ 482,709$ & $\$ 482,709$ & $\$ 482,709$ \\
\hline $\mathrm{C}-2$ Plasma furnace, $\mathrm{CO}_{2}$ retention & 1,220 & 0 & 1,220 & $\$ 0$ & $\$ 499,646$ & $\$ 499,646$ & $\$ 499,646$ \\
\hline C-3 Plasma gasification & 1,067 & 0 & 1,067 & $\$ 0$ & $\$ 482,804$ & $\$ 482,804$ & $\$ 482,804$ \\
\hline D-1 Fixed hearth pyrolyzer, $\mathrm{CO}_{2}$ retent. & 1,226 & 653 & 573 & $\$ 26,127$ & $\$ 428,271$ & $\$ 454,398$ & $\$ 500,323$ \\
\hline E-1 Rotary kiln, air, thermal desorption & 2,482 & 81 & 2,402 & $\$ 3,226$ & $\$ 745,484$ & $\$ 748,710$ & $\$ 752,043$ \\
\hline F-1 Molten salt oxidation & 1,176 & 653 & 523 & $\$ 26,127$ & $\$ 422,778$ & $\$ 448,905$ & $\$ 494,831$ \\
\hline G-1 Molten metal waste destruction & 929 & 0 & 929. & $\$ 0$ & $\$ 467,551$ & $\$ 467,551$ & $\$ 467,551$ \\
\hline
\end{tabular}


Table C-2., Cont'd.

\begin{tabular}{llllllll}
\multicolumn{1}{c}{ Treatment Technology } & $\begin{array}{l}\text { Final } \\
\text { waste } \\
\text { volume } \\
\left(\mathrm{ft}^{3} \times 1000\right)\end{array}$ & $\begin{array}{l}\text { Vitrified } \\
\text { waste } \\
\text { output } \\
\left(\mathrm{ft}^{3} \times 1000\right)\end{array}$ & $\begin{array}{l}\text { Other } \\
\text { waste to } \\
\text { disposal } \\
\left(\mathrm{ft}^{3} \times 1000\right)\end{array}$ & $\begin{array}{l}\text { Disposal cost } \\
\text { for delisted } \\
\text { vitrified waste } \\
(\$ \text { million })\end{array}$ & $\begin{array}{l}\text { Other } \\
\text { disposal } \\
\text { cost } \\
(\$ m i l l i o n)\end{array}$ & $\begin{array}{l}\text { Total } \\
\text { disposal cost } \\
\text { assuming } \\
\text { delisting }\end{array}$ & $\begin{array}{l}\text { Total } \\
\text { disposal cost } \\
\text { without } \\
\text { delisting }\end{array}$ \\
\hline H-1 Steam gasification & 1,095 & 653 & 442 & $\$ 26,127$ & $\$ 413,772$ & $\$ 439,899$ & $\$ 485,825$ \\
J-1 Joule-heated vitrification & 1,095 & 0 & 1,095 & $\$ 0$ & $\$ 485,872$ & $\$ 485,872$ & $\$ 485,872$ \\
K-1 Thermal desorption and MEO & 3,435 & 0 & 3,435 & $\$ 0$ & $\$ 829,522$ & $\$ 829,522$ & $\$ 829,522$ \\
L-1 Thermal desorption and SCWO & 3,270 & 0 & 3,270 & $\$ 0$ & $\$ 816,077$ & $\$ 816,077$ & $\$ 816,077$ \\
NT-1 Grout debris & 3,347 & 0 & 3,347 & $\$ 0$ & $\$ 822,327$ & $\$ 822,327$ & $\$ 822,327$ \\
NT-2 Desorption & 3,306 & 0 & 3,306 & $\$ 0$ & $\$ 819,047$ & $\$ 819,047$ & $\$ 819,047$ \\
NT-3 Wash & 3,411 & 0 & 3,411 & $\$ 0$ & $\$ 827,573$ & $\$ 827,573$ & $\$ 827,573$ \\
NT-4 Acid digestion & 2,710 & 0 & 2,710 & $\$ 0$ & $\$ 770,515$ & $\$ 770,515$ & $\$ 770,515$ \\
NT-5 Catalyzed wet oxidation & 2,782 & 0 & 2,782 & $\$ 0$ & $\$ 776,418$ & $\$ 776,418$ & $\$ 776,418$
\end{tabular}

